
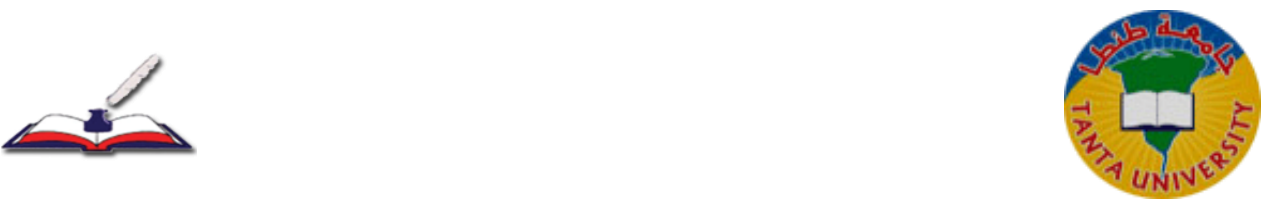

فاعلية استخدام تقتية الواقع المعزز على تنمية التحصيل المعرفي والإتجاه لاي طلاب كلية التربية

$$
\text { إعداد }
$$

د/أيمن محمد عبد الهادي

أستاذ تكنولوجيا التعليم المساعد كلية التربية - جامعة جاز ان

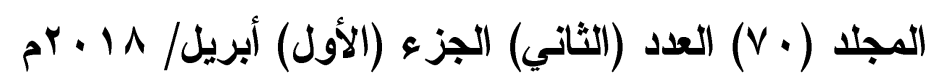


مستخلص:

هدف البحث إلى الكثف عن فاعلية استخدام تقنية الواقع المعزز على تتمية التحصيل المعرفي و الإتجاه لدي طلاب كلية التربية، استخدم البحث الحالي المنهج شبه التجريبي القائم علي تصميم مجموعة تجريبية ومجموعة ضابطة مع التطبيق القبلي و البعدي لأدوات القياس، وتكونت المجموعة التجريبية من (مس) طالب يدرسون بتقنية الواقع المعزز، وتكونت المجموعة الضابطة من (•ع) طالب بدرسون بالطريقة التقليدية، وأسفرت نتائج البحث عن عدم وجود فرق دال إحصائياً عند مستوى بون بـن (0 . •) بين متوسطي درجات طلاب المجموعة التجريبية الذين يستخدمون تقنية الواقع المعزز في القياسين القبلي والبعدي على اختبار التحصبل المعرفي ومقياس الاتجاه، وعدم وجود فرق دال إحصائياً عند مستوى (0. . .) بين متوسطي درجات طلاب المجموعة التجريبية الذين يستخدمون تقنية الواقع المعزز وطلاب المجموعة الضابطة في القياس البعدي على اختبار التحصيل المعرفي ومقياس الاتجاه، وفي ضوء ذلك أوصى البحث بأهمية تقديم ورش عمل للطالب المعلم لتدريبه على استخدام استر اتيجات التعليم الحديثة (تقنية الواقع المعزز)، وتتمية الاتجاهات الايجابية للطالب المعلم نحو استخدام استراتيجات التعليم الحديثة (تقنية الواقع المعزز)، وكذلك تطوير توصيف المقررات الدر اسية للطالب المعلم لتتضمن استراتيجات التعليم الحديثة (تقنية

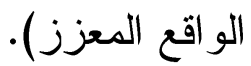
الكلمات المفتاحية: تقنية الواقع المعزز • 


\begin{abstract}
:
The objective of the research was to investigate the effectiveness of using the Augmanted reality to develop the cognitive achievement and direction of the students of the Faculty of Education. The current research used the semi-experimental approach based on the design of experimental group and control group with the tribal and remote application of measurement tools. The experimental group consisted of (35) students studying in the Augmanted areality, the control group consisted (40) students studied in the traditional way. The results of the study showed there are no statistically significant differences at level (0.05) among the average scores of the experimental group students who use the augmented reality in the Tribal and remote standards on the cognitive achievement test and Direction scale, there are no statistically significant differences at level (0.05) among the average scores of the experimental students using the augmented reality and the students of the control group in the telemetry on the cognitive achievement test and Direction scale, In the light of this, the research recommended the introduction of workshops for the student/teacher to train him to use modern education strategies (augmanted reality), develop the positive attitudes of the student/teacher towards the use of modern education strategies (augmanted reality), and As well as developing the courses specification for student/teacher to include modern education strategies (augmented reality).

Keywords: Augmanted Reality.
\end{abstract}


كم مر بنا من معلومات مجردة في الكتب وكنا نتمنى لو تجسدت هذه

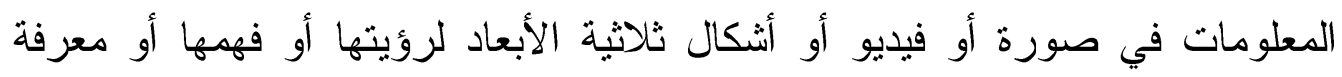

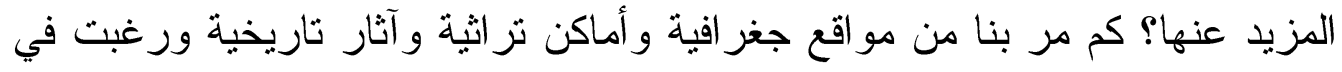

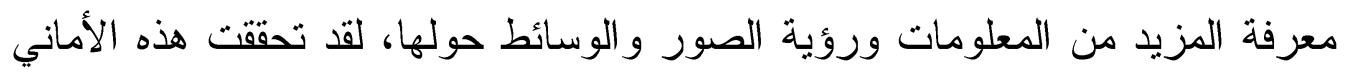
و أصبح بمجرد تعريض كاميرا هاتفك المحمول على الكتاب الورقي العادي فإنلك تبعث

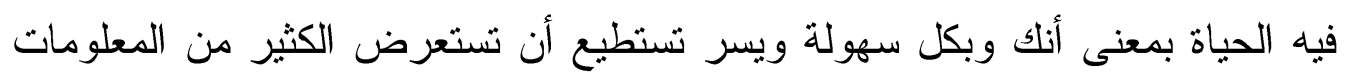

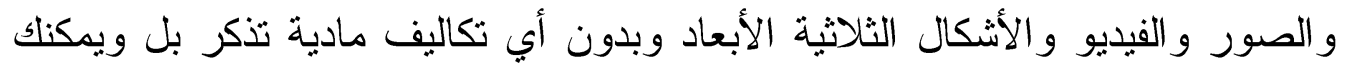

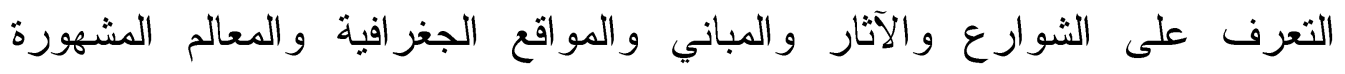

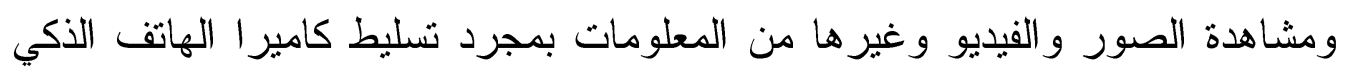
إلى هذه الأشياء وبدون أي رسوم وذلك من خلال تقنية الو اقع المعزز .

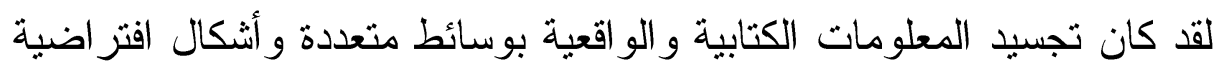

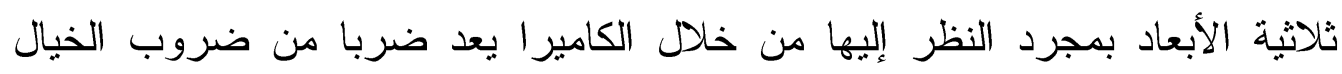

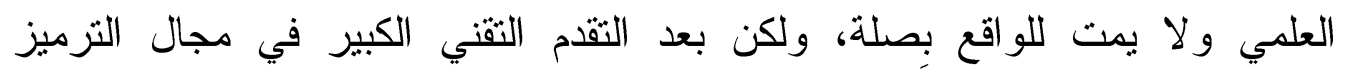

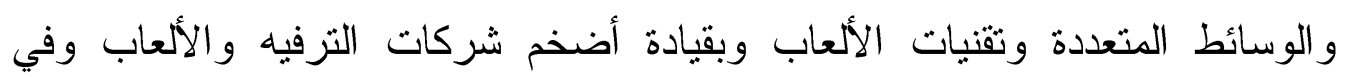

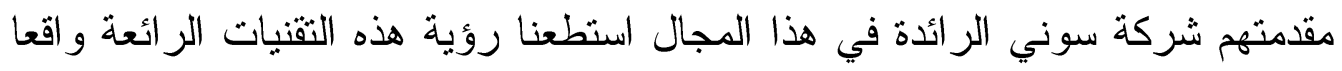

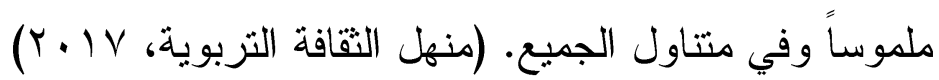
وقد أظهرت الثورة اللاسلكية والصناعية والنطور التقني الحديث و اقعاً جديداً

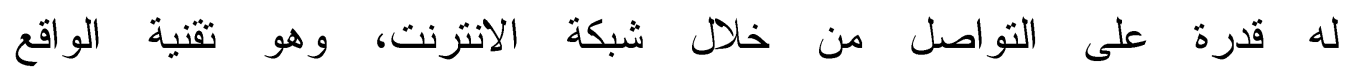

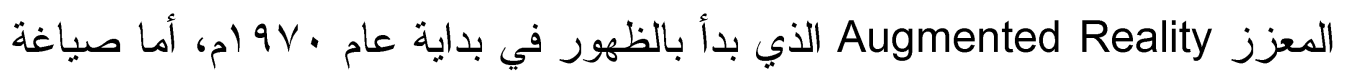

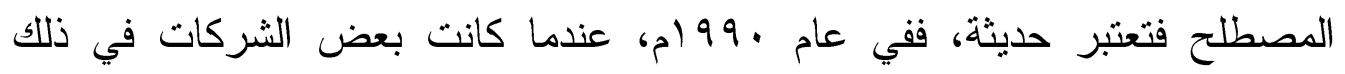

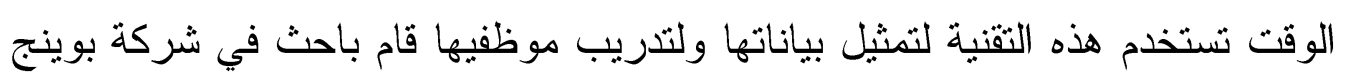
The Boeing Company رقمية كانت ترشد العمال أثناء عمهر إلى كيفية جمع الأسلاك الكهربائية في (El sayed, 2011) (الطائر ) 
ويمكن استخدام تقنية الو اقع المعزز في الألعاب التعليمية لزيادة تفاعل الطلاب مع المادة العلمية، ففي جامعة ويسكونسون الأمريكية تم استخدام برنامج (ARIS)

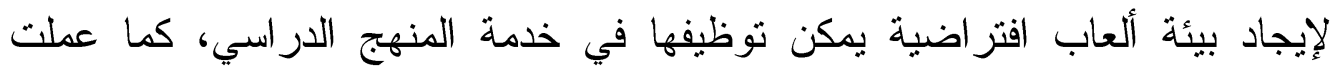
شركة (Metaio) الألمانية على تطوير كتب معززة (Augmented Books) تحتوى على عناصر من الو اقع المعزز، بحيث لو تم تسليط الكامير ا عليها فإن هذه العناصر تنفاعل مع البيئة الحقيقية. (Kipper \& Rampolla, 2013) كما أن تقنية الواقع المعزز يمكن توظيفها في العملية التعليمية بهدف تقديم

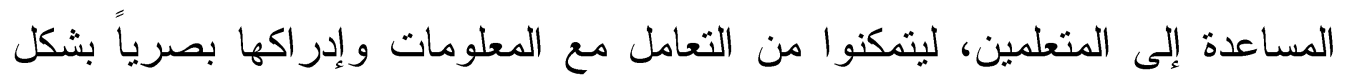

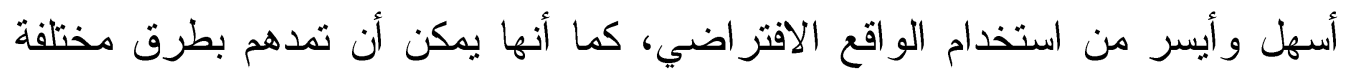
لتمثيل المعلومات واختبارها بشكل ديناميكي وسريع وسهل، كما أنها توفر تعليماً

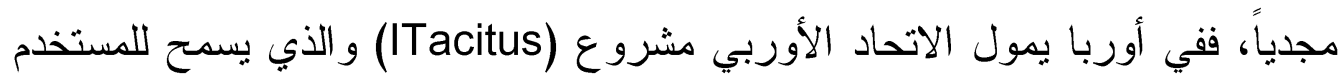

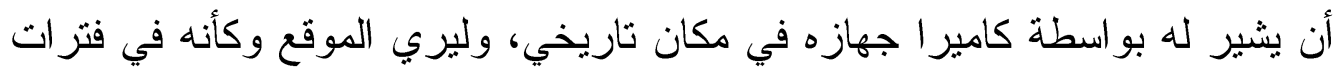
مختلفة من الماضي. (Catenazz \& Sommaruga, 2013) وتسنطيع تطبيقات وألعاب الواقع المعزز أن تتلل الطلاب إلى علم المعلومات

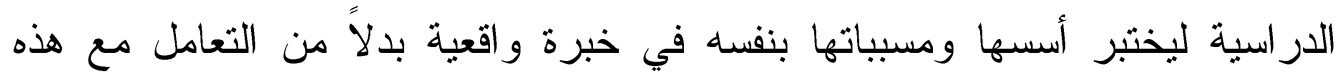
المعلومات في قالب نصي ثابت، وتدعو التقنية كذلك إلى الإطلاع على كافة المعلومات الدراسية في إطار محفز ومشوق يجمع ما بين ثقل المادة العلمية وإبهار العالم الافتراضي الذي ينتقل إليه الطلاب وتعزز التثنية الفهم والاستيعاب لديهم،

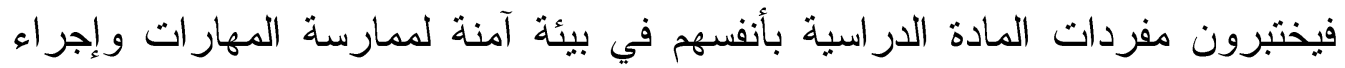
التجارب، هما يوفر درجة عالية من التفاعل الذاتي، ويحسن أسلوب التواصل بلته و التفاعل لايهم مع الآخرين. (Ivanova, 2011)

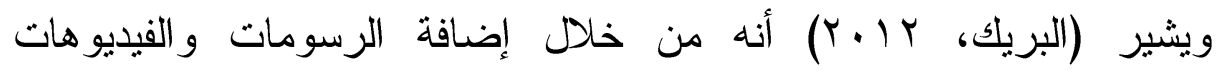

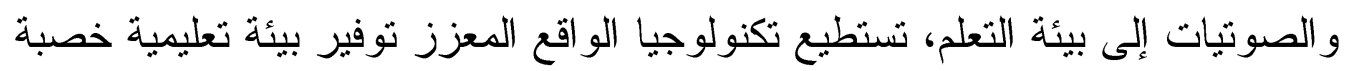
للطلاب، فعلى سبيل المثال سيستمتع الدارسين بالتعرف على المعالم السياحية المختلفة

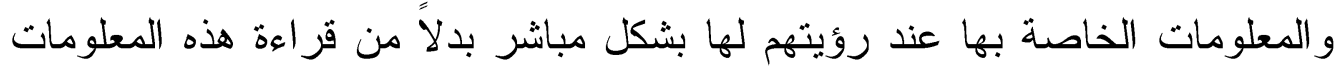

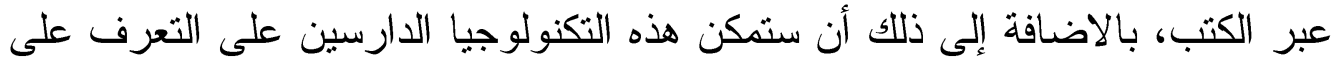


فهم الكيمياء بشكل أفضل من خلال رؤية الجزيئات والذرات وعمليات الاندماج و التفكك التي تحدث بينهم بسهولة تامة.

وتشير (الحسيني، ع (ب) أنه مع بديات تطور تقنتية الواقع المعزز لم يتبني

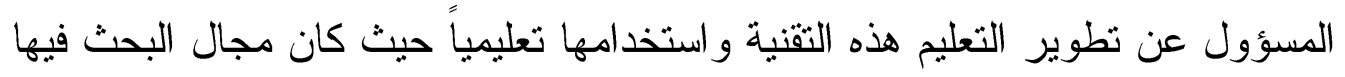
ضئيلاً ولم يكن هناك أحد على دراية كاملة بكافة المعدات والأجهزة المطلوبة لتطبيق التطبيق

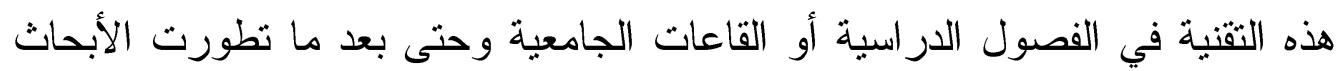

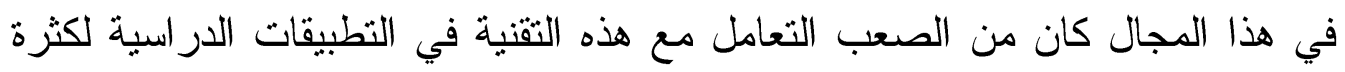

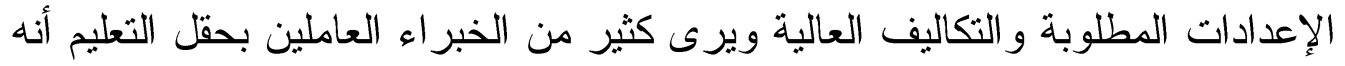

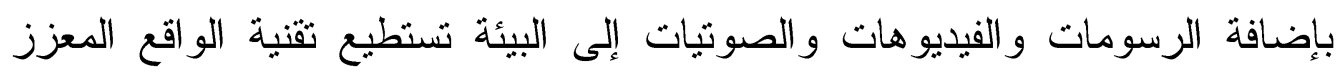
توفير بيئة نعليمية تفاعلية للطلاب.

وخلال الفترة الأخيرة شهدت تطبيقات تقنية الواقع المعزز تطوراً كبيراً يمكن

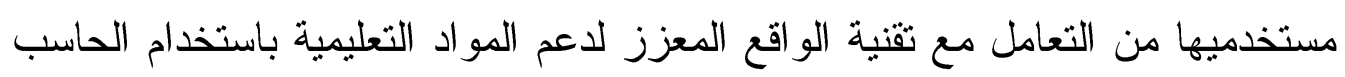

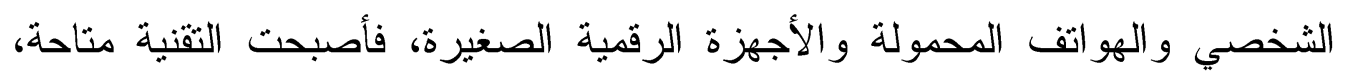
وأصبح التعامل معها أكثر عملية، وباتت مشاكل تطبيقها وارتفاع تكاليفها أقل تعقيداً.

(Kerawalla, 2006)

وتوجد العديد من الدراسات التي أكلت على أهمية ودور استخدام تقنية الواقع

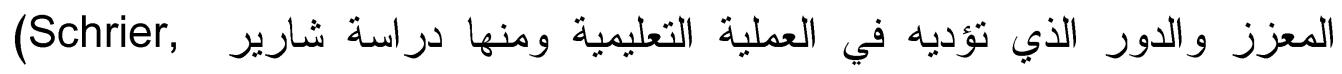

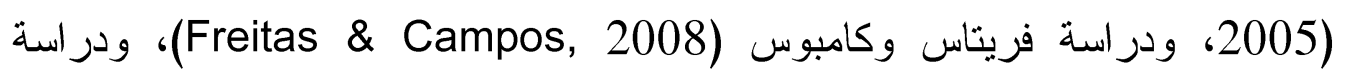

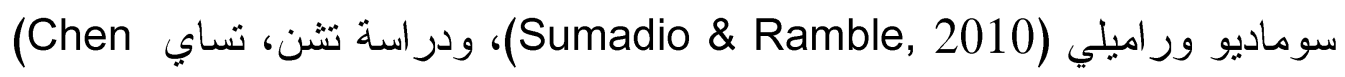

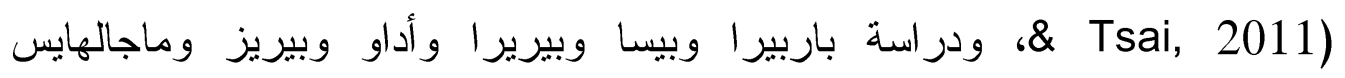
(Barreira, Bessa, Pereire, Adao, Peres \& Magalhaes, 2012)

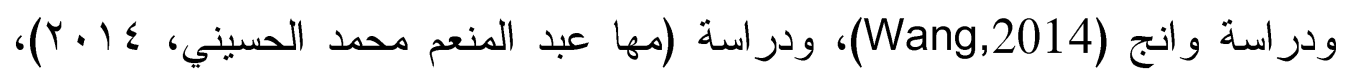

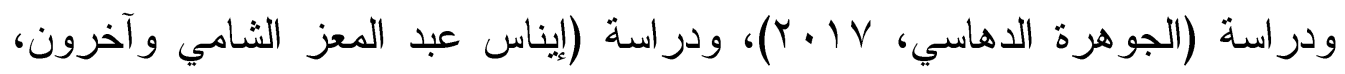
(r.lY 
مشكلة البحث

يعيش العالم في العصر الحالي ثورة علمية وثقنية كبيرة، ولم تعد العملية التعليمية في ظل استخدام تقنيات التعليم تقتصر على نقل المعرفة والمعلومات من المعلم للطالب، بل أصبح المعلم مطالب بالبحث عن استراتيجيات تعليمية حديثة تتمحور حول الطالب بحيث ثقوم هذه الاستراتيجيات على التفاعل المباشر الإيجابي بين الطالب وتثنيات التعليم بتوجيه من المعلم. وجاء في توصيات المؤتمر العلمي الثاني عشر للجمعية المصرية لتكنولوجيا

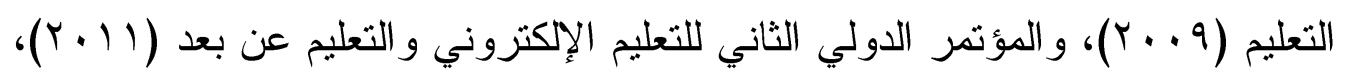

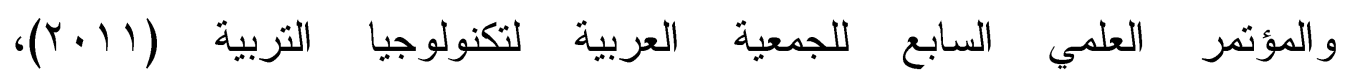
(International Symposium on Mixed and Augmented Reality - Arts, Media, and Humanities(ISMAR-AMH) (2012) لتكنولوجيا المعلومات الرقمية "الاتجاهات الحديثة في تكنولوجيا المعلومات" (r ـ ب)، و المؤتمر الدولي الثالث للتعليم الإكتروني والتعليم عن بعد (با. ب)، والتي أوصت بضرورة تطوير وتصميم بيئات إلكترونية تفاعلية، وتوظيفها بشكل يتتاسب مع الأهداف التعليمية، والاستفادة من تطبيقات التكنولوجيا والاتصالات لتحسين العملية التعليمية وجودتها. رغم أن تقنية الواقع المعزز تساهم في تقديم العديد من المزايا، التي ساعدت في رفع كفاءة العملية التعليمية، إلا أنه يوجد عدد من التحديات التي تواجه تطبيق

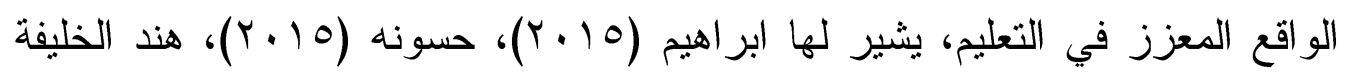

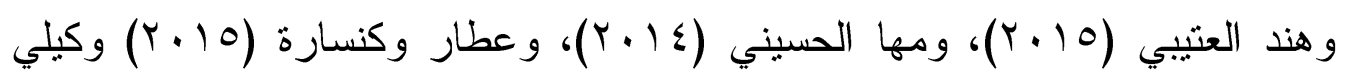
(Kelly)

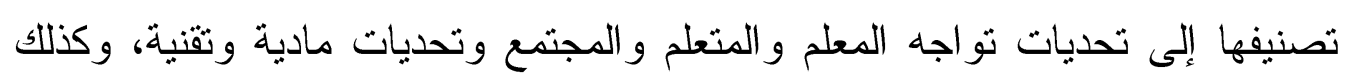
حجم الدر اسات المحلية التجريبية التي تقبس مدي فاعلية هذه التقنية في مجالات التعليم لا تز ال بسيطة نسبياً. 
مما سبق جاءت الحاجة إلى إجراء هذا البحث، مما دعا الباحث للقيام بدراسة

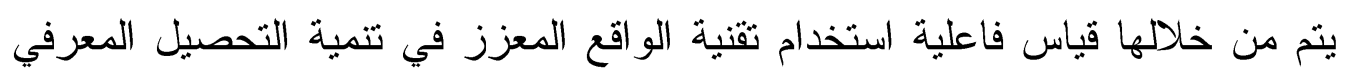
و الإتجاه لدي طلاب كلية التربية.

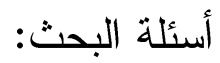

وتأسيسا على ما سبق تتحدد مشكلة البحث الحالي في السؤال الرئيسي التالي: - ما فاعلية استخدام تقنية الواقع المعزز على تلى لتمية التحصيل المعرفي والإتجاه

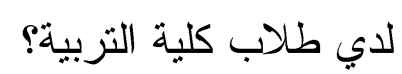

ويتفرع من السؤال الرئيسي الأسئلة الفرعية التالية:

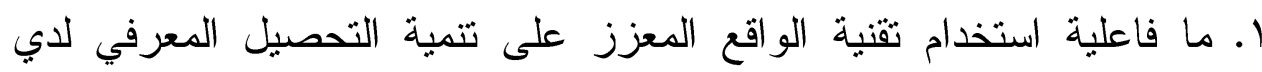

طلاب كلية التربية؟ مأبة

r. ما فاعلية استخدام تقنية الواقع المعزز على تتمية الإتجاه لدي طلاب كلية

$$
\text { التربية؟ }
$$

r. ما الفرق بين متوسطي درجات طلاب المجموعة التجريبية الذين يستخدمون تقنية الو اقع المعزز وطلاب المجموعة الضابطة في القياس البعدي على تتمية التحصيل المعرفي لدي طلاب كلية التربية؟ ـ. ما الفرق بين متوسطي درجات طلاب المجموعة التجريبية الذين بستخدمون تقنية الو اقع المعزز وطلاب المجموعة الضابطة في القياس البعدي على تتمية

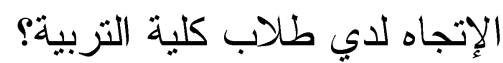
أهداف البحث: يهدف البحث الحالي إلي: ا. التعرف على فاعلية استخدام تقنية الو اقع المعزز على تتمية التحصيل المعرفي

$$
\text { لاي طلاب كلية التربية. }
$$
r. التعرف على فاعلية استخدام تقنية الواقع المعزز على تتمية الإتجاه لاي طلاب كلية التزبية. أهمية البحث: نبعت أهية البحث في أنه يمكن أن يسهر في: الهية

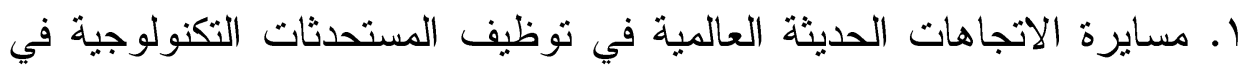
التعليم، وزيادة فاعلية العملية التعليمية، وجعل المتعلم محور العملية التعليمية. 
r. استخدام تقنية الواقع المعزز يمكن أن يسهم في تتمية التحصيل المعرفي لدي طلاب كلية التزبية. r. استخدام تقنية الواقع المعزز يمكن أن يسهم في تتمية الإتجاه لدي طلاب كلية التزبية.

$$
\text { حدود البحث: اقتصر البحث علي: }
$$

1. تقنية الواقع المعزز من خلال تطبيق AURASMA وهو من أثهر تطبيقات

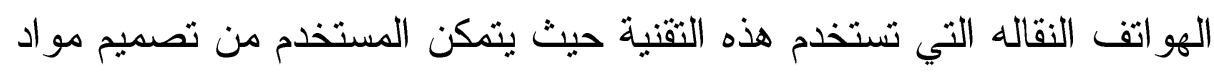

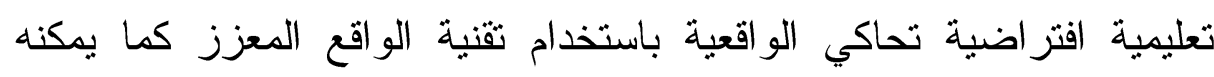

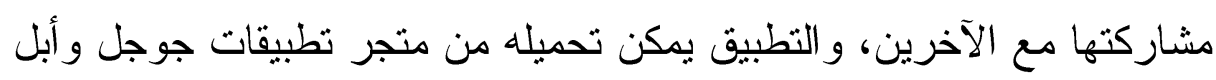
ستور، و استخدامه يسير في متتاول الجميع طلاب ومعلمين.

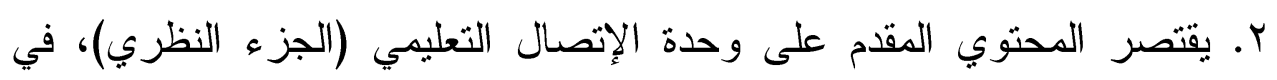

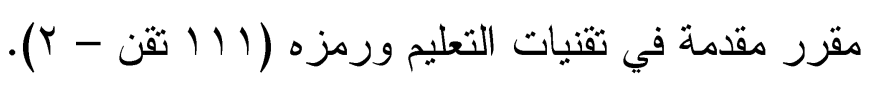
r. أجريت تجربة البحث على ثلاثة شعب من طلاب كلبة التربية - جامعة جاز ان.

$$
\text { أدوات البحث }
$$

1. اختبار التحصيل المعرفي لوحدة الإتصال التعليمي.

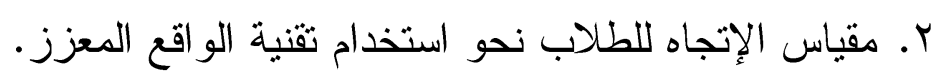
منهج البحث

استخدم البحث الحالي المنهج شبه التجريبي في بيان أثر المتغيرات المستقلة

$$
\text { التجريبية على المتغيرات التابعة. }
$$

متغيرات البحث: اشتمل البحث على المتغيرات التالية:

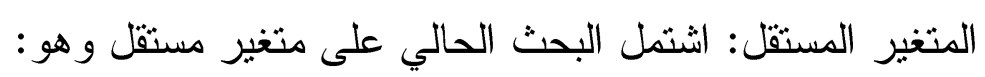

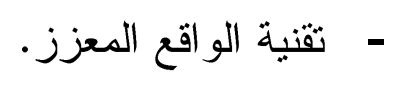

المتغير ات التابعة: اشتمل البحث على متغيرين تابعين هما: 1- التحصيل المعرفي لطلاب كلية التربية. ץ- الإتجاه نحو استخدام تقنية الواقع المعزز لطلاب كلية التزبية. 
فروض البحث

1- لا يوجد فرق دال إحصائياً عند مستوى (0 . . ) بين منوسطي درجات طلاب

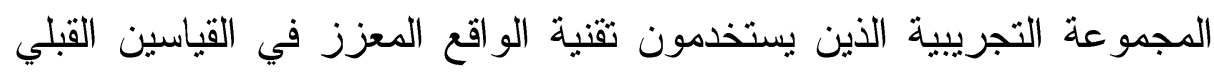

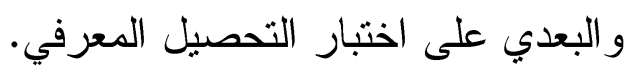

ץ- لا يوجد فرق دال إحصائياً عند مستوى (0. . •) بين منوسطي القياسين القبلي

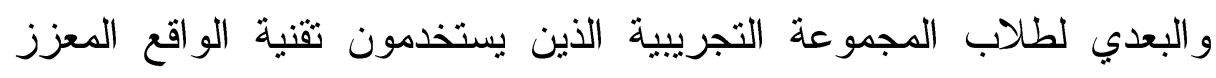
على مقياس الإتجاه.

ب- لا يوجد فرق دال إحصائياً عند مستوى (0. . .) بين متوسطي درجات طلاب الإن

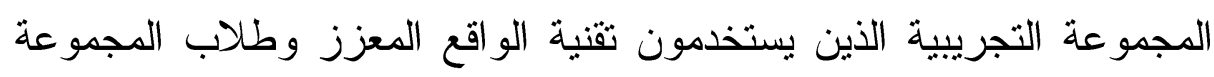

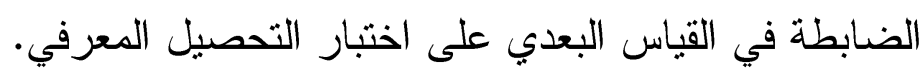

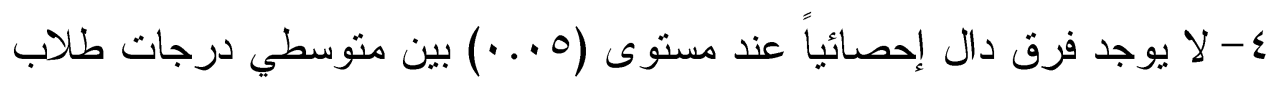

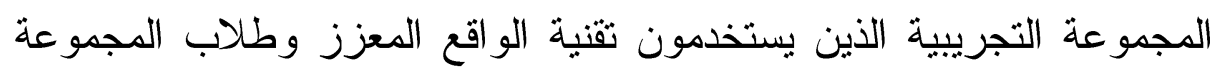
الضابطة في القياس البعدي على مقياس الإتجاه. مصطلحات البحث:

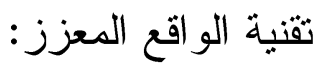
يعرف الواقع المعزز إجر ائياً بأنه "أحد أنواع الواقع الإفتراضي والذي يهدف

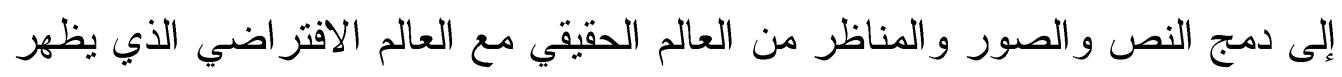

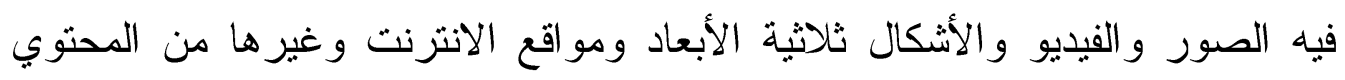

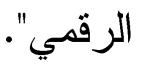

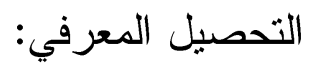
يعرف التحصيل المعرفي إجرائياً بأنه "الدرجة التي يحصل عليها المتعلم في

الاختبار التحصيلي المقدم له". الإتجاه: - الإن

يعرف الإتجاه إجرائياً بأنه "الثعور العام والثابت نسبياً لدى طلاب كلية

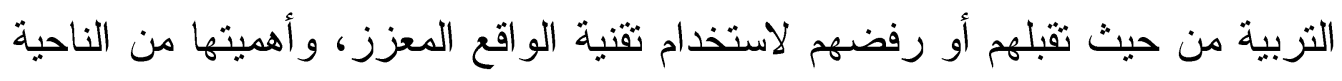


العلمية والعملية، بحيث يكون هذا الشعور موجهاً لهم لاتخاذ موقف التأييد أو المعارضة لتقنية الو اقع المعزز". الإطار النظري للبحث

لما كان البحث الحالي يهدف إلى قياس فاعلية استخدام تقنية الواقع المعزز

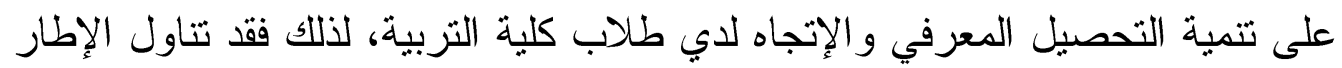

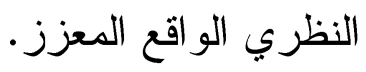

تمهيد:

إن الواقع المعزز من المصطلحات الجديدة التي ظهرت مؤخراً، وبحكم انفتاح التعليم على التكنولوجيا سعي رواده ومنظريه إلى الاستفادة من أحدث ما جادت به التكنولوجيا فى تحفيز المتعلمين وجعل عملية التعلم أكثر متعة وتشويقاً و إثارة، لذا فقدا لفال وجدت تقنية الو اقع المعزز طريقها بسهولة في مجال التعليم.

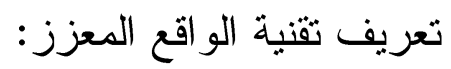

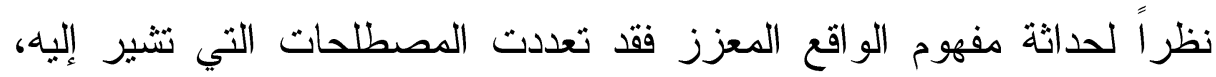

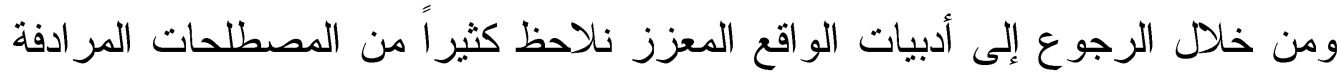

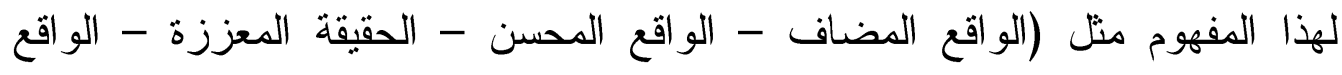

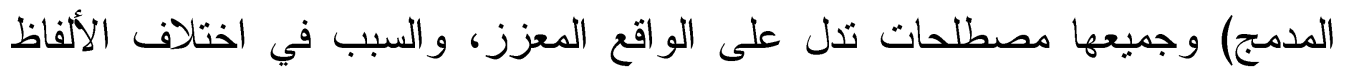

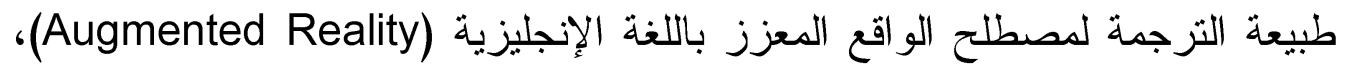

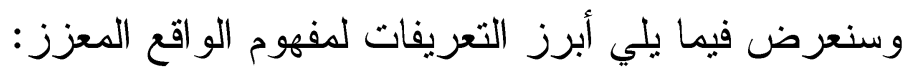
عربّت (Asuma,1997,365) الواقع المعزز بأنه: "تقنية تفاعلية متزامنة

تدمج خصائص العالم الحقيقي مع العالم الأفتر اضي بشكل ثنائي أو ثلاثي الأبعاد". عرِّت دونيليفي وديدي (Dunleavy,Dede,2006,p.7) الو اقع المعزز بأنه:

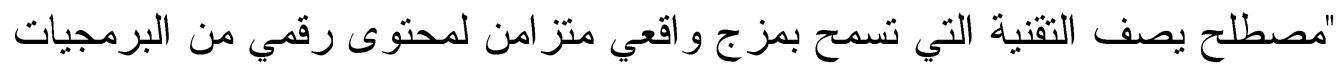
و الكائنات الحاسوبية مع العالم الحقيقي".

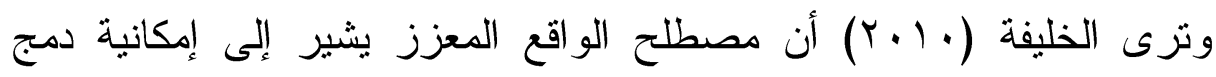

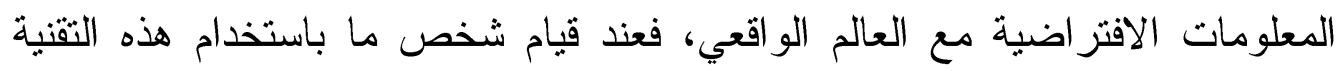

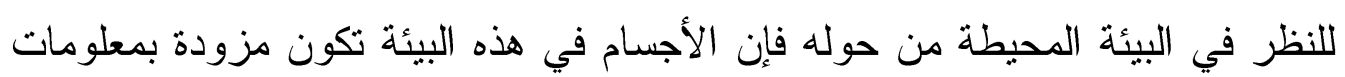


تسبح حولها وتتكامل مع الصورة التي ينظر إليها الثخص، وقد ساعد التطور التقني

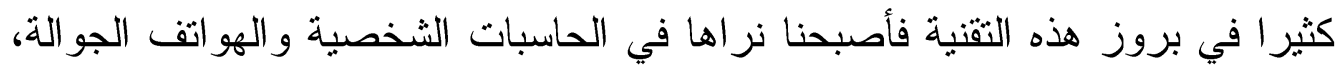
بعد أن كانت حكر ا على معامل الأبحاث في الثركات الكبرى.

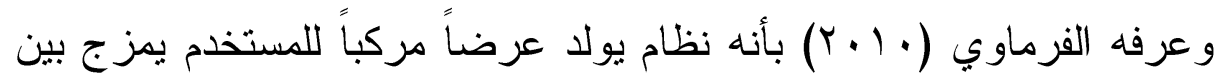
المشهد الحقيقي الذي ينظر اليه المستخدم والمشهد الظاهري الذي تم إنثاؤه بواسطة

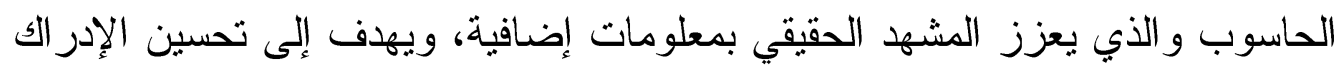

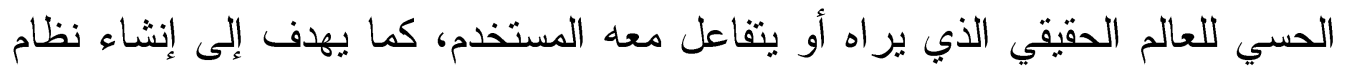

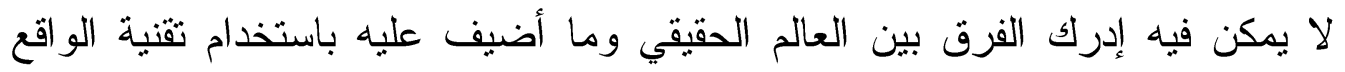
المعزز، فعند قيام شخص ما باسخدام هذه التقنية للنظر فى البيئة المحيطة به فإن

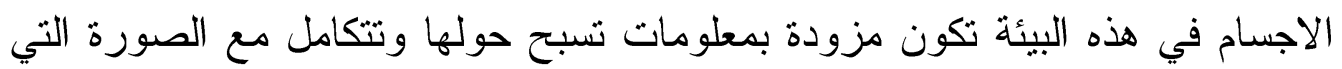

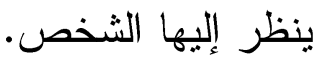

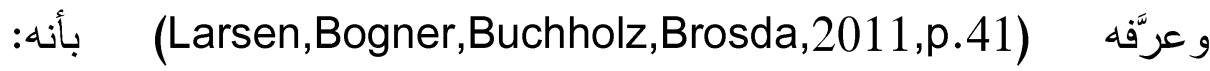
"إضافة بيانات رقمية وتركيبها وتصوير ها واستخدام طرق رقمية للو اقع الحقيقي للبيئة

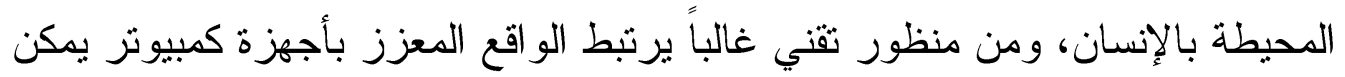
ارنداؤها، أو أجهزة ذكية يمكن حملها".

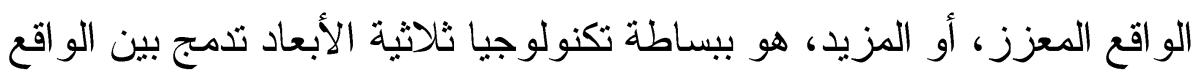

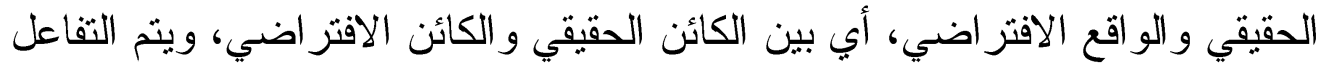
معها في الوقت الحقيقي، أثناء قيام الفرد بالمهمة الحقيقية ومن ثم فهو عرض مركب التبر

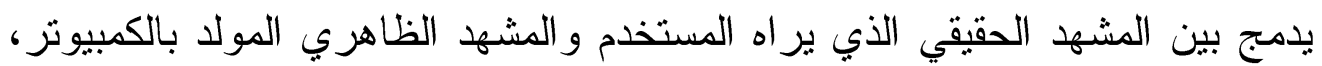

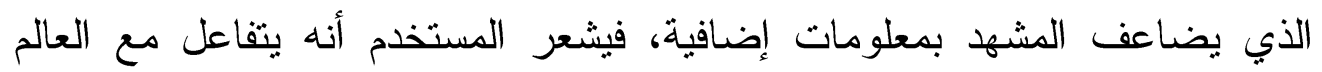
الحقيقي وليس الظاهري، بهدف تحسين الإدر الك الحسي للمستخدم.

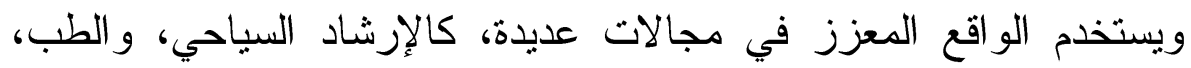
و الإنشاء، كما يستخدم في البيئات الافتر اضية حيث يتفاعل المستخدم مع المعروضات الئات وكأنها حقيقية بالصوت والصورة، وبالتالي يتمكن من رؤية وسماع الأشياء

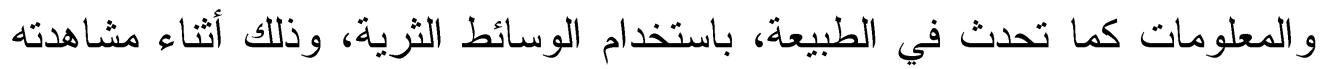

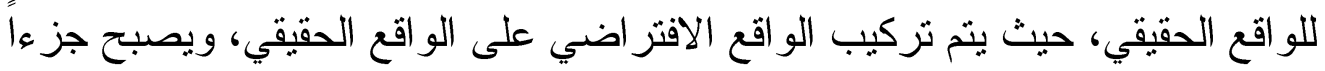


منه، ويتفاعل معه كأنه يتفاعل مع الحقيقي، ويكون الافتراضي أكثر وضوحاً من الحقيقي، حيث يضيف المواقع المعزز معلومات إلى المشهد. (خميس، 10 . ب) ويعرف البحث الواقع المعزز بأنه: "تقنية تفاعلية تشاركية تز امنية تستخدم أجهزة يمكن ارتداؤها أو حملها لإضافة بيانات رقمية للواقع الحقيقي عبارة عن (صور - صوت - مقاطع فيديو - رو ابط) بأشكال متعددة الأبعاد.

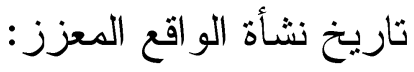
تم تقسيم التطور التاريخي لتقنية الو اقع المعزز إلى ثلاث مر احل وهي كالآتي:

(Yuen,Yaoyuneyong,Johnson,2011,p.122) (Choi,Hebert,Estes, 2016,169)؛ مرحلة ظهور الفكرة: - مرن في هذه المرحلة ظهر الوقع المعزز كوصف للفكرة التي يقوم عليها، فقي عام 19 19 وصف فر انك باوم مجموعة من النظارات الإلكترونية التي يمكن من خلالها رؤية شخصيات في قصته (حكاية خيالية). مرحلة الانتشار المحدود: وفي هذه المرحلة تحولت الفكرة من خيال إلى واقع ومن أبرز ما تم في هذي المرحلة بلورة مصطلح ثقنية الواقع المعزز، وفيما يلي نستعرض رواد ثقنية الواقع المعزز وما أحدثوه من نقلة نو عية فيها:

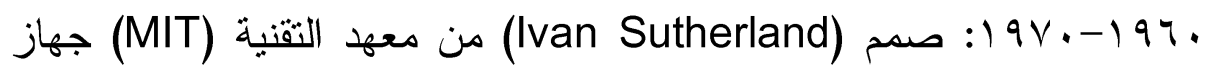
يقدم صوت وصورة ثلاثية الأبعاد، وكان الفارق الجوهري بين هذا الجهاز ورسومات الحاسب هو تغير الرسومات بناءً على المكان الذي يقف فيه المستخدم، من خلال مستشعر رئيسي يقيس الموقع وزاوية الرأس، وبناءً عليه يتغير نظام الكائنات الافتر اضية، https://www.youtube.com/watch?v=Hp7YgZAHLos 19V0 أنظمة لمسية تخدم تقنية الواقع المعزز متصلة بأجهزة الحاسب الآلي (Connecticut) لتنفيذ (Video Place) الذي يتيح للمستخدم التفاعل مع حركة صورة الشخص بشكل 
تزامني، ويمكن التعرف أكثر على (Video Place) من خلا الرابط التالي: https://www.youtube.com/watch?v=dqZyZrN3P10

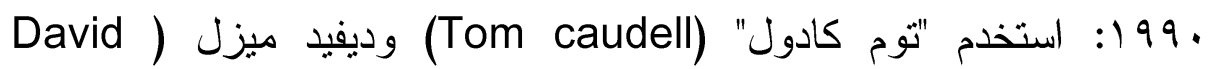

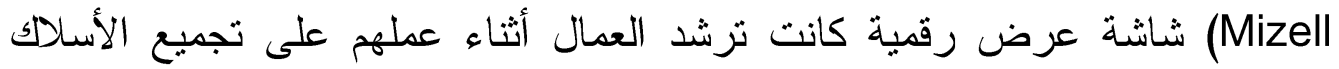

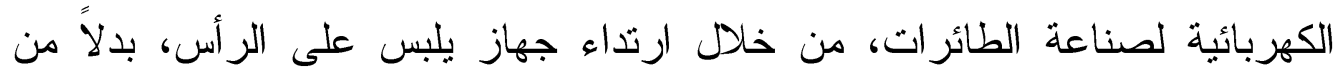

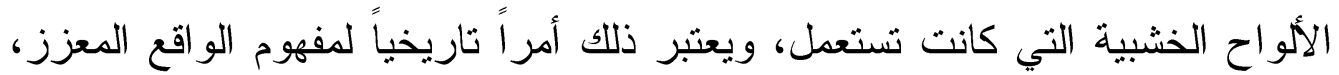
حيث يعتبر "كادول" أول من صاغ مصطلح الو اقع المعزز . ع 99 ا: ابتكر (Azuma) بتعاون مع شركة تعمل في معامل بحوث (HRL) جهاز تعقب مهجن يتيح للمستخدم حرية الحركة بشكل أكبر، ويعتبر تطور في تقنية

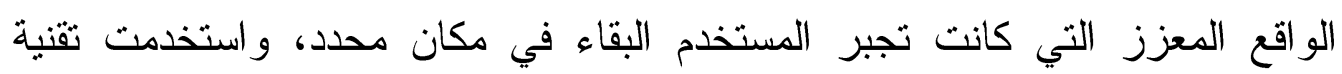
أزوما في عرض الإعلانات النصية الافتراضية على المباني، وهذه التقنية تعد خطوة أولى لتقنية الو اقع المعزز التي أصبحت عالمية الإتخدام.

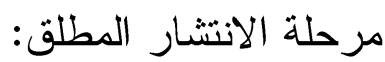

في أو اخر التسعينات وبداية الألفية الثالثة خطت تقنية الو اقع المعزز العديد من التحن

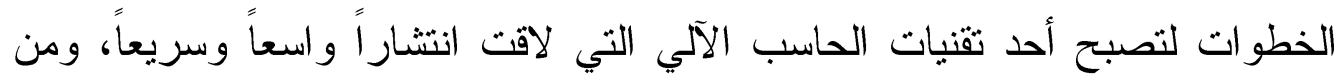

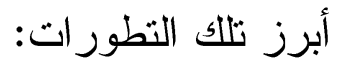

1991: بدأ تنظيم عدد من المؤتمرات المخصصة لدراسة تقنية الو اقع المعزز

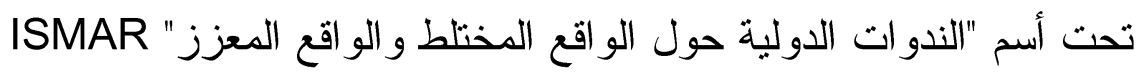
وفي نهاية التسعينات ظهر عدد من المشاريع و البحوث في سنغافورة وألمانيا و التي ركزت على تطوير تقنية الو اقع المعزز. وتعتبر الألفية الثالثة ومع مرحلة ظهور الأجهزة و الهو اتف الذكية مرحلة

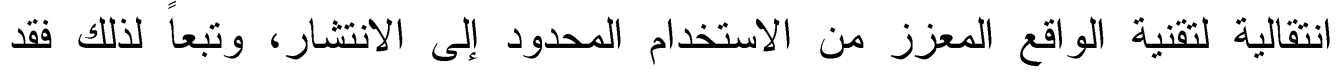

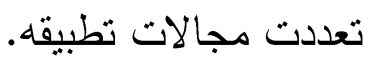




$$
\text { أنواع الو اقع المعزز : }
$$

قسم (Dunleavy, M, \& Dede,2014) أنو اع الو اقع المعزز على أساس:

$$
\text { 1- 1-تييز الموقع: }
$$

توفر الوسائط الرقمية للمستخمين بواسطة الهواتف الذكية أو الأجهزة

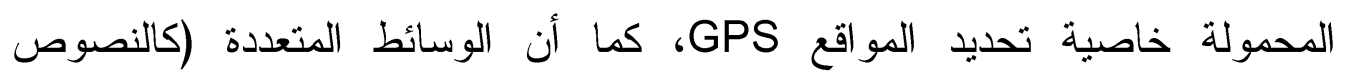

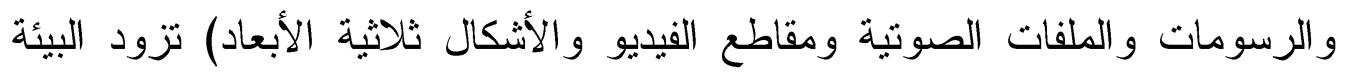
المادية بمعلومات أكاديمية أو ملاحية ذات صلة بالمعات العوقع.

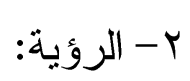

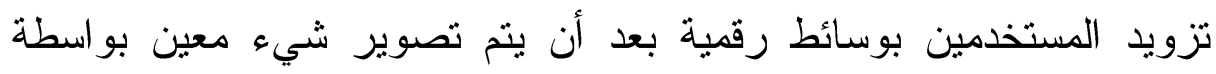

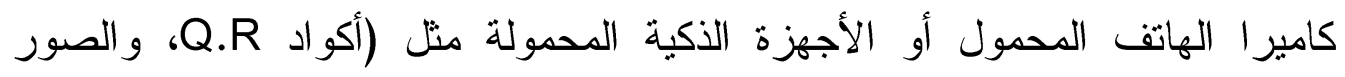

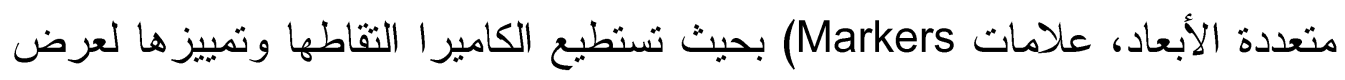
المعلومات المرتبطة بها. طبيعة عمل تقنتية الو اقع المعزز :

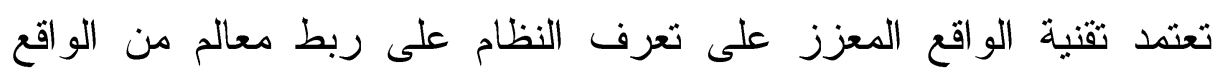

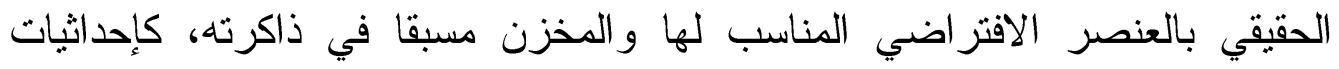

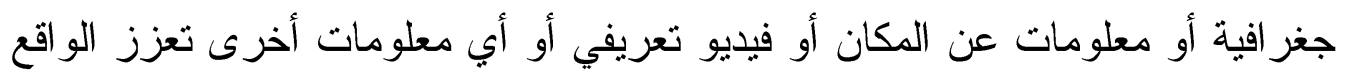

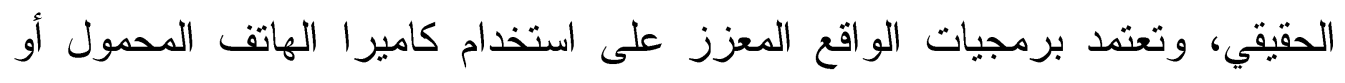

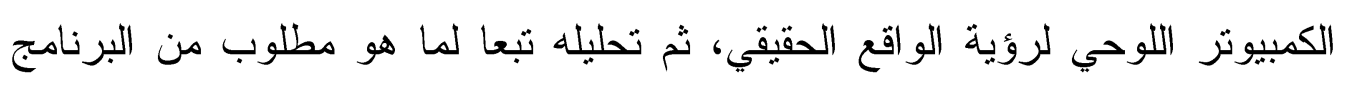

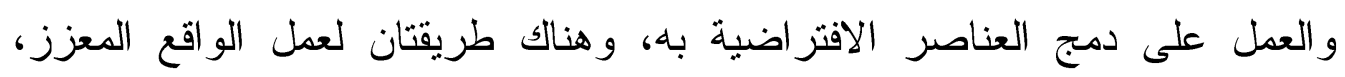

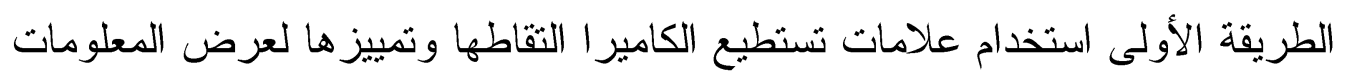

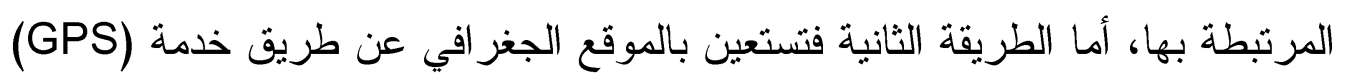

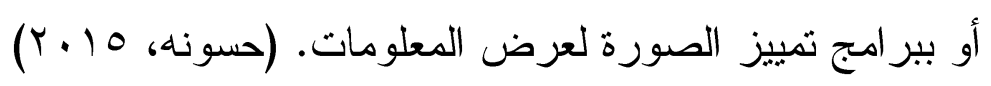




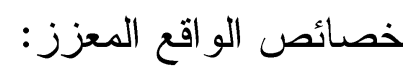

Azuma, Baillot, Behringer, Feiner, Julier \& 10) أثنار

(Machntyre, 2001, p.

ا- يمزج الحقيقية الافتر اضية، في بيئة حقبقية.

r- باعلية تكون في وقت استخدامها.

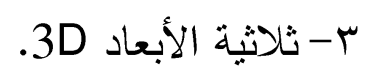

وأضاف (Anderson, Liarokapis, 2014, p.2) الخصائص التالية:

1- نوفر معلومات و اضحة ودقيقة.

r- إمكانية ادخال المعلومات بطريقة سهلة وفعالة.

ب- إمكانية التفاعل بين طرفين مثل: (معلم ومتعلم).

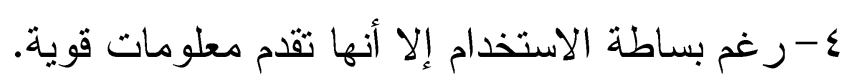

0- جعل الإجر اءات المعقدة سهلة للمستخدمين.

צ- فعالة من حيث التكلفة وقابلة للتوسع بسهولة.

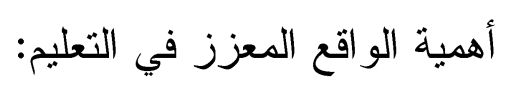

يعرف مفهوم التعلم المعزز بأنه تقنية تعلم عند المتعلم، حيث تتبنى بيئات

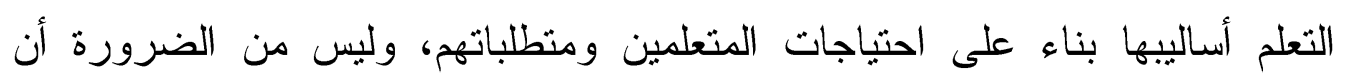

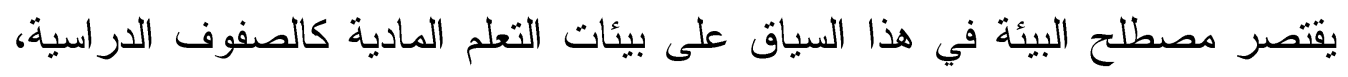
بل قد يشبر إلى بيئات التعلم الرقمية حيث يستطيع المتعلمون من خلالها تحفيز قدرتهم

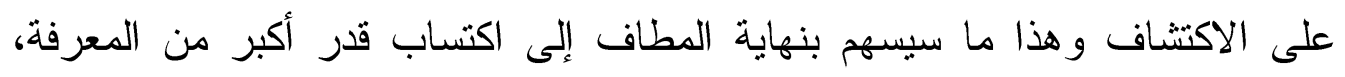

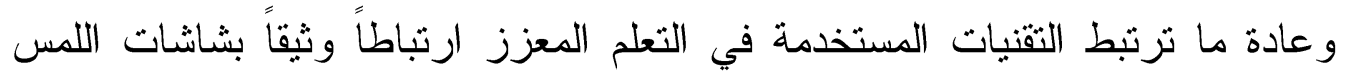

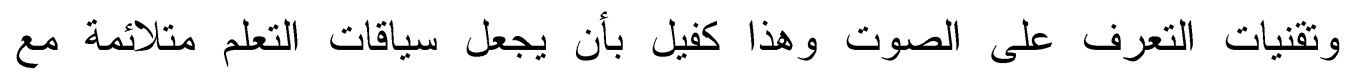
احتياجات المنعلم عن طريق عرض نصوص وصور و اضحة إضافة إلى مقاطع فيديو أو مقاطع صوتية، فعلى سبيل المثال لا الحصر، من الممكن باستخدام تقنية التعلم

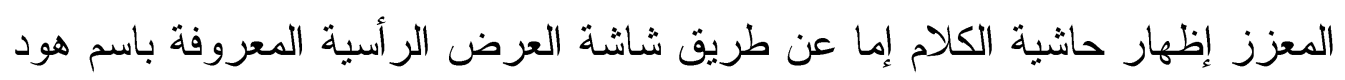

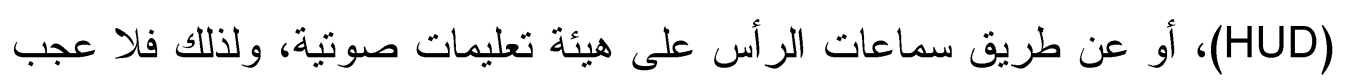


أن أثنتت تقنيات التعلم المعزز قدرتها على تطوير أداء التعلم نظراً لدورها البارز في رفع كفاءة التعليم.

ويمكن توضيح دور الواقع المعزز في التعليم كما أثشار إليه (الخليفة، • 1 ب بم؛

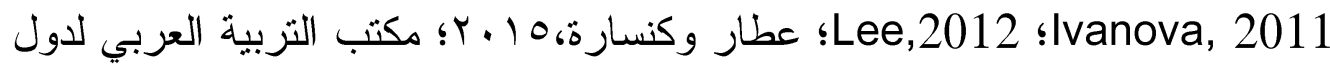
الخليج، 10 • ب إن في النقاط التالية:

إن نجاح توظيف تقنية الواقع المعزز في التعليم يتوقف على درجة امتلاك المعلم للمعارف و المهار ات اللازمة لاستخدام هذه التقنية و التعامل معها.

يوفر الواقع المعزز مساحة تعليم ابتكارية وذللك عن طريق دمج مواد الدهاد التعليم

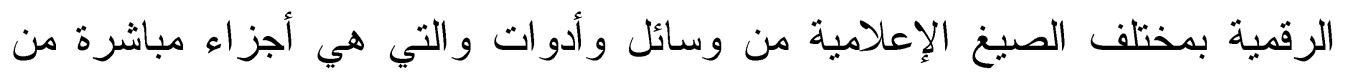

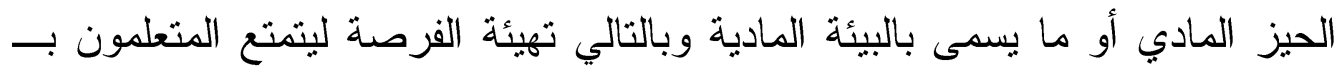
(التعلم الموقفي).

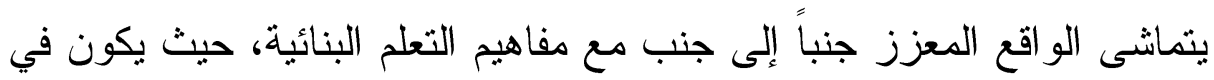

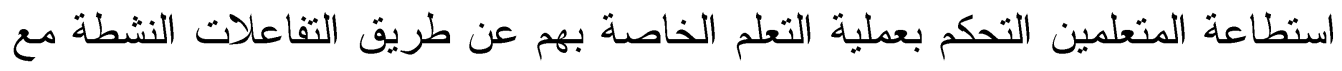

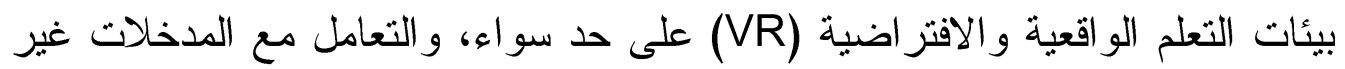
الو اقعية في بيئات التعلم هذه، وبالتالي اكتساب قدر أكبر من المهارة و المعرفة. يترجم الو اقع المعزز النظرية البنائية إلى واقع ملموس يمكن تطبيقه، ولطالما

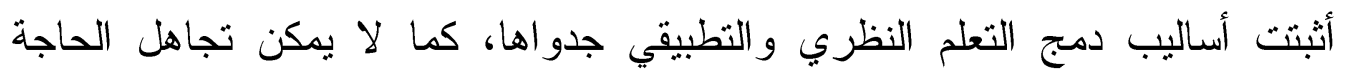
المتزايدة و الملحة في تطبيق مفاهيم التعلم الإلكتروني وإعمال مختلف التقنيات بشكل فعال، ومن هذا المنطلق فإن الواقع المعزز كفيل بأن يسد الثغرة الحاصلة بين التعليم

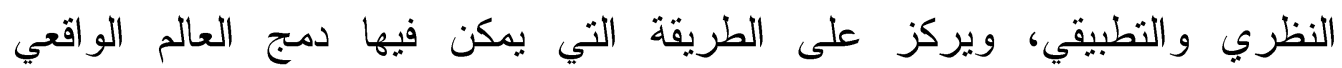
و الافتراضي معاً، لتحقيق مختلف أهداف التعلم الإلكتروني ومنطلباته بل حتى بيئاته أيضاً. تضيف تقنية الو اقع المعزز بعدا إضافيا جديدا لتدريس المفاهيم مقارنة بطرق

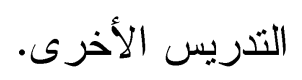


زيادة الفاعلية التزبوية، يحقق الواقع المعزز نتائج ملموسة في عمليات التعلم

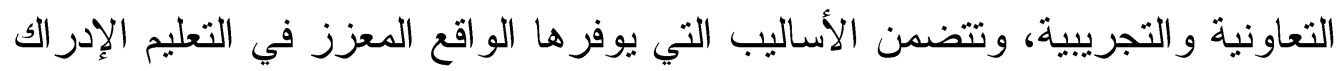
البدني، و الإدر الك المتجسد، و التعلم الموقفي، و العمل العقلي. ونسئ.

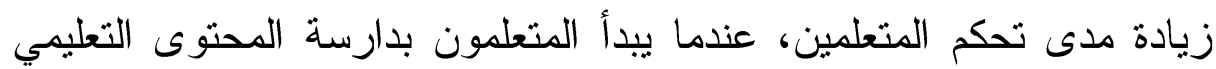
باستخدام جهاز الحاسوب، فإنهم يتوجب عليهم عادة اكتساب معرفة تتعلق بطريقة

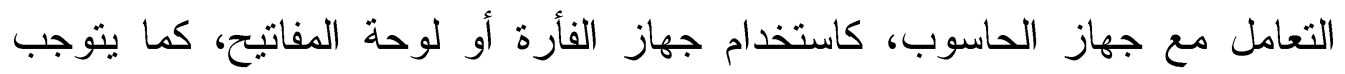

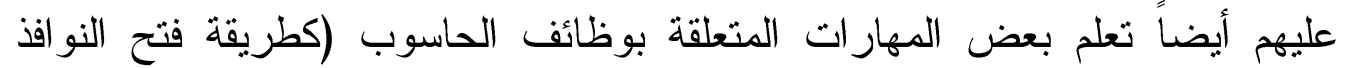

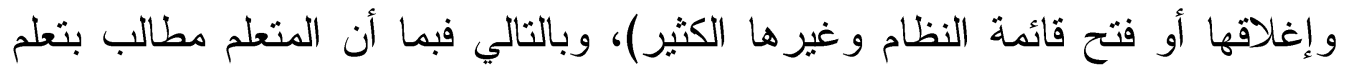

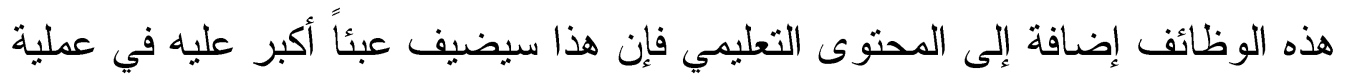

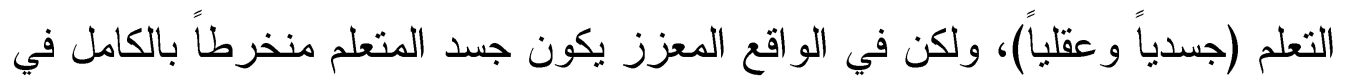

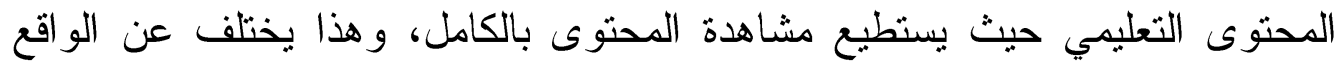

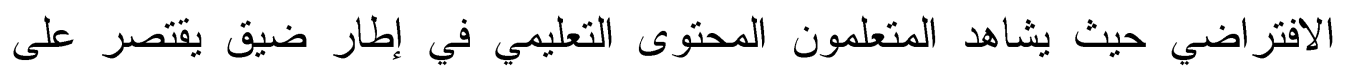
العالم المحيط بهم و على أجسادهم. تطبيقات و ألعاب الواقع المعزز التعليمية التعلمية تنقل المتعلم إلى عالم المعلومات الدر اسية، ليختبر أسسها ومسبباتها بنفسه في خبرة و اقعية محفزة ومشوقة بدلاً من التعامل مع هذه المعلومات في قالب نصي ثابت.

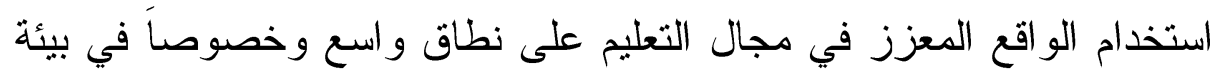

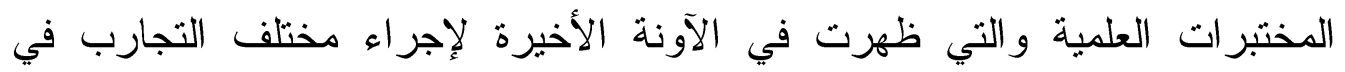
الصفوف الدر اسية الحقيقية. تحفيز المتعلمين على المشاركة، لا يخفى على الجميع أن التحفيز يلعب دوراً

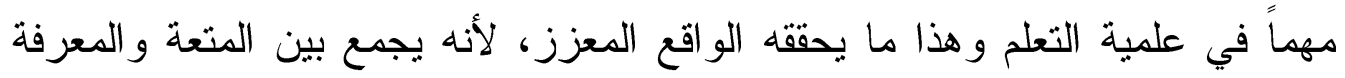

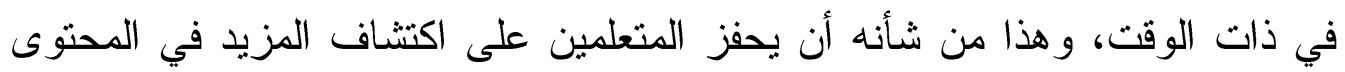

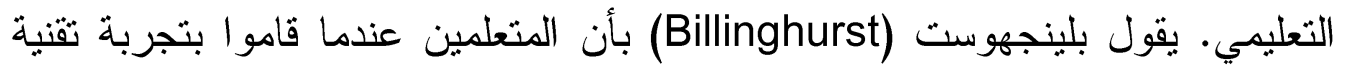

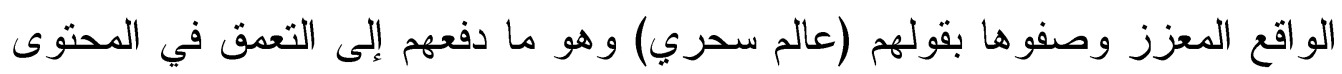

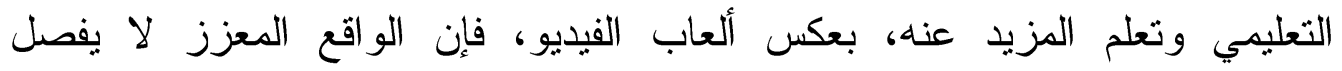

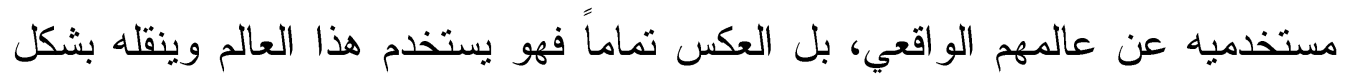




\section{$r \cdot r$}

و اقعي إلى عالم رقمي وهذا كفيل بأن يرفع مستوى الفضول و الدهشة لدى المتعلمين

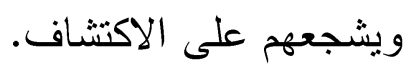

زيادة كفاءة المعلم في التعليم، تؤدي تقنيات الواقع المعزز دوراً مهماً في

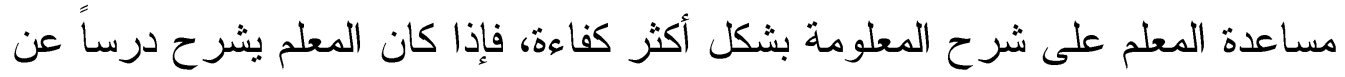

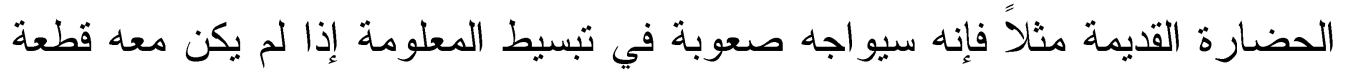

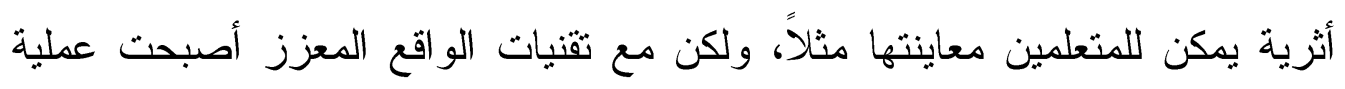

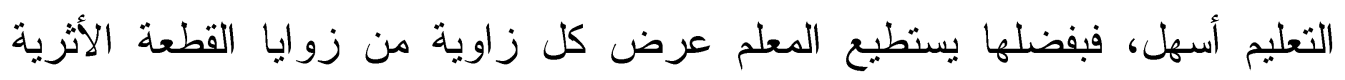
ويستطيع المتحلمون معاينتها.

وأضافت شامينا بارفيين (Shameena Parveen) المشاركة في تأسيس إيدوتك (Edutech) للتنريب: "حتى يتمكن المتعلمون من تطوير المهارات المطلوبة في عملية التعلم، ينبغي على المدارس أن تغير مفهوم (أنا أوضح الدرس ونس أنتح

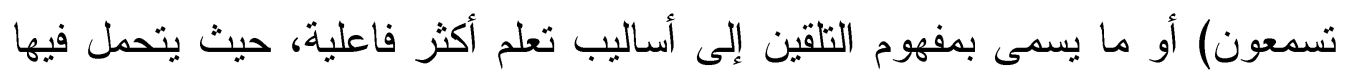
المتعلمون مسؤولية عملية التعلم ويكونون مشاركين نشطين أكثر من كونهم مجرد

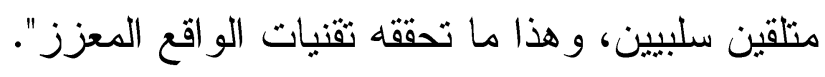

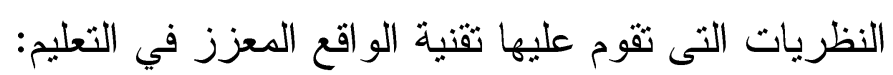

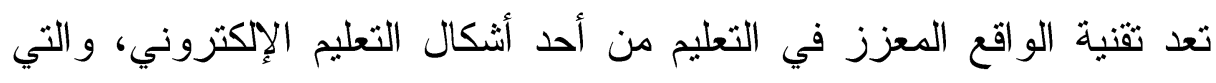

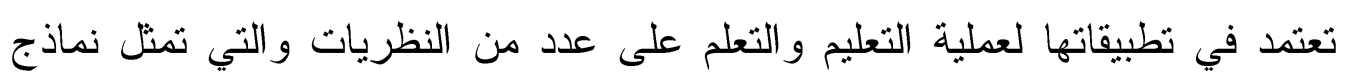

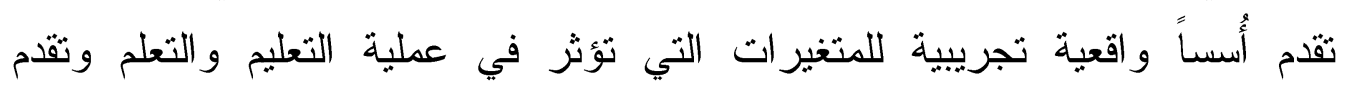
توضيحات حول السبل التي يمكن أن يحدث بها هذا التأثير.

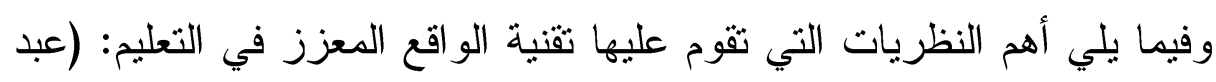

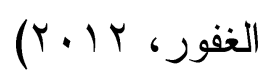
النظرية السلوكية (سكنر): ووفقاً لهذه النظرية فإن السلوك إما أن يكون متعلماً

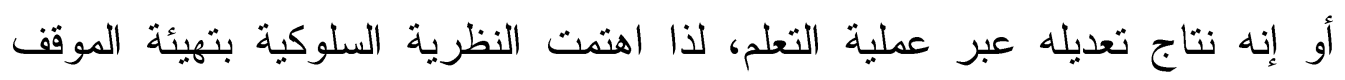

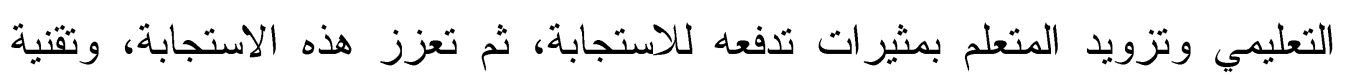

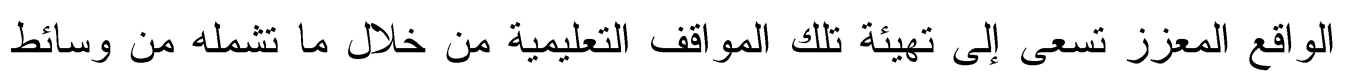
متعددة تعمل كمثير ات للتعلم. 
النظرية البنائية: بيئات التعلم البنائي ترتبط ارتباطاً وثيقاً بالتعلم الإلكتروني

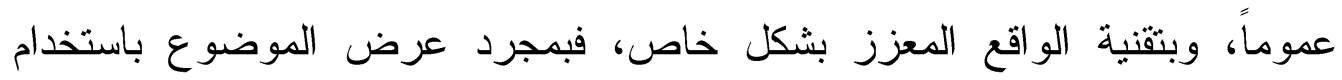

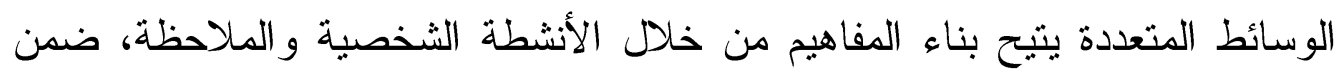
بيئات تفاعلية غنية، والذي بدوره يؤدي إلى تعلم أفضل، فمن مبادئ النظرية البنائية

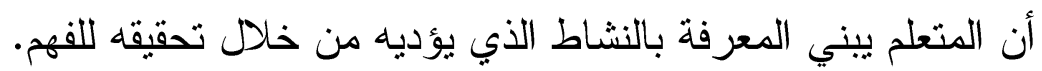

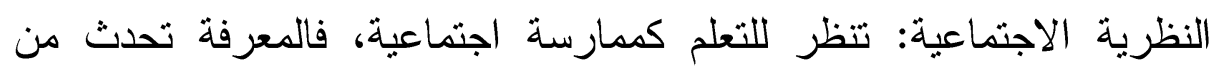
خلال مجتمعات الممارسة، وبالتالي فإن نتائج التعلم تتطوي على قدرات المتعلمين

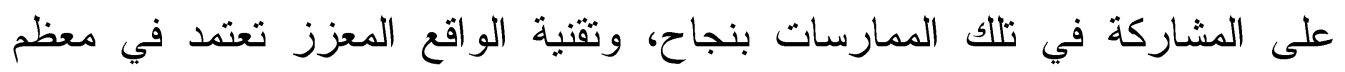
تطبيقاتها على التعلم من خلال المشاركة مع الأقران.

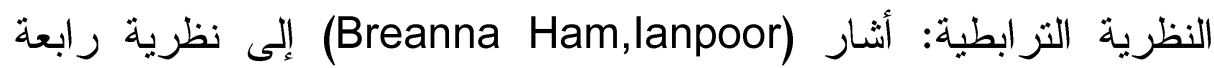

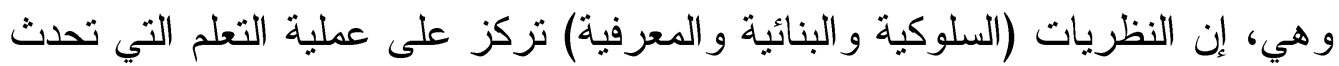

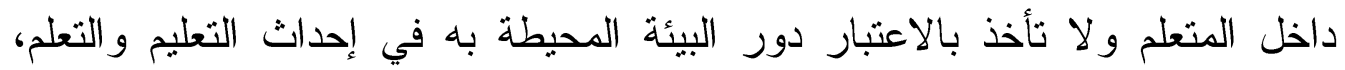
وبظهور تقنية التعليم والتي تركز على كيفية التعلم وليس كمية ما ينم تعلمه، أدى ذلك اللك

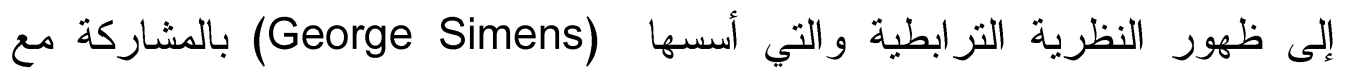
(Downe)

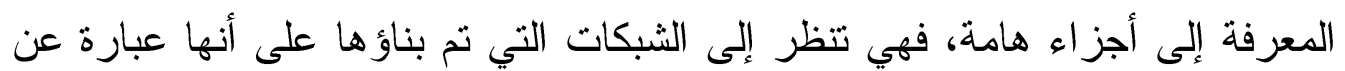

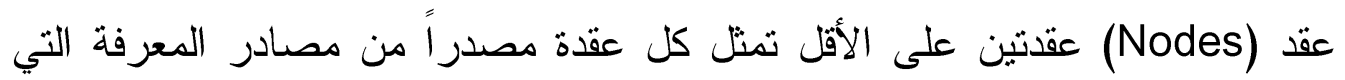
تتصل فيما بينها برو ابط، وعملية التعلم تتم من خلال قدرة المتعلم على الوصول لتلك التك الروابط بين العقد والمعلومات المختلفة بفاعلية، وتقنية الواقع المعزز تعتمد على أحد

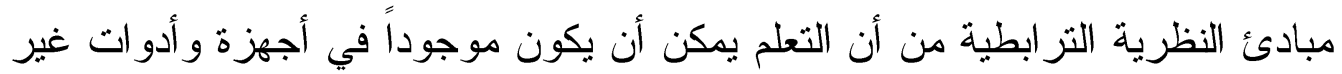

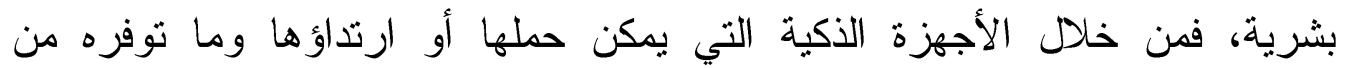
تطبيقات يمكن من خلالها احداث التعلم. الأدوات التي تدعم تقنية الو اقع المعزز :

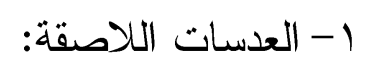

بجانب النظارات، سيتم توفير عدسات لاصقة تقنية، هذه العدسات ستأتي

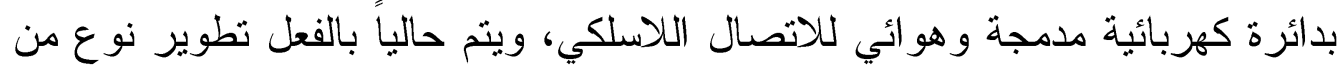


العدسات للجيش الأمريكي يمكن الجندي من رؤية الأهداف القريبة منه والتي تم التعديل عليها من خلال تكنولوجيا الواقع المعزز، بالإضافة إلى رؤية الأهداف الحقبقية البعيدة عنه في نفس الوقت. r- الهواتف الذكية و الأجهزة اللوحية:

معظم الأجهزة المحمولة الجديدة تتضمن العناصر المطلوبة لدعم التكنولوجيا الجديدة، وتتقسم هذه العناصر إلى المعالج المركزي، شاشة العرض، أجزةة الاستشعار ، و أجهزة الإدخال.

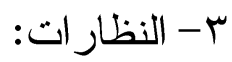

سيتم في المستقبل توفير نظارات داعمة لتكنولوجيا الواقع المعزز، هذه النظار ات ستتضمن كاميرات للتعرف على البيئة المحيطة و إعادة عرضها للمستخدم بعد إضافة الرسومات و المعلومات الخاصة بها، و العرض بأكمله يتم على عدسات النظارة نفسها، نظار ات جوجل الذكية لا توفر هذه الميزة، ولكن بعض الشركات قامت بتصميم تطبيق خاص بها يمكن نظارات جوجل من الاستفادة ببعض هذه المميزات.

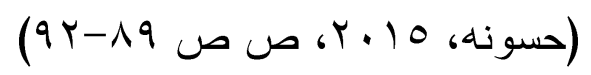
التطبيقات التي استخدمث تقنية الواقع المعزز : استخدام تقنية الواقع المعزز في التعليم لا يزال في بدايته إلا أنه في ازدياد، حيث يسهم استخدام تقنية كهذه في تحفيز المتعلمين وبث روح الإثارة والتشويق فيهم، وخلق بيئة تعليمية مميزة لا يشعر فيها المتعلم بأي خمول أو ملل، إن هذه التقنية تقوم بتحويل الصور و النص في الكتب إلى شئ حي متحرك بمجرد توجيه عدسات الأجهزة عليها، ومن بين التطبيقات و البرامج والمنتجات التي استخدمت فيها هذه التقنية في التعليم ما يلي: Elements 4D منتج يستخدم تقنية الواقع المعزز، يمكن من خلاله خلق تفاعلات كيميائية افتز اضية من خلال الأجهزة الذكية. 
Anatomy 4D -

تطبيق يمكن للمتعلم من خلاله تشريح الجسم البشري واستكثاف أجززته

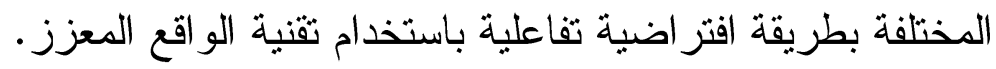

iTacitus.org -

مشروع اعتمده الاتحاد الأوروبي لتدريس تاريخ أوربا بطريقة افتراضية من

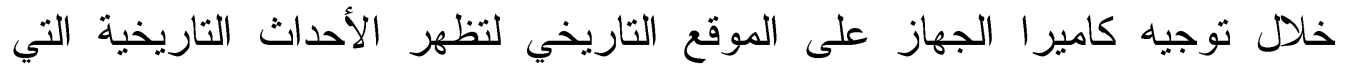
حدثت فيه.

ARIS -

برنامج يستخدم تقنية الو اقع المعزز يمكن من خلاله خلق بيئة ألعاب افتراضية

داعمة للمنهج الدراسي.

\section{AURASMA -}

من أثهر تطبيقات الهواتف النقاله التي تستخدم هذه التقنية حيث يتمكن

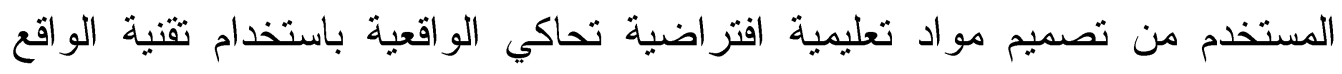

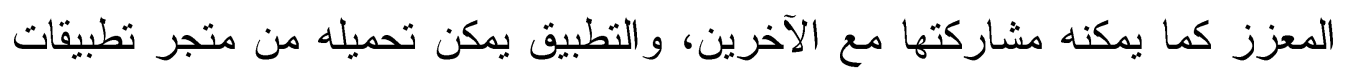

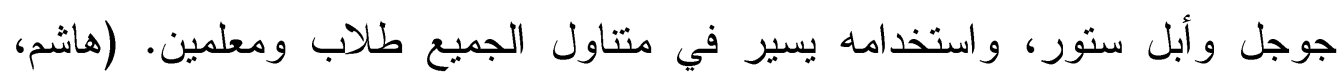

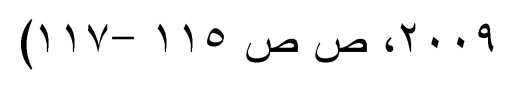$$
\text { تطبيقات الو اقع المعزز في التعليم: }
$$

إن الإمكانات الواعدة التي توفرها تقنية الواقع المعزز في التعليم دفعت الدول

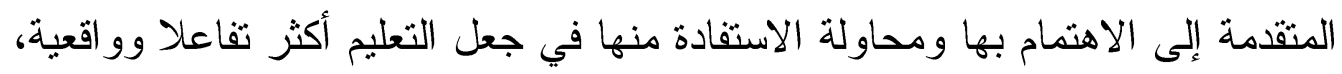
وفي هذا الإطار، اعتمد الاتحاد الأوروبي مشروع (ITacitus.org) لتعليم تاريخ

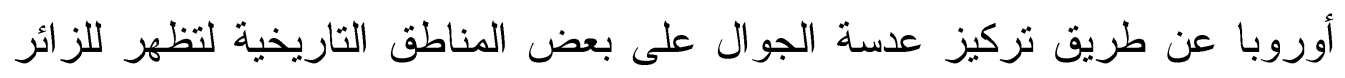

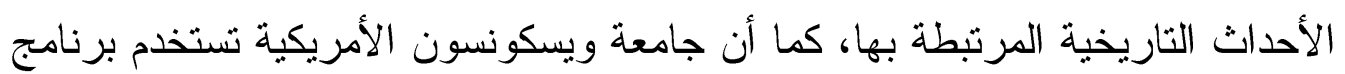

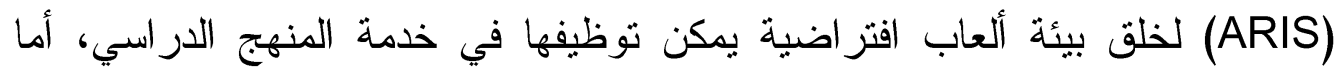

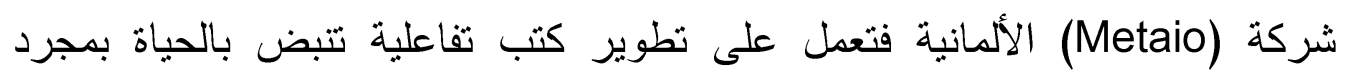
تسليط كامير ا الجو ال عليها، وتتحدد تطبيقات الو اقع المعزز في التعليم فيما يلي: 


$$
\text { 1- تشجيع الو الدين: }
$$

يتم تسجيل موجز للآباء والأمهات يقومون من خلالها بتشجيع أطفالهم، ولصق الصق

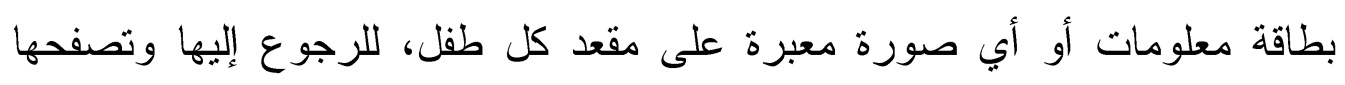
بواسطة الهاتف النقال كلما احتاج المتعلم لتشجيع وتحفيز و الديه.

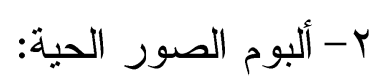

يمكن إعداد ألبوم صور لأنشطة السنة الدراسية، من حفلات وندوات وما

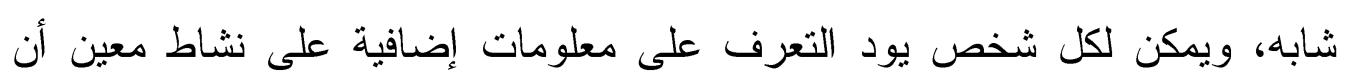

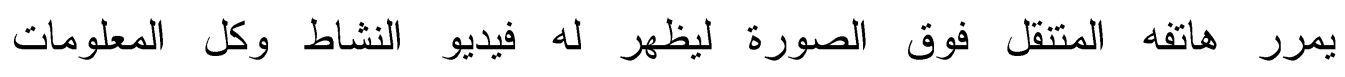
و الإحصائيات و الثقاريز المتعلقة به.

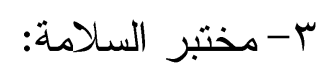

يتم إعداد صور أو بطاقات رمز السلامة، وتعلق في جميع أنحاء مختبر العلوم

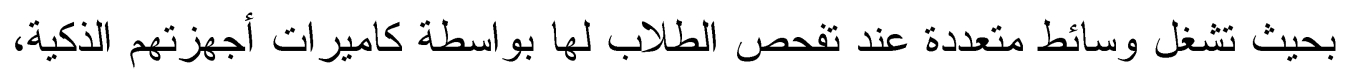

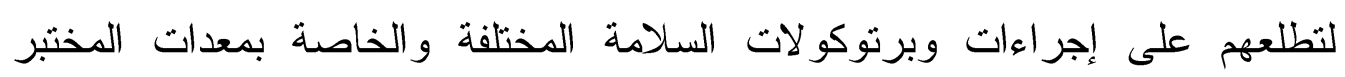

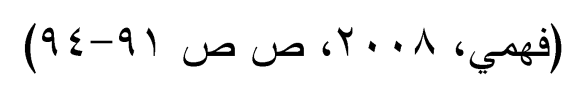

ع - بطاقات تعليمية للصم وضعاف صن السمع:

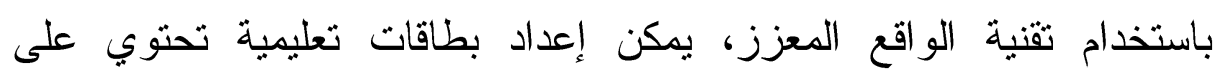

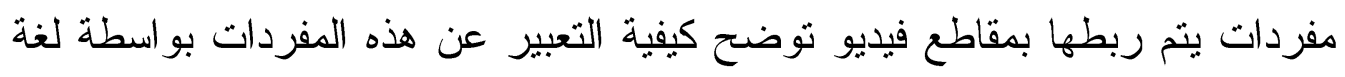

$$
\text { 0- الو اجبات المنزلية المدعمة بالشر ح: }
$$

يمكن استخدام تقنية الواقع المعزز لدعم المتعلمين ومصاحبتهم حين إنجاز هم المثرح

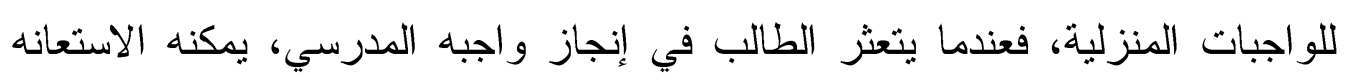

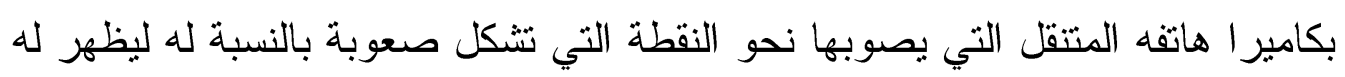

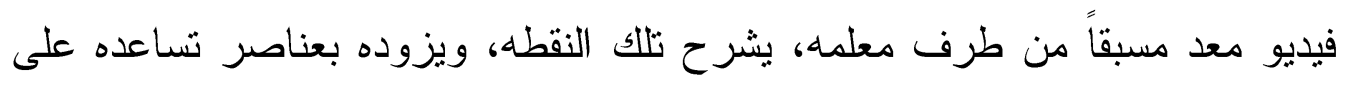
حل المشكلة. 
צ- (1) عرض حول كتاب:

يقوم الطلاب بتسجيل عرض موجز للكتاب الذي انتهوا للتو من قراعته، يتم تحويل العرض إلى بطاقة معلومات رقمية مرفقة بواسطة برنامج معلوماتي معد لهذا

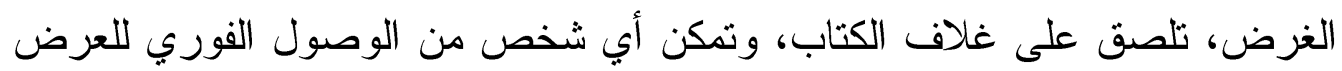
المسجل والتعرف على موضوعات الكتاب عبر مسح بطاقة المعلومات بواسطة

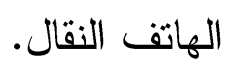

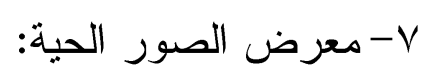

يمكن استغلال تقنية الواقع المعزز في إعداد معرض لصور هيئة التدريس

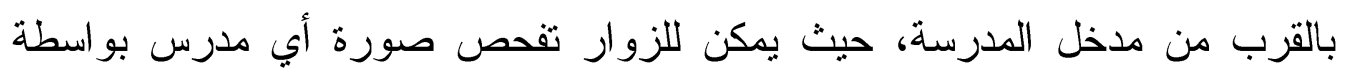
هو اتفهم النقالة، لتدب الحباة في هذه الصورة وتحدث الزئه ائر عن صاحبها. 1- نطبيقات الفصول الدر اسية:

هناك تطبيقات عدة يمكن توظيفها لجلب تقنية الواقع المعزز لفصلك الدئه الدراسي،

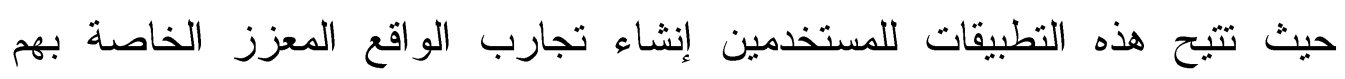
والإندماج فيها، بكل سهولة ويسر وبتوظيف أجزاتهم الثخصية أو الددرسية.

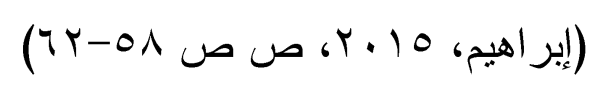

التحديات التي تواجه توظيف تقنية الواقع المعزز في التعليم: آلته

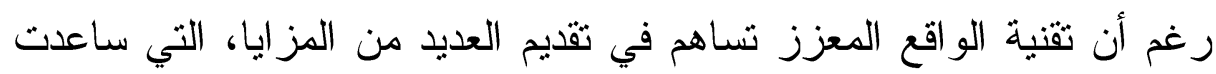

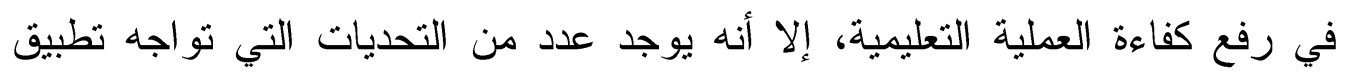

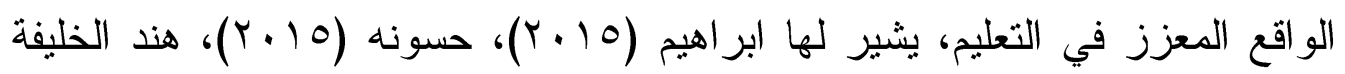

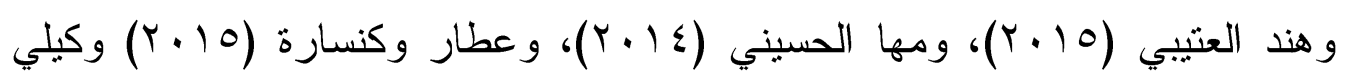
(Kelly) تصنيفها إلى تحديات تو اجه المعلم و المتعلم و المجتمع وتحديات مادية وتقنتية.

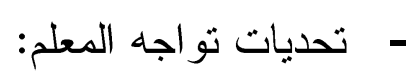
1- افتقار المعلم إلى آليات تقنية الو اقع المعزز ، وكثرة الأعباء المطلوبة منه، وقلة

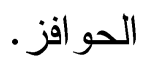
ץ- انعدام وجود منهجية لنأطير التعامل مع نهر المعلومات المتذفق. 
ץ- تتطلب خبر اء ومصممين محترفين لمساعدة المعلم في إيجاد المحتوى المناسب

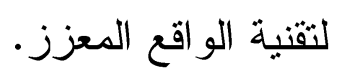

ع- عدم توفر القناعة الكافية لدى المعلم بهذا النوع من التعليم، وعدم تفعيله

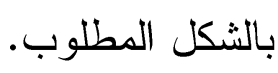

0-حجم الدراسات الدحليه التجريبية التي تقبس مدى فاعلية هذه التقنية في مجالات التعليم لا تز ال بسيطة نسبياً.

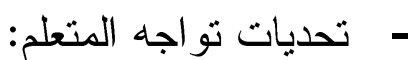

1- عدم توفر القناعة الكافية لدى المتعلم بهذا النوع من التعليم، وعدم تفاعله

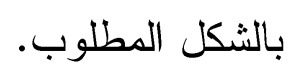

r- تقتصر على مجمو عات صغيرة من المتعلمين وغير متوفرة على نطاق و اسع.

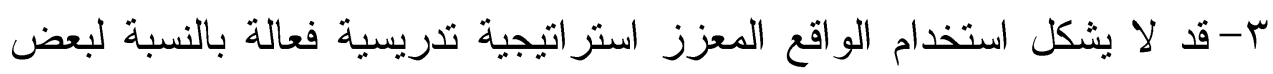
المتعلمين. ع - التركيز على كم كبير من المعلومات المتداخلة، قد يؤثر على الدماغ مما يؤدي إلى تشتت الرؤية لاى المتعلم.

0- تباين قدر ات المتعلمين في التعامل مع التقنيات الحديثة ( الو اقع المعزز ). -

1- العجز المادي للبدء في مشرو ع استخدام تقنية حديثة كثقنية الو اقع المعزز . ץ- تعذر الحصول على إثارات (GPS) أحياناً، داخل الفصول الدراسية، (العامل

$$
\text { الرئيس في عمليات المحاكاة في الو اقع المعزز ). }
$$

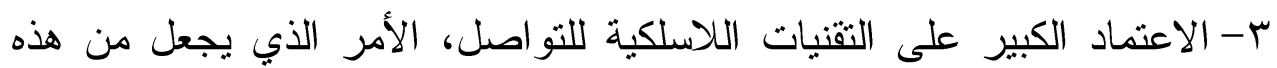
التقنية استهلاك كبير للطاقة. ع - التطور السريع و المتلاحق في تقنية الواقع المعزز ونماذجه يجعل من مو اكبته

$$
\text { أمر أ ليس سهلاً. }
$$

ه- ارتباط التعليم باستخدام الواقع المعزز لعوامل تكنولوجية أخرى مثل كفاءة

$$
\text { شبكات الاتصال، ومدى سهولة توفر ها. }
$$

צ- عدم تو افر الأجهزة و البرامج التي تحتاجها. 


$$
\text { - }
$$

ا- المخاوف الأخلاقية التي باتت تفرضها تقنية الواقع المعزز عموماً والأجهزة

$$
\text { القابلة للارتذاء على وجه الخصوص. }
$$

ץ- الأمية التكنولوجية في المجتمع ونقص الوعى بتكنولوجيا الواقع المعزز. ب-تشكيك المجتمع حول فاعلية تقنية الو اقع المعزز بالمقارنة مع الطرق التقليدية. ع- يعد الواقع المعزز انتهاكا لخصوصية الآخرين، وقد يؤثر على مستوى التو اصل و التفاعل الإنساني.

$$
\text { إجراعات البحث }
$$

$$
\text { منهج البحث: }
$$

استخدم البحث الحالي المنهج شبه التجريبي القائم علي تصميم مجموعة

\begin{tabular}{|c|c|}
\hline المجمو عة الضابطة & المجمو عة التجريبية \\
\hline الطريقة التقليدية & تقنية الو اقع المعزز \\
\hline مج (Y) & مج (1) \\
\hline
\end{tabular}
تجريبية ومجموعة ضابطة مع التطبيق القبلي و البعدي لأدوات القياس كما هو موضح

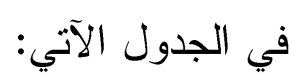

جدول (1) التصديم التجربيجي للبحث

للتعرف على فاعلية استخدام تقنية الواقع المعزز على تتمية التحصيل المعرفي و الإتجاه لدى طلاب كلية التربية تم إجر اء ما يلي:

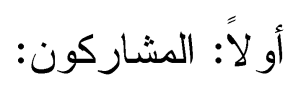

تم اختبار المشاركون من طلاب مرحلة البكالوريوس تخصص (تربية خاصة وتربية فنية وتزبية بدنية) بكلية التزبية جامعة جاز ان بصورة مقصودة حيث بدرس الباحث لثلاث شعب من هؤلاء الطلاب مقرر مقدمة في تقنيات التعليم، وتم تقسيم المشاركين إلى مجمو عتين. 
1- المجموعة الأولي (التجريبية) تكونت من (مץ) طالب، ويدرسون بثقنية الو اقع المعزز.

ץ- المجموعة الثانية (الضابطة) تكونت من (•؛) طالب، ويدرسون بالطريقة

التقليدية. ثانياً: إعداد أدو ات القياس:

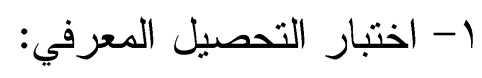

تم إعداد الاختبار التحصيلي المرتبط بوحدة الاتصال التعليمي من مقرر مقدمة في تقنيات التعليم، وتم اتباع الخطوات التالية عند إعداد الاختبار : أ- تحديد الهذف من الاختبار:

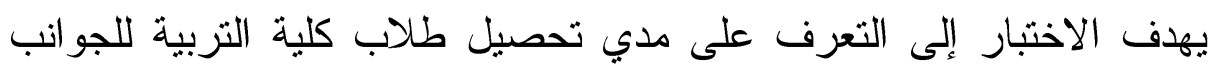
المعرفية لوحدة الاتصال التعليمي، وفقا للمستويات المعرفية: التذكر و الفهم و التطبيق.

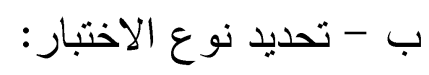
تم اختيار مفردات الاختبار التحصيلي من النوع الموضوعي، وذلك لما يتميز

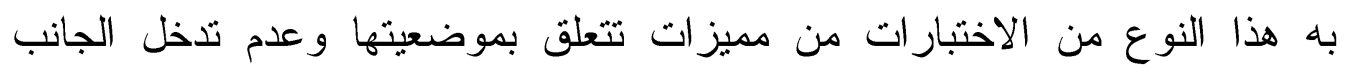

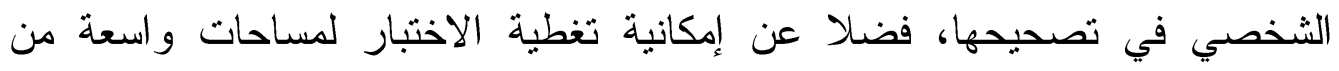

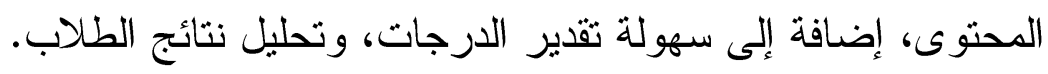
ج- بناء الاختبار:

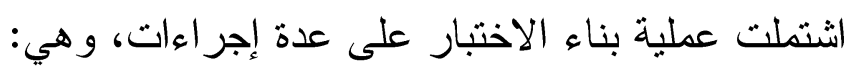

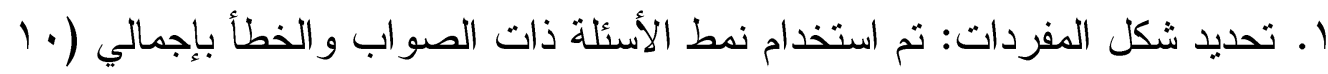

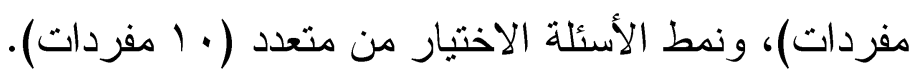

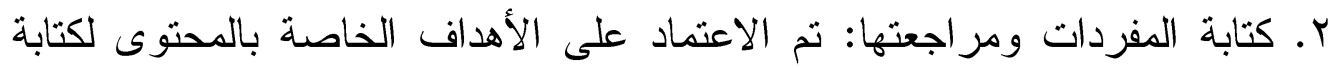
مفرداته بحيث تمثل جميع الدروس و الأهداف التعليمية التي تمت در استها.

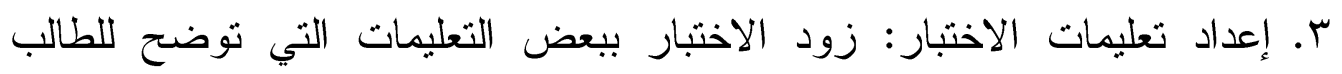

$$
\text { طريقة إجابة الاختبار . كائ. }
$$

ع. تحديد نظام تقدير الدرجات: تم اعداد مفتاحا لتصحيح الاختبار وتقدير الدرجات على أساس درجة للإجابة الصحيحة، ولا شيء للإجابة الخاطئة. 
د- إعداد الاختبار في صورته النهائية:

اشتملت عملية إعداد الاختبار في صورته النهائية وتقنينه على عدة إجراءات

$$
\text { و - تحديد صدق الاختبار: }
$$

حيث تم عرض الاختبار على مجموعة من المحكمين - الخبراء و المتخصصين في مجال تكنولوجيا التعليم و المناهج وطرق التدريس - وذلك للتأكد

$$
\text { - - مداسبة مناسبة الاختبار للمشاركون. }
$$

وقد تم إجراء التعديلات في صياغة بعض المفردات طبقا لآراء المحكمين. التجربة الاستطلاعية للاختبار :

تم اختيار مشاركون من طلاب كلية التربية عددهم (ب) طالب وذللك للحصول على بيانات تساعد على تحديد المواصفات الإحصائبة للاختبار مثل: الثبات، وخصائص المفردات (التمبيز، و السهولة)، ومن خلال التطبيق في التجربة الاستطلاعية تم التوصل إلى النتائج التالية:

حساب معاملات السهولة و الصعوبة لكل مفردة من مفردات الاختبار : تقاس سهولة أي مفردة بحساب عدد الإجابات الصحيحة، مقسومة على عدد

$$
\text { الاجابات الصحيحة مضافاً اليها عدد الاجابات الغير صحيحة. لئرة }
$$

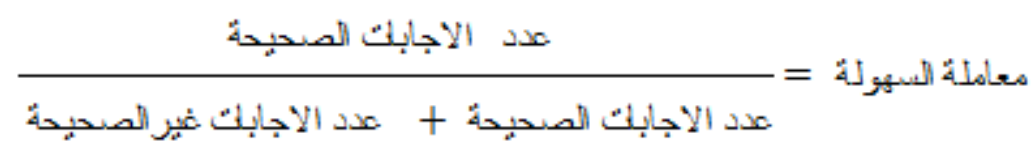

$$
\text { ومعامل الصعوبة = 1- معامل السهولة. }
$$

وتم اعتبار الأسئلة التي معامل سهولتها أكبر من (.9\%) شديدة السهولة،

و المفردات التي يصل معامل سهولتها أقل من ( ب٪\%) شديدة الصعوبة.

وبعد حساب معاملات السهولة ومعاملات الصعوبة لمفردات الاختبار، اشارت

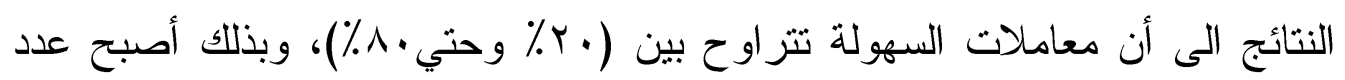


مفردات الاختبار التحصيلي (•r) مفردة، جميعها لبست شديدة السهولة وليست شديدة

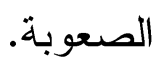

حساب معامل التمييز لكل مفردة: ابه

يعبر معامل التمييز عن تمييز المفردة للطالب الممتاز والطالب الضعيف،

ولتعيين معامل التمييز لكل مفردة من مفردات الاختبار التحصيلي نم حساب معامل تلين

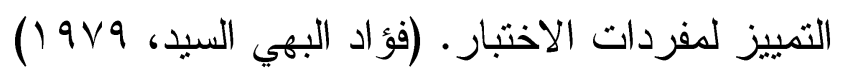

وتم اعثبار المفردة غير قادرة على التمييز إذا قل معامل التمييز لها عن

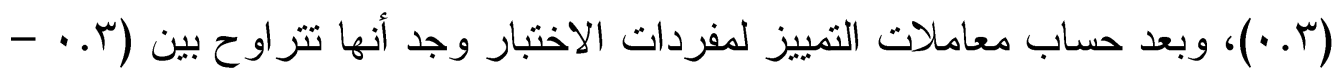

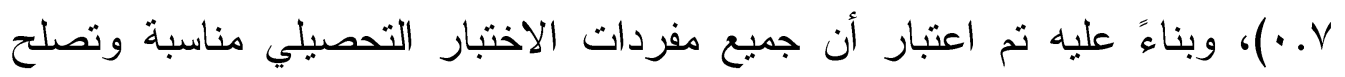

للنطبيق.

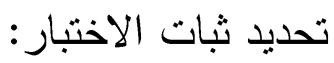

نم حساب ثبات الاختبار باستخدام طريقة التجزئة النصفية، وتم حساب معامل

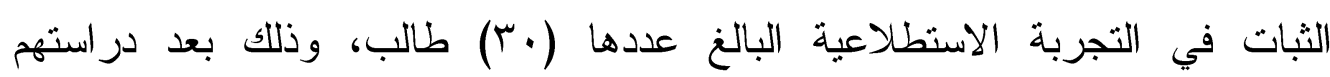

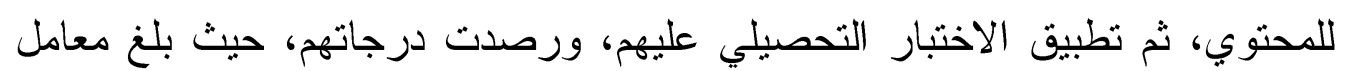

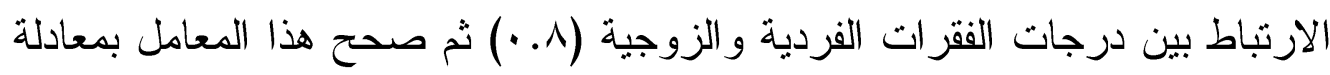

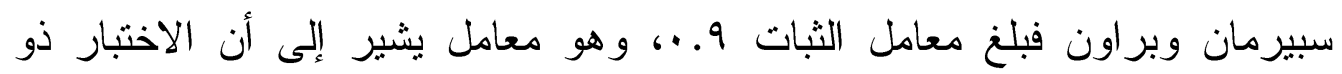
درجة عالية من الثبات، الأمر الذي يجعل الباحث مطهئن إلى استخدامه كأداة للقياس. إعداد الصورة النهائية للاختبار:

بعد أن تم الانتهاء من خطوات إعداد الاختبار التحصيلي و التأكد من صدقه

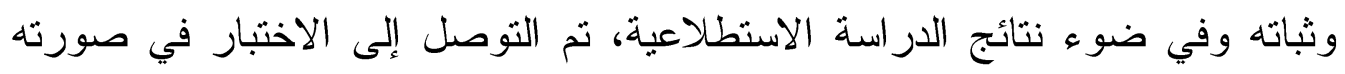

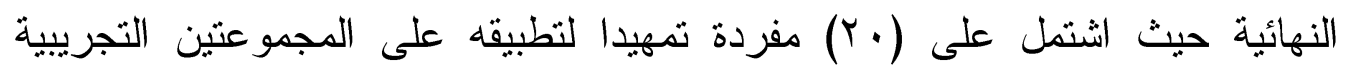

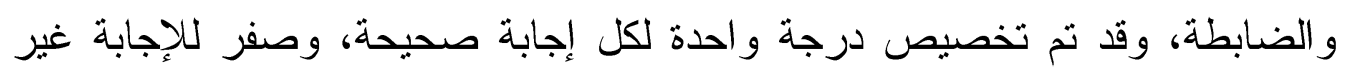

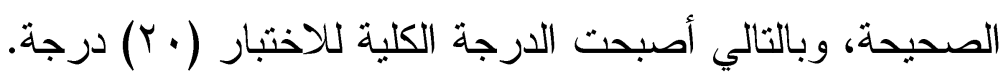

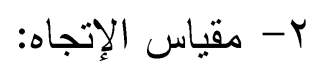

تم بناء أداة البحث "الإستبانة" في صورتها الأولية، بالاعتماد على المصادر التالية: 1- الهدف من المقياس. 
ب- المر اجع ذات الصلة بموضوع البحث.

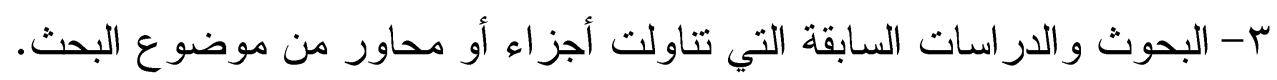
ع- آراء المحكمين الذين عرضت عليهم الإستبانة في صورتها المبدئية ومقابلة بعض المختصين في مجال البحث و الاستفادة من آرائهم حول مقياس الإتجاه

المستخدم في البحث وطريقة صياغة عبار اته بما يتتاسب مع أهداف البحن البحث. تكونت الإستبانة في صورتها النهائية من محورين هما: المحور الأول: الاتجاه الثخصي نحو استخدام ثقنية الواقع المعزز

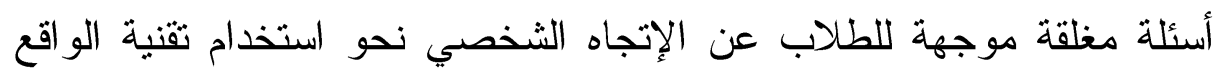

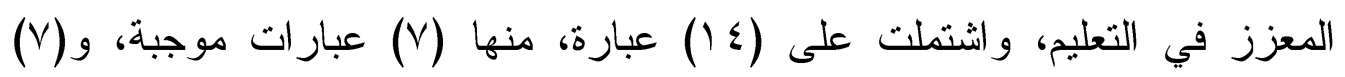

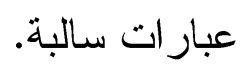
المحور الثاني: الاتجاه التعليمي نحو استخدام تقنية الواقع المعزز

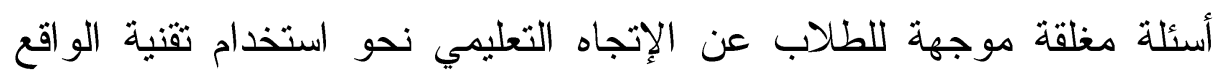

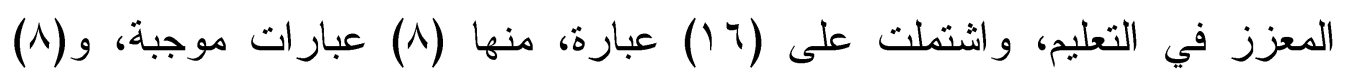
عبار ات سالبة. نم الاعتماد في إعداد الإستبانتين معتمدا على الثكل المغلق الذي يحدد

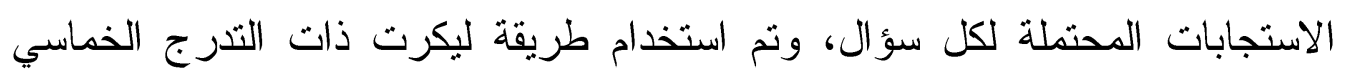

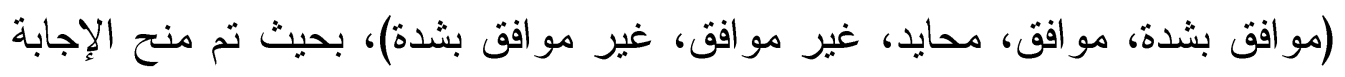

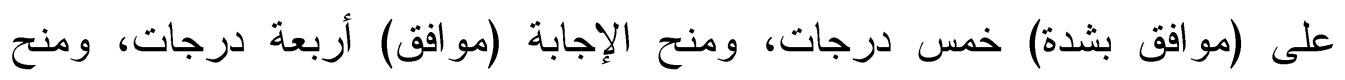

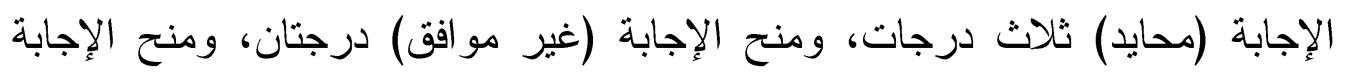

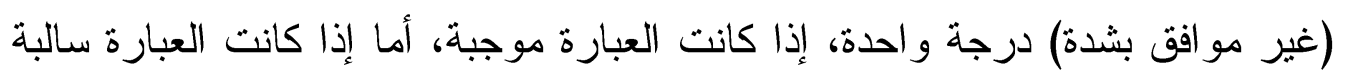

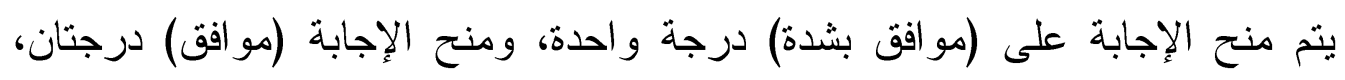

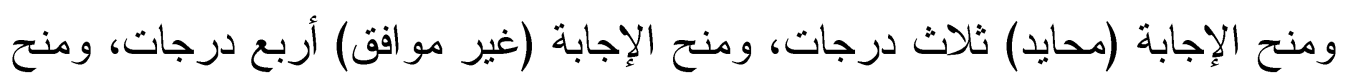
الإجابة (غير مو افق بشدة) خمس درجات. 


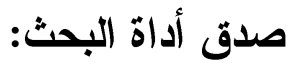
الصدق الظاهري (الخارجي) للأداة: ييحث هذا النوع من الصدق في التحقق من أن مقياس الإتجاه يقبس فعلا ما لألماء

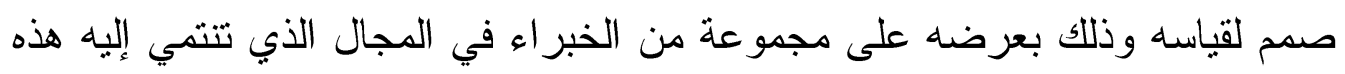

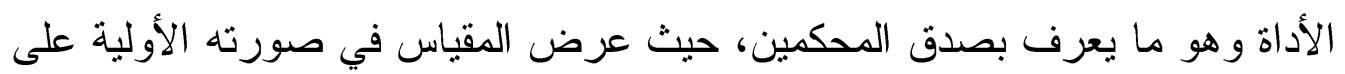
مجموعة من الأساتذة الجامعيين المتخصصين في مجال تكنولوجيا التعليم والمناهج

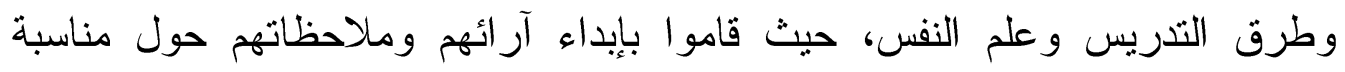

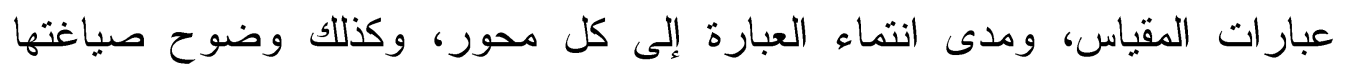

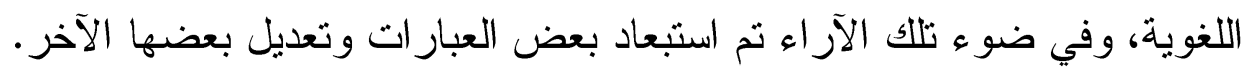

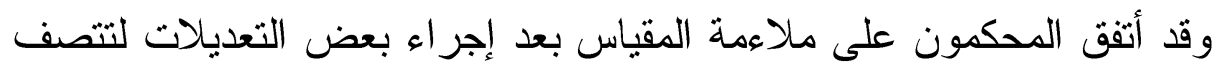

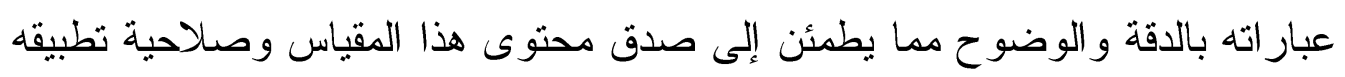

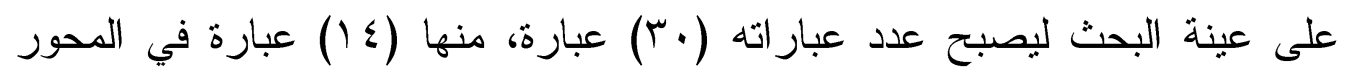

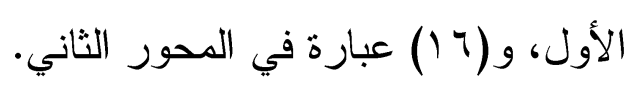
صدق الاتساق الداخلى لمقياس الإتجاه:

للتأكد من الصدق الداخلي لمقياس الإتجاه، تم تطبيقه ميدانيا على المشاركين،

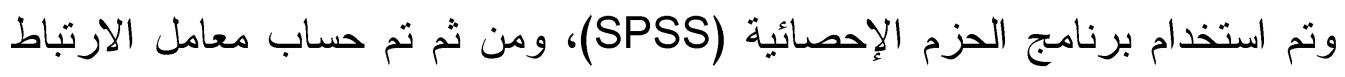
بيرسون لمعرفة الصدق الداخلي للمقياس وذلك عن طريق حساب معامل الارنباط بين درجة كل عبارة من عبار اته والدرجة الكلية للمحور ثم الدرجة الكلية للإستبانة، وجاءت النتائج كما توضحها الجداول التالية: صدق الاتساق الداخلي للمحور الأول (الاتجاه الشخصي نحو استخدام تقنية الواقع المعزز): 
جدول (T) معاملات الارتباط بين درجة العبارة والدرجة الكلية للمحور الأول

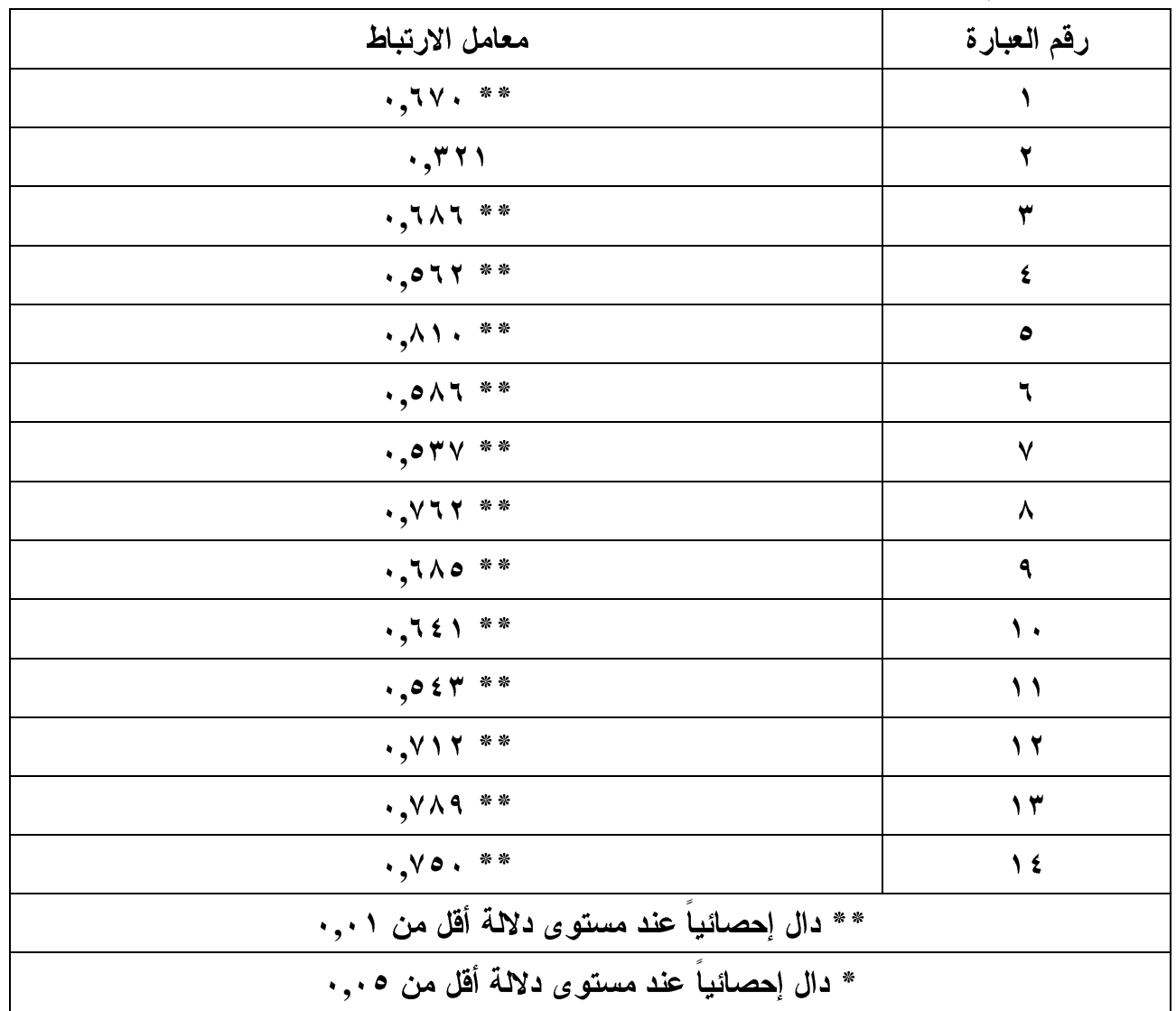

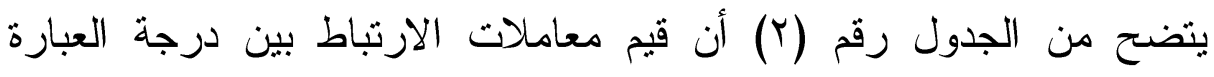

و الدرجة الكلية للمحور الأول (الإتجاه الثخصي نحو استخدام تقنية الواقع المعزز)،

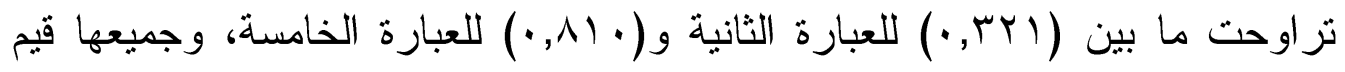

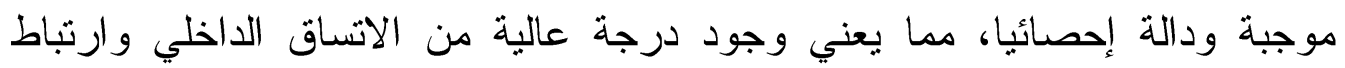
المحور الأول بعبار اته بما يعكس درجة عالية من الصدق لعبارات المحور الأول.

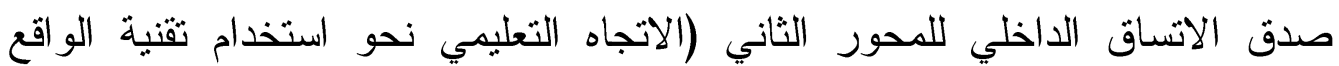

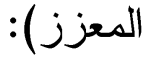




\section{YIV}

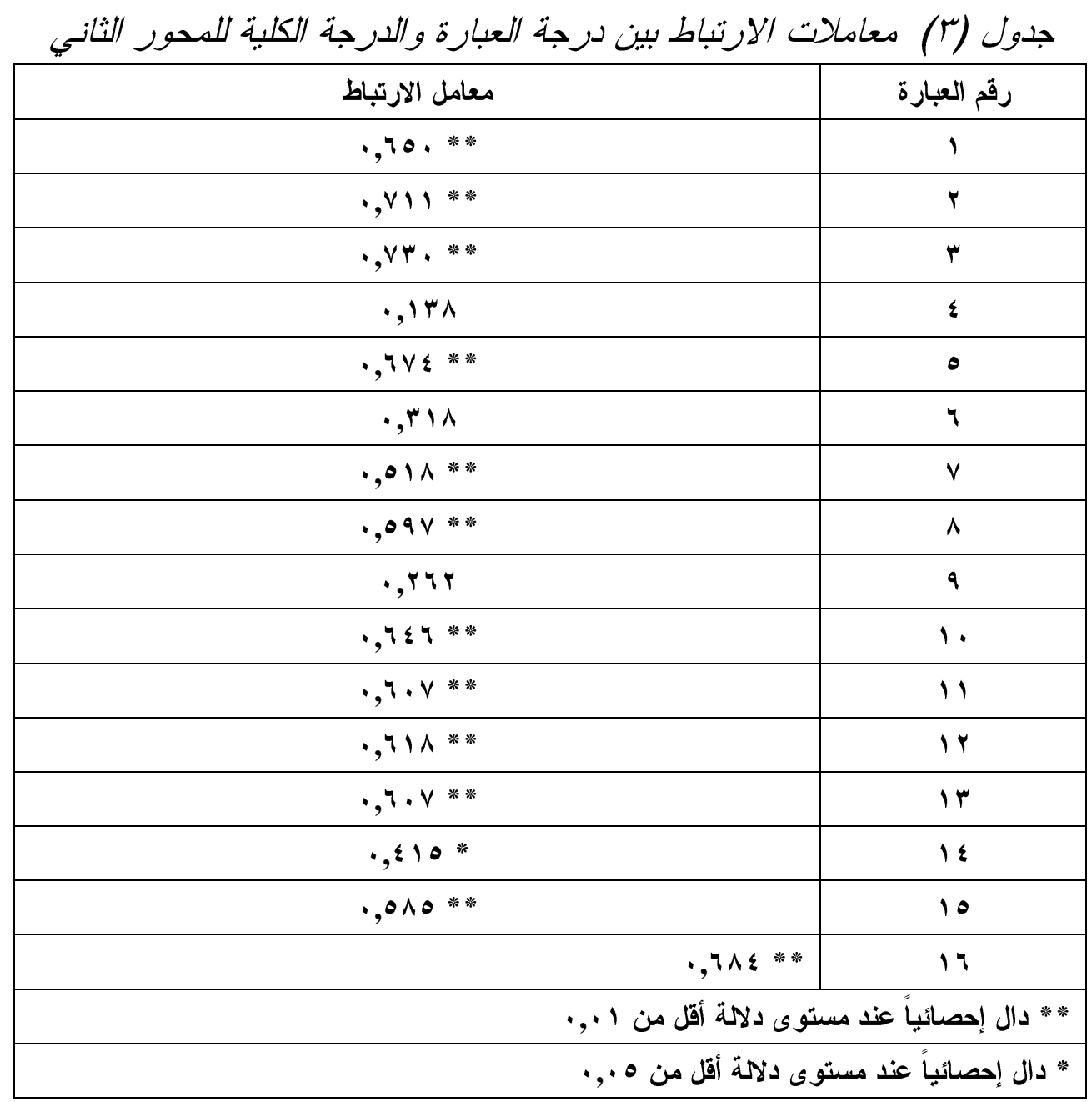

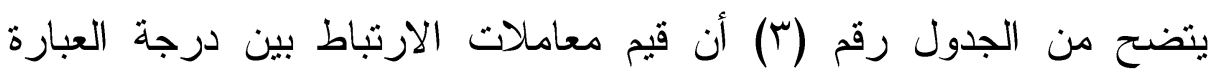

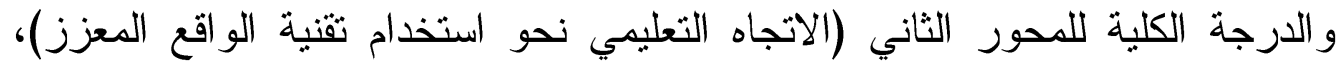

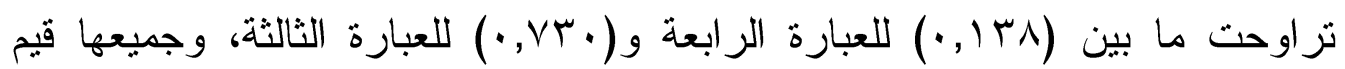
موجبة ودالة إحصائيا، مما يعني وجود درجة عالية من الاتساق الداخلي وارتباط المحور الثاني بعبار اته بما يعكس درجة عالية من الصدق لعبارات المحور الثاني.

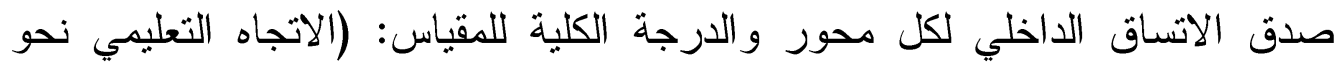

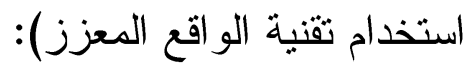


جدول (ع) معاملات الارتباط لكل محور والدرجة الكلية للمقباس

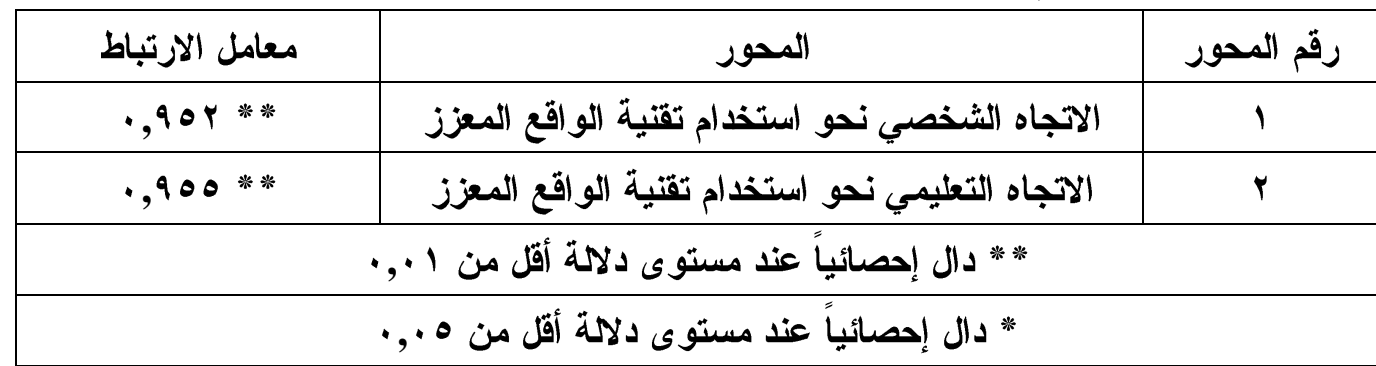

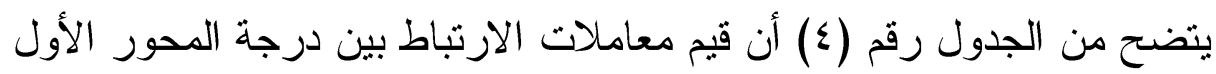

(الاتجاه الثخصي نحو استخدام تقنية الواقع المعزز) والدرجة الكلية للمقياس بلغت (90Y, • •)، بينما قيم معاملات الارتباط بين درجة المحور الثاني (الاتجاه التعليمي نحو استخدام تقنية الواقع المعزز) و الدرجة الكلية للمقياس بلغت (900, •)، وجميعها قيم موجبة ودالة إحصائيا، مما يعني وجود درجة عالية من الاتساق الداخلي وارتباط المحور الأول والثاني بالدرجة الكلية للمقياس بما يعكس درجة عالية دن الصدق لعبار ات المقياس وصلاحيته للتطبيق الميداني للبحث.

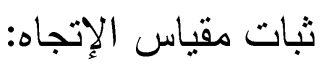

ثبات مقياس الاتجاه يعني التأكد من أن الإجابة ستكون واحدة ثقريبا إذا تكرر تطبيقه على الأشخاص ذاتهم (العساف، 990 ())، ولقياس مدي ثبات المقياس استخدم الباحث (معادلة ألفا كرونباخ)، و الجدول رقم (0) يوضح معاملات الفا كرونباخ. جدول (0) معامل الثبات ألفا كرونباخ

\begin{tabular}{|c|c|c|}
\hline قيمة ألفا & عدد العبار ات & 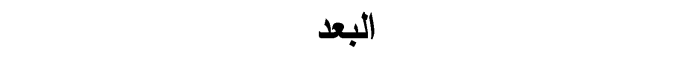 \\
\hline$\cdot, \wedge 91$ & $1 \varepsilon$ & الاتجاه الشخصي نحو استخدام تقنية الواقع المعزز \\
\hline$\cdot, \wedge \varepsilon r$ & 17 & الاتجاه التعليمي نحو استخدام تقنية الواقع المعزز \\
\hline$(\cdot, 9 \times \bullet)$ & r. & الاتجاه الكلي \\
\hline
\end{tabular}

ويتضح من الجدول (0) أن معاملات الثبات ألفا كرونباخ لجميع الأبعاد مرتفعة حيث بلغ معامل الثبات في المحور الأول الاتجاه الثخصي نحو استخدام تقنية الو اقع المعزز (19,人, ·)، وبلغ معامل الثبات في المحور الثاني الاتجاه التعليمي نحو استخدام تقنية الواقع المعزز (Y乏,_,·)، وبلغ معامل الثبات في الاتجاه الكلي 
(9 9 9 •)، وجميعها معاملات ثبات مرتفعة، مما يدل على أن مقياس الاتجاه يتمتع بدرجة عالية من الثبات وبالتالي يمكن الاعتماد عليه في التطبيق الميداني للبحث.

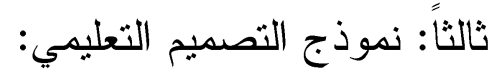

قام الباحث بدارسة نماذج التصميم التعليمي المختلفة، واختار نموذج التصميم

التعليمي العام (ADDIE) لتطبيقه في البحث، وذلك للمبرر اتلفات التالية:

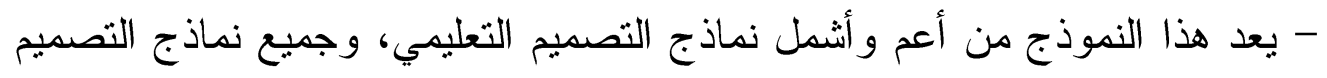

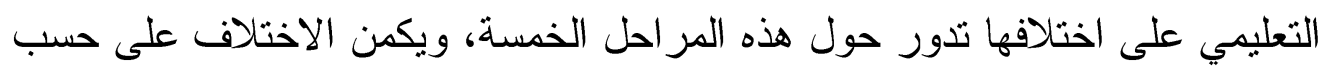
التركيز و التوسع في عرض مرحلة دون الأخرى.

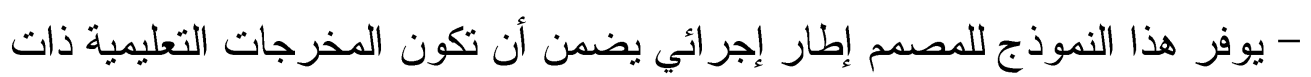
كفاءة وفاعلية عالية في تحقيق الأهداف. - وضوح خطو اته الإجر ائية وسهولة تتفيذها ومرونته وقابليته للتعديل و التطوير،

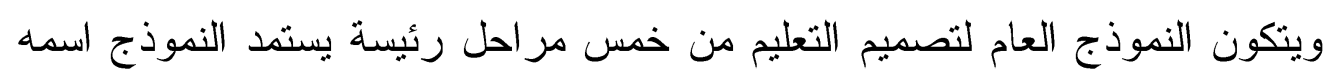
هنها، وهي كالتالي: (Instructional Design expert. Com, 2010) (Analysis) مرحلة التحليل و هي المرحلة التي يتم فيها تحديد المشكلة وايجاد الحلول العملية لها، وتضمنت الخطوات التالية: أ- تحليل خصائص الفئة المستهدفة: المشاركون من طلاب كلية التزبية تخصص

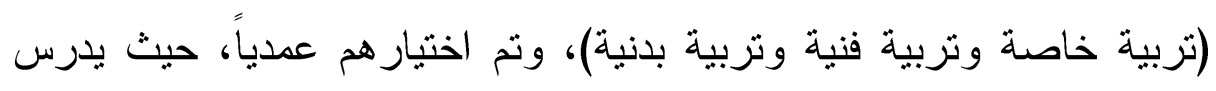
الباحث لثلاث شعب من هؤلاء الطلاب مقرر مقدمة في ثقنبات التعليم.

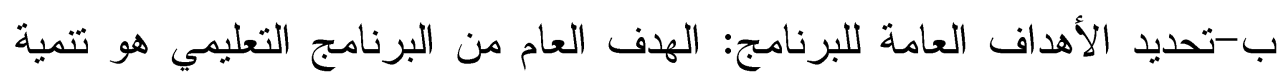

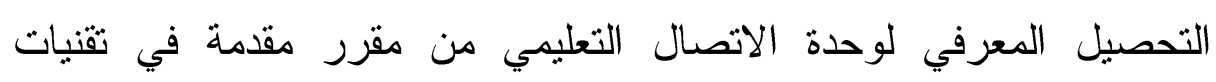

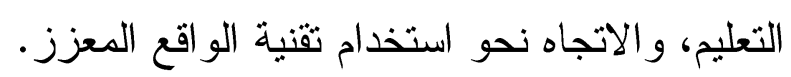

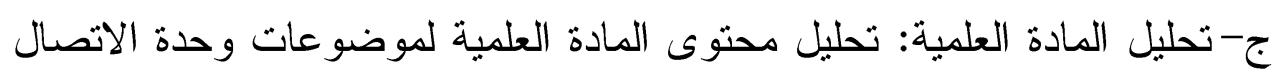
التعليمي من مقرر مقدمة في تقنيات التعليم، وهي (تعريف عملية الاتصال

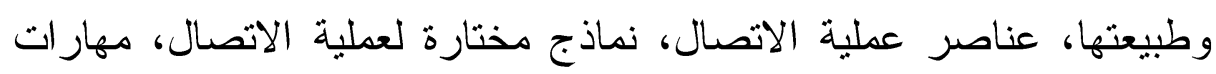
الاتصال التعليمي، معيقات الاتصال التعليمي وكيفية التغلب عليها). 


\section{rr.}

د- تحديد المهام المطلوب إنجازها: اشتملت علي اختبار التحصيل المعرفي لوحدة

الاتصال التعليمي.

ه- تحليل البيئة التعليمية: الدراسة باستخدام تقنية الواقع المعزز للمجموعة التجريبية بعد التأكد من استخدامهم الاجهزة الذكية ونوفر خدمة الانترنت لدي لئي

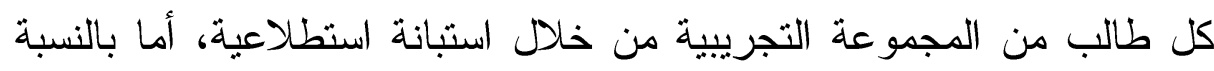
للمجموعة الضابطة فدرست باستخدام الطريقة التقليدية من خلال القاعات

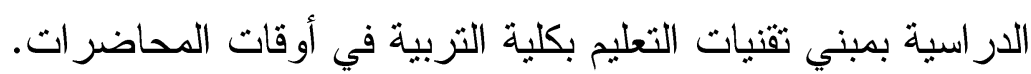

ب- برحلة التصميم (Design)

وهي المرحلة التي يتم فيها وضع المو اصفات و الإجر اءات للخطة المقترحة لتنفيذ العملية التعليمية، وتتكون من:

تصميم الأهداف التعليمية وتحليلها وتصنيفها: في ضوء تصنية تحديد العناصر

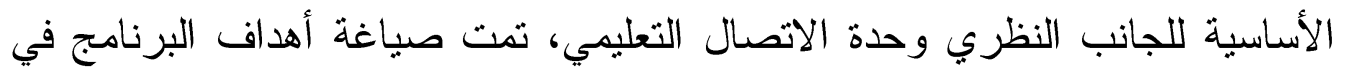
عبار ات سلوكية تحدد بدقة التغيير المطلوب إحداثه في سلوك المتعلم بحيث تكون قابلة للقياس بموضوعية، وتصبح موجهات لاختبار فاعلية البرنامج وفى اختيار و إعداد لئل أدوات القياس و التقويم الملائمة.

تم إعداد قائمة بهذه الأهداف في صورتها المبدئية، وعرضها لفائها على مجموعة من الاساتذة المتخصصين في مجال تكنولوجيا التعليم وذلك بهدف استطلاع رأيهم فيما يلى: - دقة صياغة كل هدف من أهداف القائمة، و اقتز اح الصياغة المناسبة فوق الأهداف التي تحتاج إلى تعديل في الصياغة. - مدى تحقيق كل هدف للسلوك التعليمي المر اد تحقيقه. - نتائج التحكيم على قائمة الأهداف السلوكية:

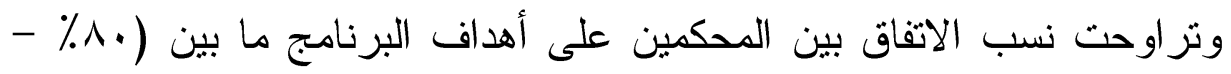

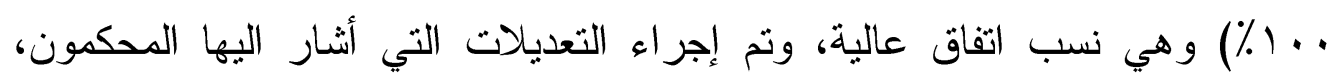

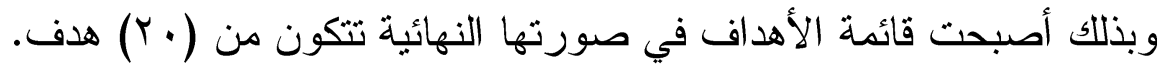


تحديد محتوي البرنامج التعليمي: إن استخدام تقنية الواقع المعزز لا بد وأن

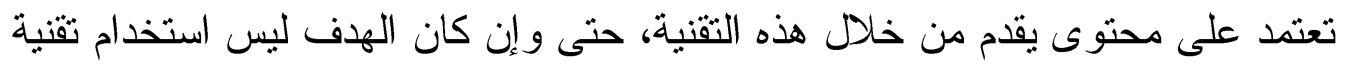

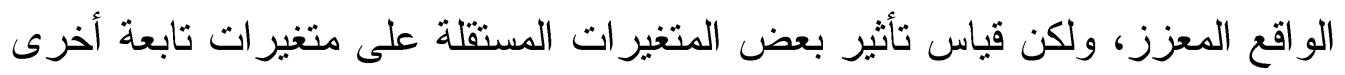

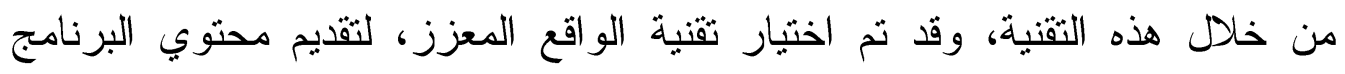

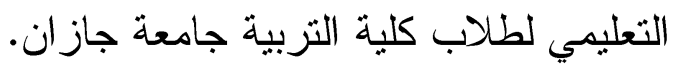
تأسيسا على ذلك تم دراسة أهداف الجانب النظري لوحدة الاتصال التعليمي بمقرر مقدمة في تقنيات التعليم و الذي يدرس للطلاب من كتاب مدخل إلى تكنولوجيا

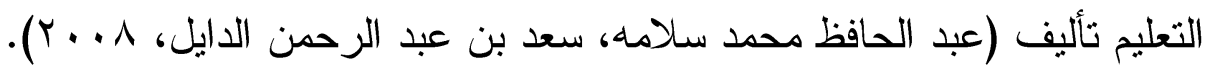

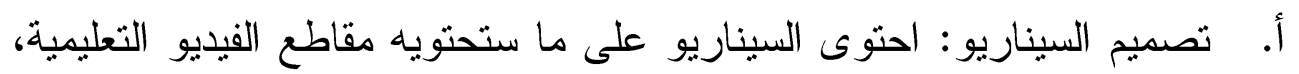

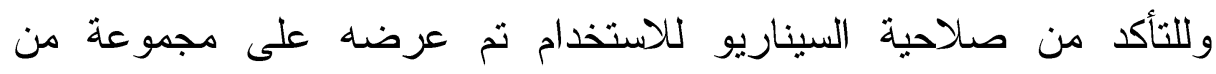
المحكمين المتخصصين في مجال تكنولوجيا التعليم، وقد أبدوا ملاحظاتهر عليه

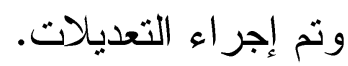
ب. تحديد مصادر التعلم: تقنية الواقع المعزز، الولاء اتس أب. ج. تصميم أساليب التقويم: تصنئ - التقويم القبلي: النطبيق القبلي للاختبار التحصيلي المعرفي لوحدة الاتصال التعليمي في مقرر مقدمة في تقنيات التعليم. - - التقويم البعدي: التطبيق البعدي للاختبار التحصيلي المعرفي لوحدة الاتصال

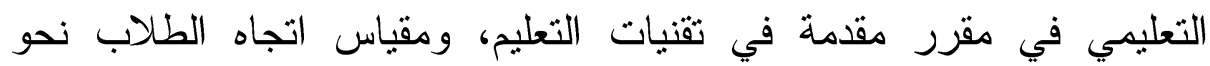

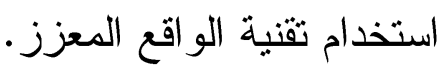
r- مرحلة النظوير (الإنتاج) (Development): و هي المرحلة التي تتم فيها ترجمة عملية التصميم من مخططات وسيناريو هات إلى نى مو اد تعليمية حقيقة عن طريق تطوير التقنيات التعليمية التي ستستخدم فيه، و الدصادر

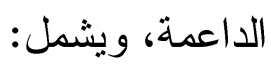
أ- انتاج مقاطع فيديو تعليمية وانتاج الوسائط المتعددة من نصوص وصوت ورسوم وصور ثابتة ومتحركة، يعرض من خلائه ولاهلها المحتوبي التعليمي للطلاب، وبالانتهاء من عملية تصميم و انتاج مقاطع الفيديو التعليمية تكون 
عملية الإنتاج قد اكتملت في صورتها المبدئية وللتأكد من صلاحية مقاطع الفيديو التعليمية للاستخدام تم عرضها على مجموعة من المحكمين

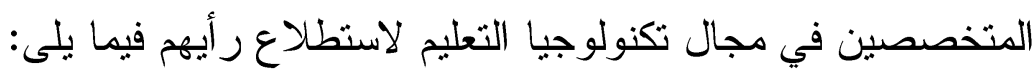

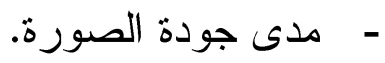
- - مدى جودة لقطات الفيديو.

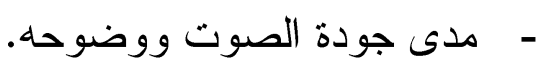
- مدى تو افق الصوت مع الصورة. وجاءت آراء المحكمين واحدة بالنسبة لدقاطع الفيديو التعليمية وقد أسفرت آراء المحكمين عن تعديلات عدة منها: - تحسين جودة الصوت وجعل حجمه أكبر لزيادة وضوحهـ.

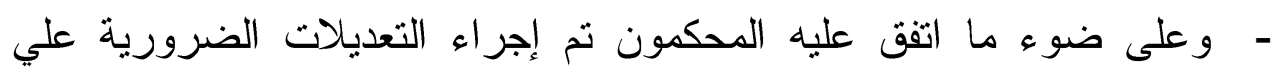

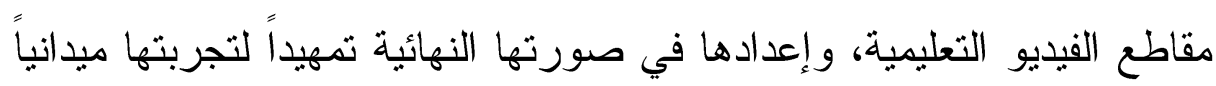
على عينة اسنطلاعية من الطلاب للتأكد من صلاحيتها للاستخدام على المستوى الميداني.

ب-انتاج Auras لكل صفحة من صفحات فصل الاتصال التعليمي بواسطة برنامج HP Reveal Aurasma وذلك كالتالي: - تحميل تطبيق HP Reveal Aurasma على أنظمة تشغيل الهواتف الذكية بو اسطة متجر Apple Store Or Android - - إنشاء Account على النطبيق. -

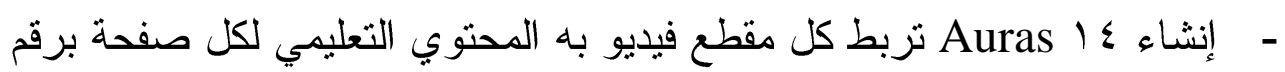
- كل صفحة من صفحات فصل الاتصال التعليمي من مقرر مقدمة في تقنبات

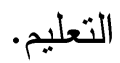




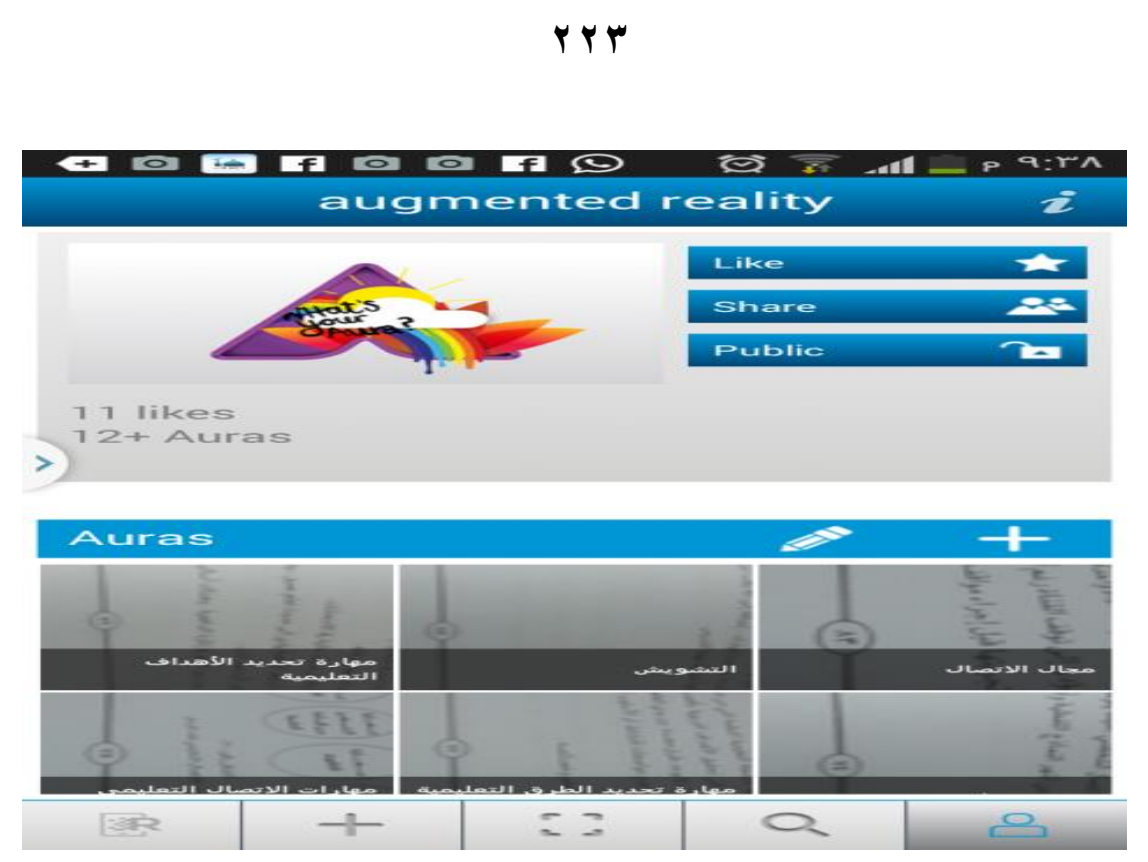

شكل رقم (1)

انشاء قناة واقع معزز لمحتوى الاتصال التعليمي

ع - مرحلة النطبيق (Implementation)

وهي المرحلة التي يتم فيها تطبيق استخدام تقنية الواقع المعزز، وتهذف هذه المهاء

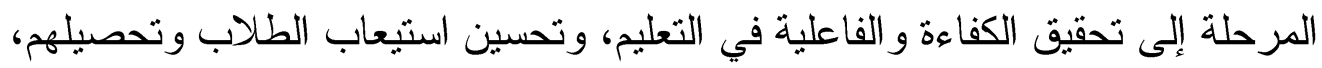

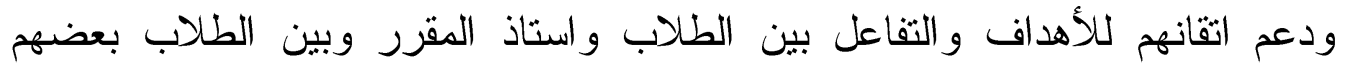

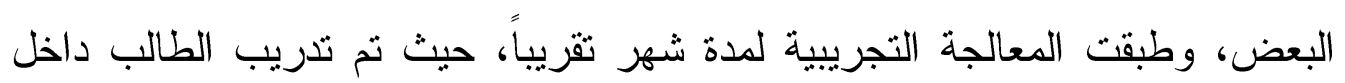

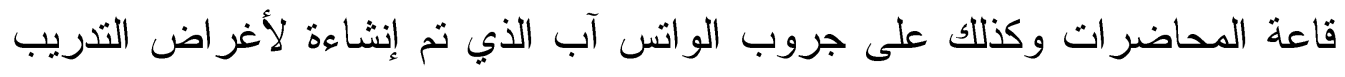
و التفاعل بين الطلاب واستاذ المقرر وبين الطلاب بعضهم البعض ومتابعة أداء

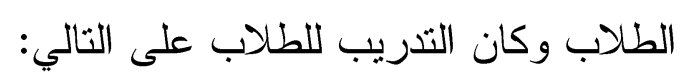
- - تحميل تطبيق HP Reveal Aurasma من على أنظمة تثغيل الهو اتف الذكية Apple Store Or Android دواسطة متجر - البحث عن Channel باسم augmented reality ثم عمل Like - الضغط على زر لتشغيل الكامير ا ومن ثم توجيه الكامير ا نحو رقم الصفحة لتشغيل الفيديو التعليمي المرتبط بمحتوى هذه الصفحة. 


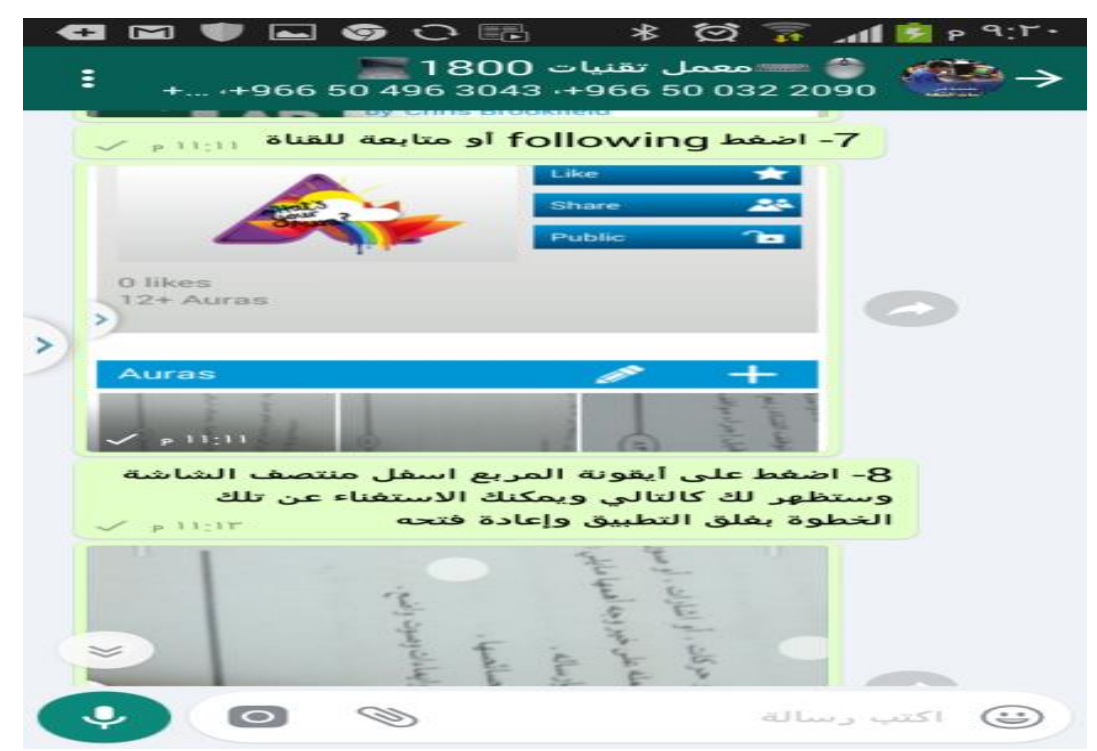

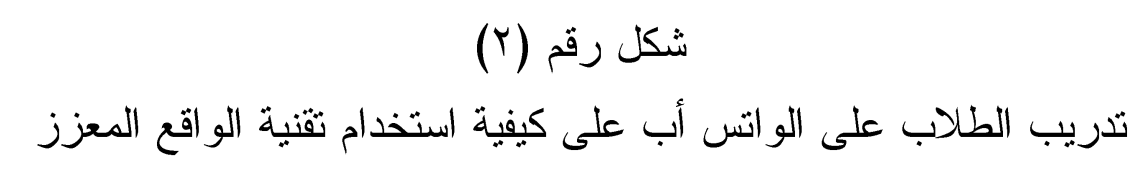
0- مرحلة التقويم (Evaluation) بعد الإنتهاء من إنتاج وتصميم تقنية الواقع المعزز عن طريق عمل Auras لكل

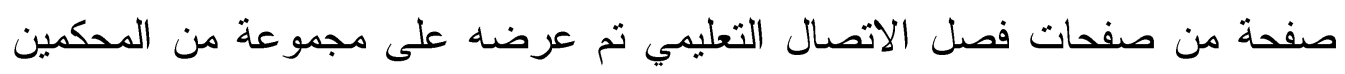
المتخصصين في مجال تكنولوجيا التعليم لاستطلاع رأيهم ومقترحاتهم على صلى صلاحيته

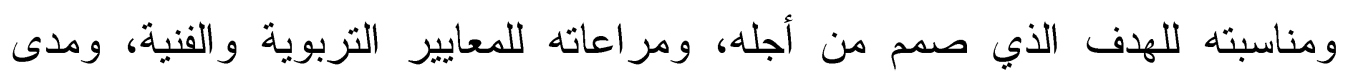

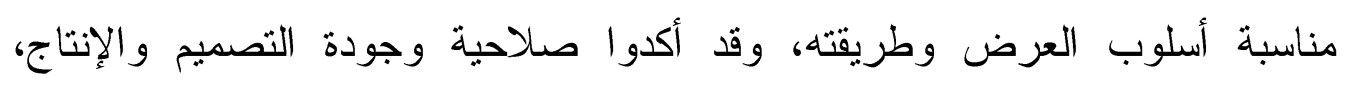

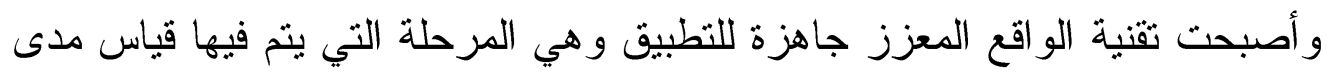
فاعلية استخدام تقنية الواقع المعزز، وذللك من خلال تقييم التحصيل المعرفي واتجاه

$$
\text { رابعاً: النطبيق القبل استخدام ثقنية الو اقع المعزز. }
$$

تم تطبيق أدوات القياس المتمتلة في اختبار التحصيل المعرفي ومقياس اتجاه

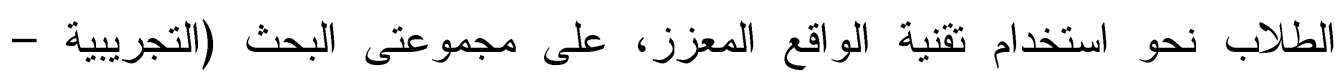
الضابطة) وذلك للحصول علي المعلومات القبلية التي تساعد في العمليات الإحصائية 
الخاصة بنتائج البحث، ولبيان مدي تكافؤ المجموعتين، يوضح الجدول التالي نتائج التطبيق القبلي لأدوات البحث. جدول (T) قيمة (T) لهعرفة الفروق بين متوسطي درجات طلاب الدجموعة التجريبية وطلاب المجدوعة الضابطة في القياس القبلي على اختبار التحصيل لتوسيل

\begin{tabular}{|c|c|c|c|c|c|c|c|}
\hline \multicolumn{8}{|c|}{ المعرفي ومقياس الاتجاه } \\
\hline $\begin{array}{c}\text { الاحتمال } \\
\text { sig ) } \\
\text { (p.value }\end{array}$ & الحرية & المحسوبة & الالحراف & المتوسط & الأفر اد & المجموعة & ألبحث \\
\hline \multirow[b]{2}{*}{. } & \multirow[b]{2}{*}{ VY. 91} & \multirow[b]{2}{*}{.01} & r.04 & Ir.Ao & $\varepsilon$. & الضابطة & \multirow{2}{*}{ اختبار } \\
\hline & & & r.A 9 & ir.1V & ro & التجريبية & \\
\hline \multirow{2}{*}{..$v \cdot 1$} & \multirow{2}{*}{$r+9}$. & \multirow{2}{*}{.$\mu_{10}$} &. .49 & $r . . r$ & $\varepsilon$. & الضابطة & \multirow{2}{*}{ مقياس } \\
\hline & & & .0 . & $r .91$ & ro & التجريبية & \\
\hline
\end{tabular}

يتضح من جدول (T) ما يلي: الجناه

أن قيمة (T) لمعرفة الفروق بين مجموعتى البحث (التجريبية - الضابطة)

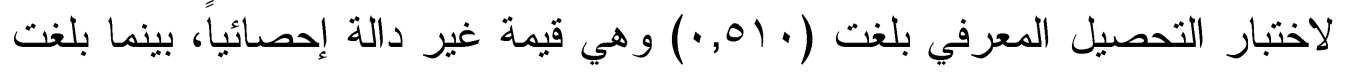

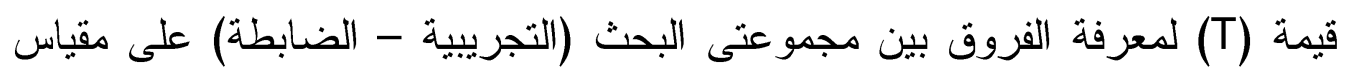

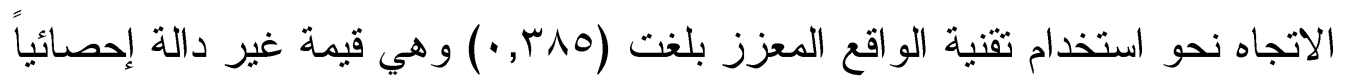
مما يشير إلى تكافؤ دجموعتى البحث (التجريبية - الضابطة) في القياس القبلي. خامساً: إجر اء التجربة الأساسية للبحث: - تم تقسيم الطلاب مجموعتى البحث (التجريبية - الضابطة) وفق التصميم التجريبي للبحث. - تم إنشاء جروب على تطبيق "الواتس أب" على الجوال باسم رقم الشعبة يضم

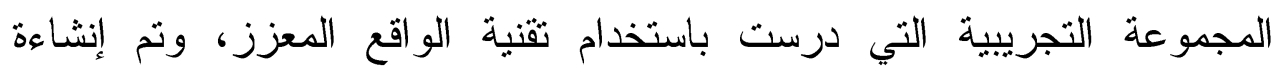

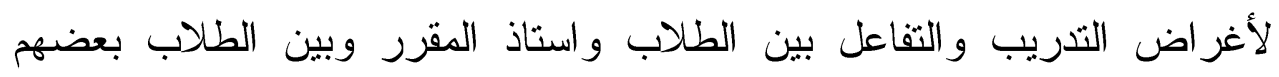
البعض ومتابعة أداء الطلاب. - - استغرق تطبيق التجربة الأساسية شهر. - م ت تمبيق أدو ات البحث بعدياً. 
- تم رصد درجات اختبار التحصيل المعرفي ومقياس اتجاه الطلاب نحو استخدام تقنية الو اقع المعزز، تمهيداً لمعالجتهما إحصائياً. - عرض النتائج ومناقشتها وتفسير ها: أ- عرض نتائج البحث:

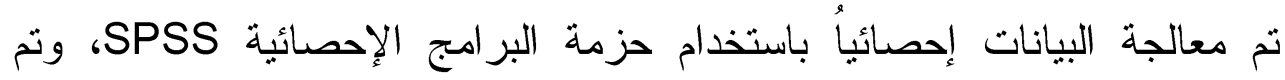
استخدام معادلة T Test لعينة غير مستقلة لحساب الفروق بين القياسين القبلي

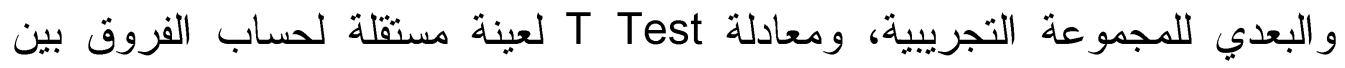

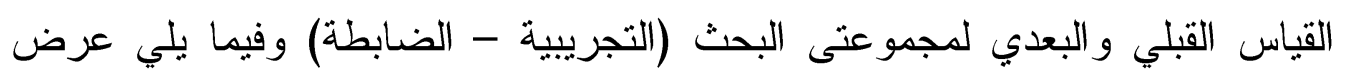

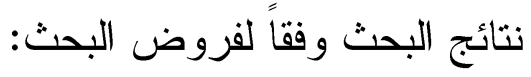
لاختبار صحة الفرض الأول الذي ينص علي: "لا يوجد فرق دال إحصائياً

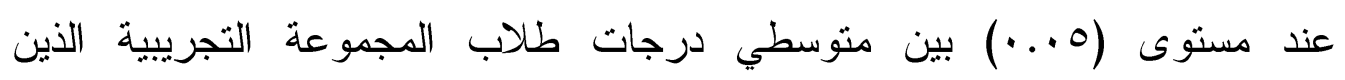

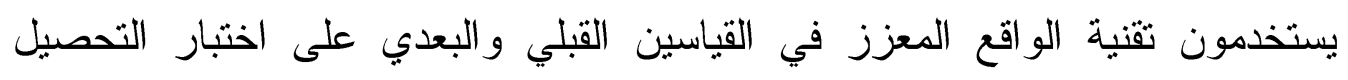

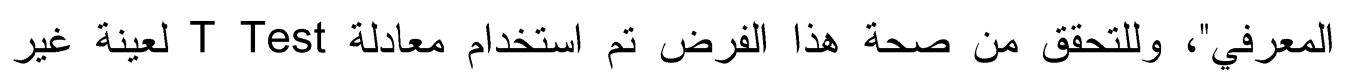
مستقلة، لبيان دلالة الفروق بين متوسطي درجات طلاب المجموعة التجريبية في

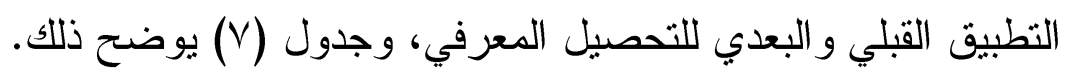

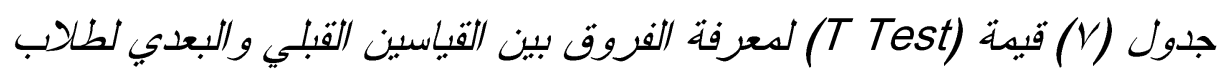

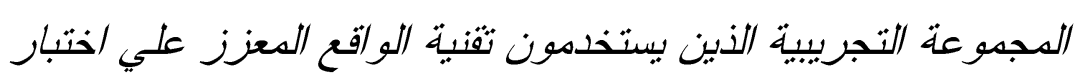

\begin{tabular}{|c|c|c|c|c|}
\hline \multicolumn{5}{|c|}{ التحصبل الدعرفي } \\
\hline \multirow{2}{*}{$\begin{array}{c}\text { الاحتمال } \\
\text { (sig p.value) }\end{array}$} & \multicolumn{2}{|c|}{ المتوسط } & \multirow{2}{*}{$\begin{array}{c}\text { درجة الحرية } \\
\text { (df) }\end{array}$} & \multirow{2}{*}{ قليمة (T) } \\
\hline & بعد & قبل & & \\
\hline . & $|r . v|$ & $15.1 \mathrm{v}$ & & $1.7 \times 4-$ \\
\hline
\end{tabular}

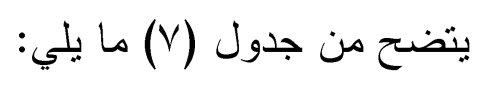

أن قيمة (T) لمعرفة الفروق بين القياسين القبلي و البعدي للمجموعة التجريبية التى لتى

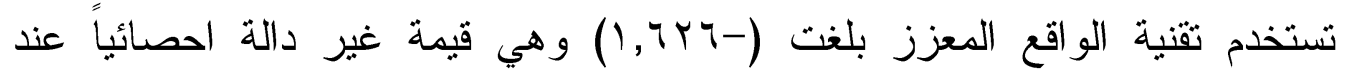
مستوي (0.0.) مما يشير إلى عدم وجود فروق ذات دلالة إحصائية بين القياسين

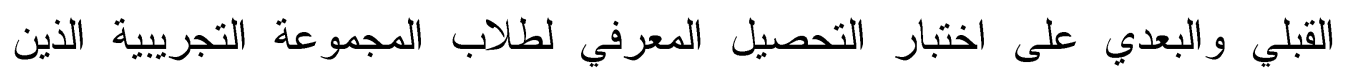




\section{rrV}

يستخدمون تقنية الو اقع المعزز، مما يشير إلى عدم فاعلية استخدام تقنية الو اقع المعزز علي تتمية التحصيل المعرفي لدي طلاب كلية التربية.

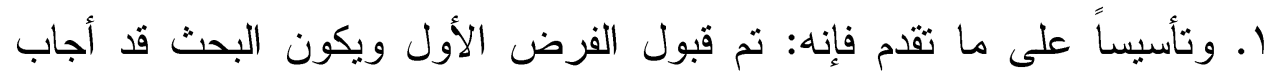

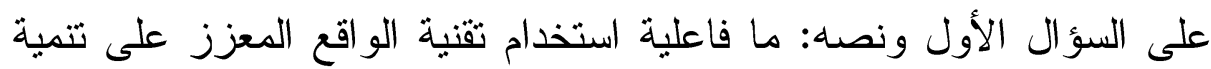

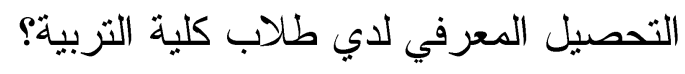

لاختبار صحة الفرض الثاني الذي ينص علي: "لا يوجد فرق دال إحصائياً

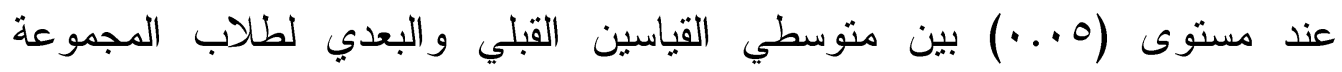

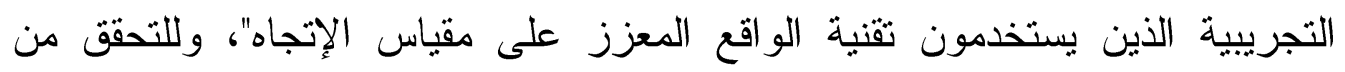
صحة هذا الفرض تم استخدام معادلة Test لعينة غير مستقلة، لبيان دلالة الفروق بين متوسطي القياسين القبلي و البعدي لطلاب المجموعة التجريبية الذين بستخدمون

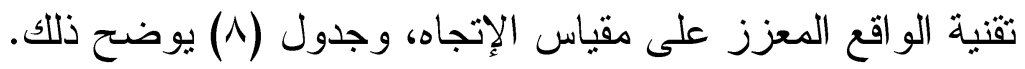

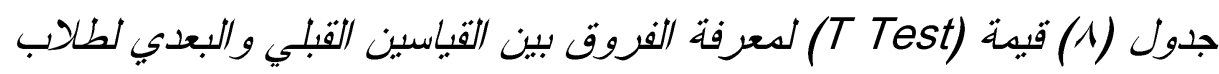
الدجموعة التجريبية الذين بيتخدمون تقنية الواقع الدعزز على مقياس الإتجاه

\begin{tabular}{|c|c|c|c|c|}
\hline \multirow{2}{*}{$\begin{array}{c}\text { الاحتمال } \\
\text { (sig p.value) }\end{array}$} & \multicolumn{2}{|c|}{ المتوسط } & \multirow{2}{*}{ درجة الحرية (df) } & \multirow{2}{*}{ ليمسبة (T) } \\
\hline & بعد & قبل & & \\
\hline . TAV & r.人 & $r .99$ & $r \varepsilon$ & $1 . . r \wedge$ \\
\hline
\end{tabular}

$$
\text { يتضح من جدول (^) ما يلي: الئ }
$$

أن قيمة (T) لمعرفة الفروق بين متوسطي القياسين القبلي والبعدي لطلاب المجموعة التجريبية الذين يستخدمون تقنية الواقع المعزز على مقياس الإتجاه بلغت

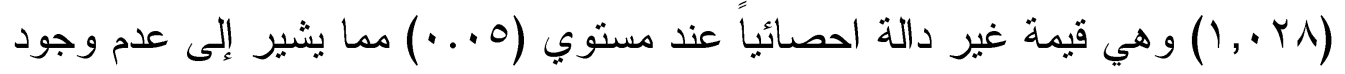

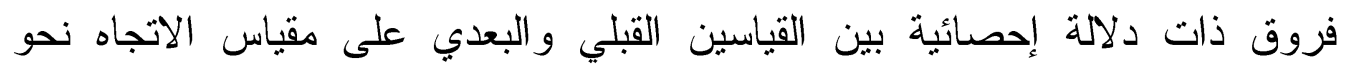

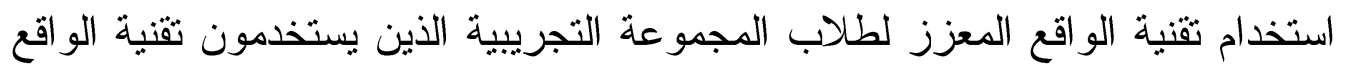

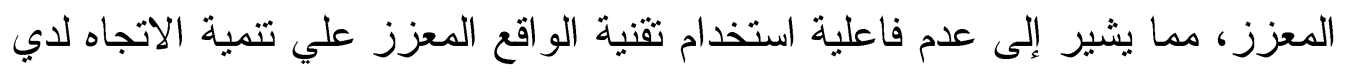
طلاب كلية الثزبية. وتأسيساً على ما تقدم فإنه: نم قبول الفرض الثاني ويكون البحث قد أجاب على السؤال الثاني ونصده: ما فاعلية استخدام تقنية الواقع المعزز على على تتمية الإتجاه 
لاختبار صحة الفرض الثالث الذي ينص علي: "لا يوجد فرق دال إحصائياً

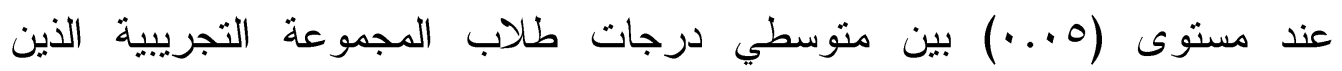

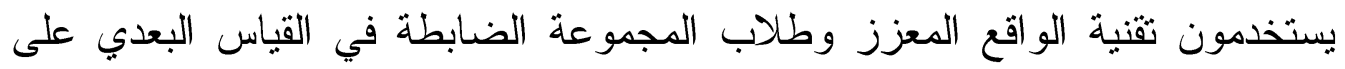
T اختبار التحصيل المعرفي"، وللتحقق من صحة هذا الفرض تم استخدام معادلة

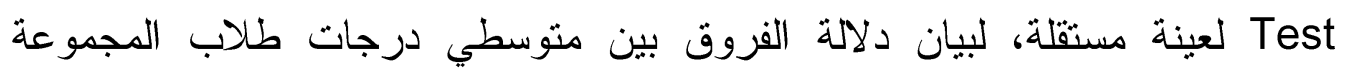

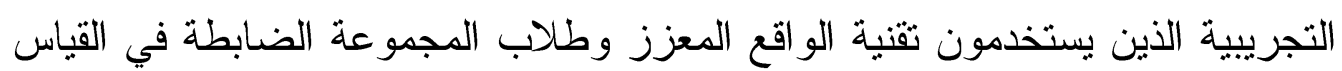

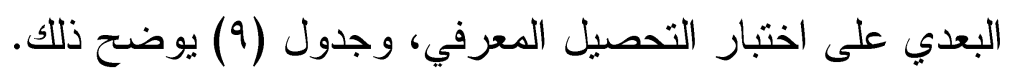
جدول (9) قبية (T) لمعرفة الفروق بين متوسطي درجات طلاب المجموعة التجريبية

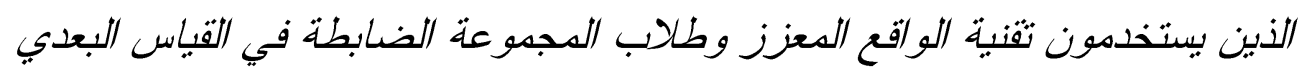
على اختبار التحصيل الدعرفي

\begin{tabular}{|c|c|c|c|c|c|c|}
\hline $\begin{array}{c}\text { الاحتمال } \\
\text { sig ) } \\
\text { (p.value }\end{array}$ & $\begin{array}{l}\text { الحرية } \\
\text { (df) } \\
\end{array}$ & قاليمسة (T) & الالاحياري & المتوسط & عدد الأفراد & المجموعة \\
\hline \multirow{2}{*}{. v04 } & \multirow{2}{*}{ V1.94 } & \multirow{2}{*}{. TIY } & r.00 & 15.9 & $\varepsilon$. & الضابطة \\
\hline & & & $r .09$ & Ir.v & ro & التجريبية \\
\hline
\end{tabular}

يتضح من جدول (9) ما يلي:

أن قيمة (T) لمعرفة الفروق بين متوسطي درجات طلاب المجموعة التجريبية

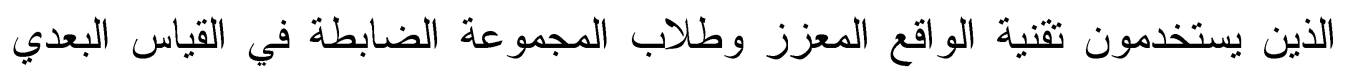

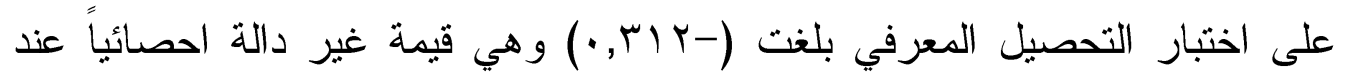

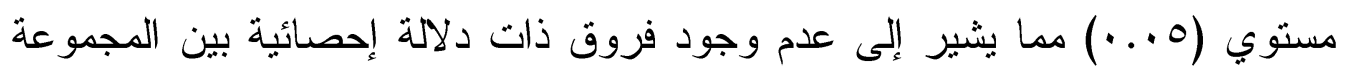

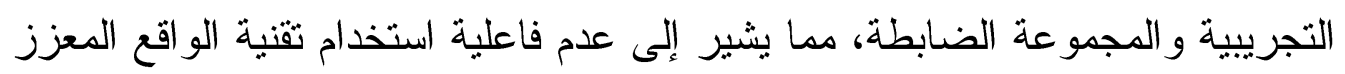
في تتمية التحصيل المعرفي لدي طلاب كلية التربية.

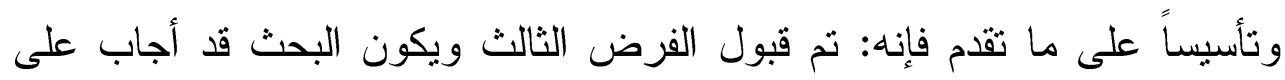
السؤال الثالث ونصده: ما الفرق بين متوسطي درجات طلاب المجموعة التجريبية

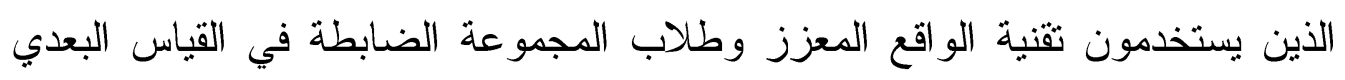

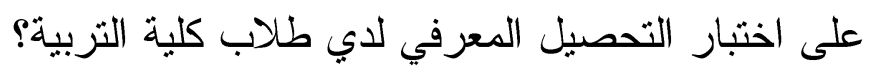


لاختبار صحة الفرض الرابع الذي ينص علي: "لا يوجد فرق دال إحصائياً

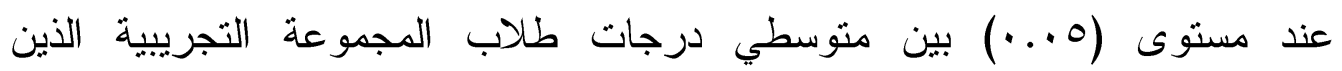

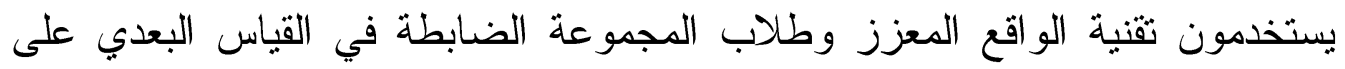
مقياس الإتجاه"، وللتحقق من صحة هذا الفرض نم استخدام معادلة T Test لعينة مستقلة، لبيان دلالة الفروق بين متوسطي درجات طلاب المجموعة التجريبية الذين

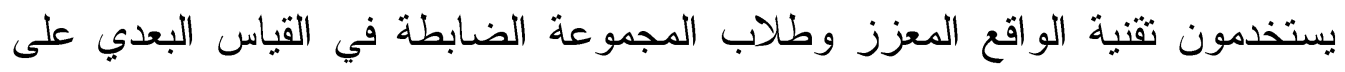

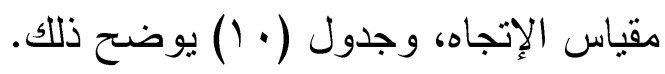

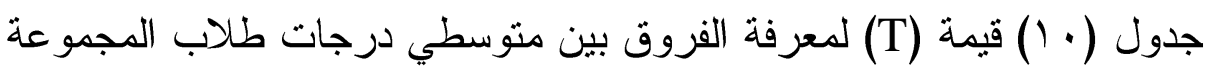

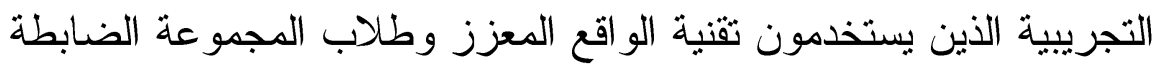
في القياس البعدي على مقياس الإتجاه

\begin{tabular}{|c|c|c|c|c|c|c|}
\hline $\begin{array}{c}\text { الاحتمال } \\
\text { sig ) } \\
\text { (p.value }\end{array}$ & الحرية & قالمحسو (T) & الالحعر اف & المتوسط & الأفر اد & المجمو عة \\
\hline \multirow{2}{*}{. TYKA } & \multirow{2}{*}{ T.T.T } & \multirow{2}{*}{$. .910-$} & . . & T.97 & $\varepsilon$. & الضـابطة \\
\hline & & & $.0 r$ & r.人T & م & التجريبية \\
\hline
\end{tabular}

يتضح من جدول (· (1) ما يلي:

أن قيمة (T) لمعرفة الفروق بين متوسطي درجات طلاب المجموعة التجريبية

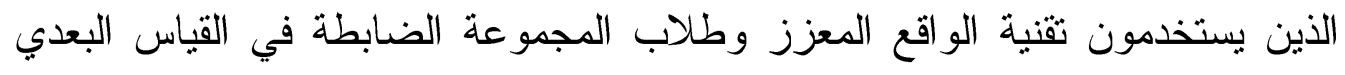

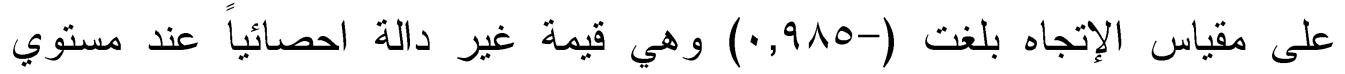
(0. . .) مما يشير إلى عدم وجود فروق ذات دلالة إحصائية بين المجموعة التجريبية

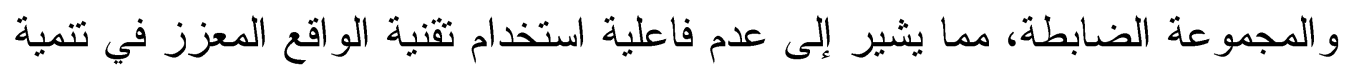
الإتجاه لدي طلاب كلية التربية.

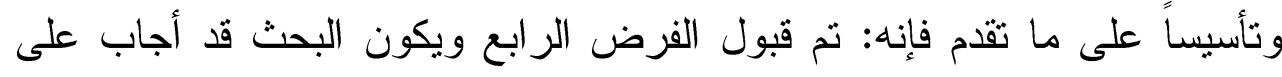
اللؤال الرابع ونصد: ما الفرق بين منوسطي درجات طلاب المجموعة التجريبية

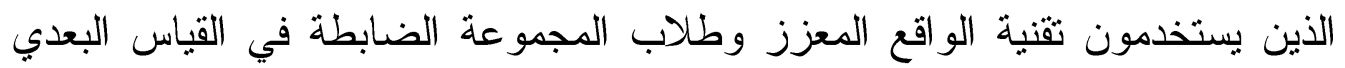
على مقياس الإتجاه لدي طلاب كلية التربية؟ لئه 
ب-مناقشة النتائج وتفسير ها:

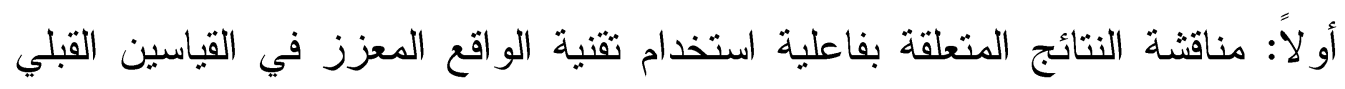
و البعدي على اختبار التحصيل المعرفي.

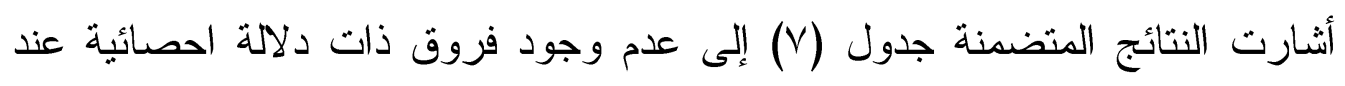

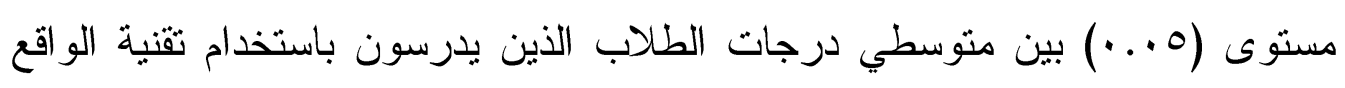

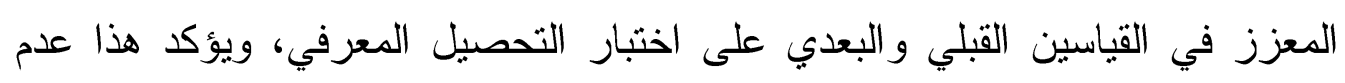

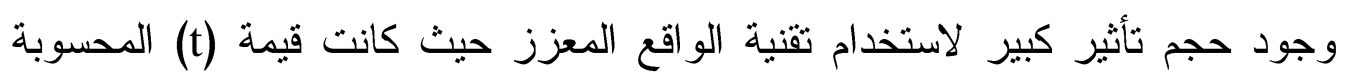

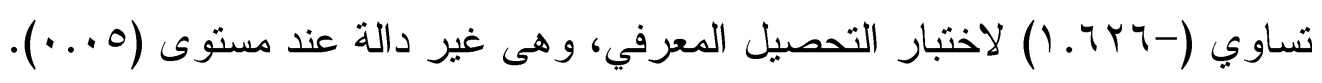

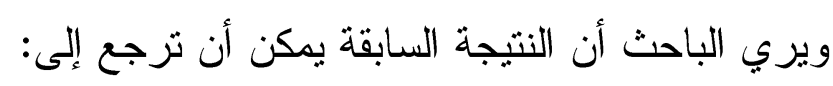

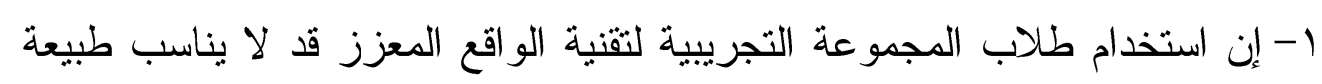
المقرر النظرى الذى درسوه (مقدمة فى تقنيات التعليم).

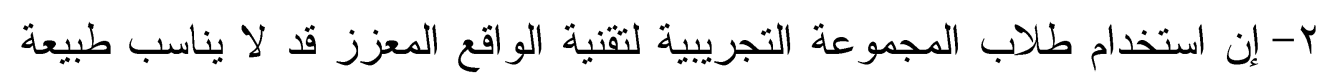

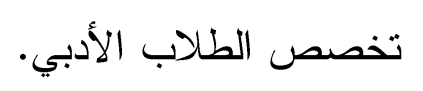

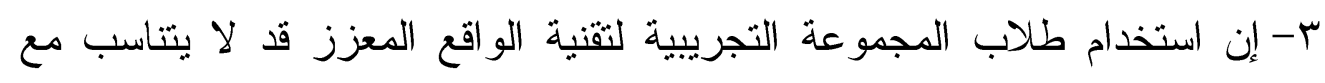
قدرات الطالب في التعامل مع هذه التقنية.

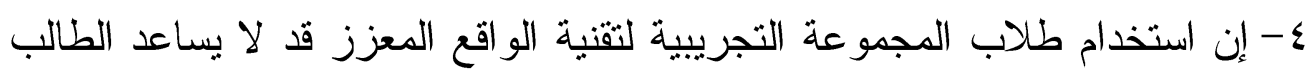
على تفاعله مع المحتوى بالثكل المطلوب أنثاء عملية التعلم.

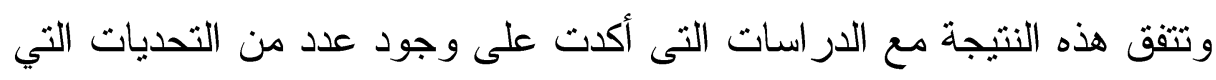

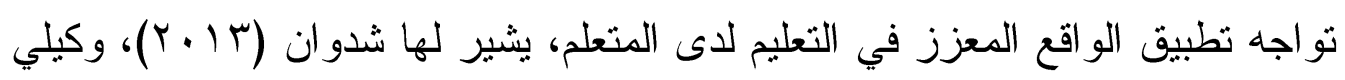
(Kelly)

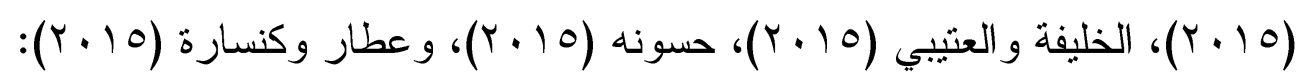

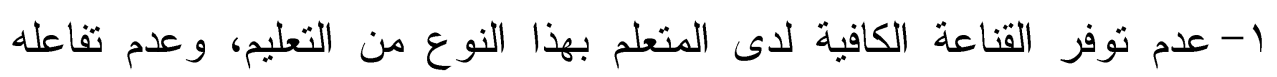

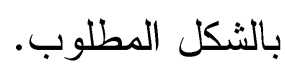
r- تقتصر على مجموعات صغيرة من المتعلمين وغير متوفرة على نطاق و اسع.

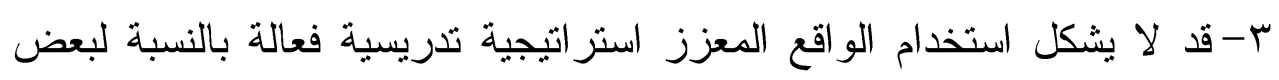
المتعلمين. 
ع - التركيز على كم كبير من المعلومات المتداخلة، قد يؤثر على الدماغ مما يؤدي

$$
\text { إلى تشتت الرؤية لاى المتعلم. }
$$

0- تباين قدرات المتعلمين في التعامل مع التقنيات الحديثة (الواقع المعزز). بينما تختلف هذه النتيجة مع نتائج بعض الدراسات التي أكدت علئ على أهمية استخدام تقنية الواقع المعزز والدور الذي تيؤديه في العملية التعليمية ومنها دراسة لهاني

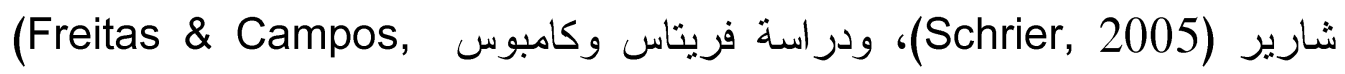

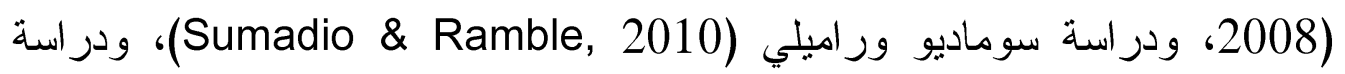
تشن، تساي (Chen \& Tsai, 2011)، ودراسة باربير ا وبيسا وبيرير ا وأداو وبيريز

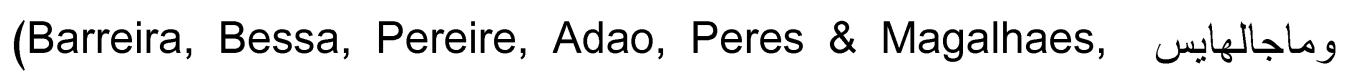

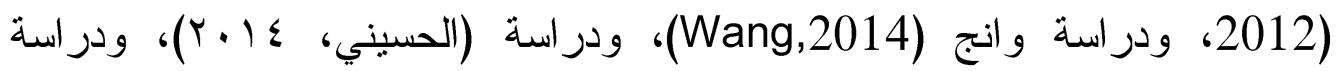

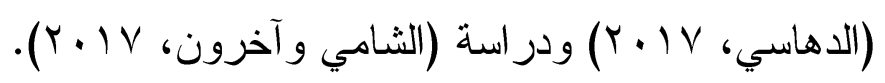

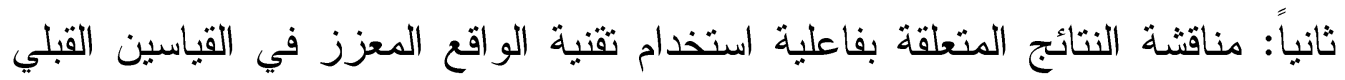

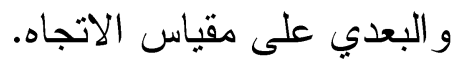

أثنارت النتائج المنضمنة جدول (^) الإنى عدم وجود فروق ذات دلالة احصائية عند مستوى (0...) بين متوسطي قياسات الطلاب الذين يدرسون باستخدام تقنية

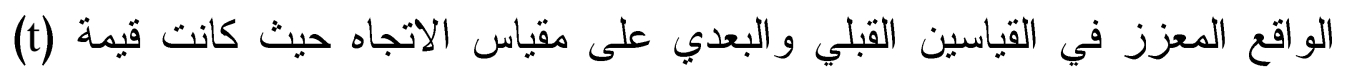

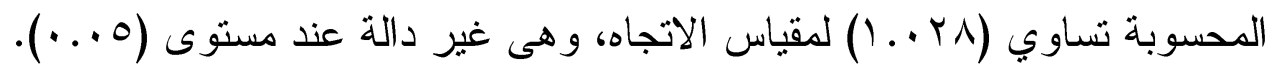
ويري الباحث أن النتيجة السابقة يمكن أن ترجع إلى الى: الجاهي

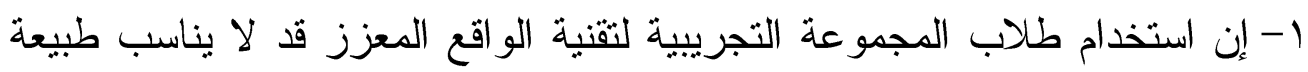
المقرر النظرى الذى درسوه (مقدمة فى تقنيات التعليم). ץ- إن استخدام طلاب المجموعة التجريبية لتقنية الواقع المعزز قد لا يناسب طبط طبيعة

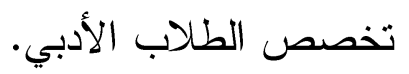
ץ- إن استخدام طلاب المجموعة التجريبية لتقنية الواقع المعزز قد لا يتتاسب مع قدر ات الطالب في التعامل مع هذه التثنية.

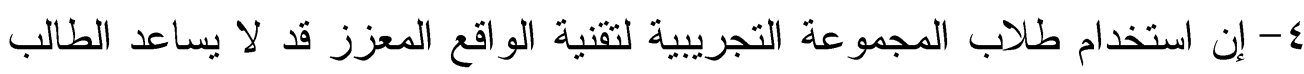
على تفاعله مع المحتوى بالثكل المطلوب أثناء عملية التعلم. 
وتتفق هذه النتيجة مع الدر اسات التى أكدت على وجود عدد من التحديات التي

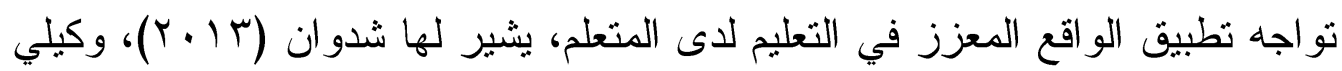
(Kelly)

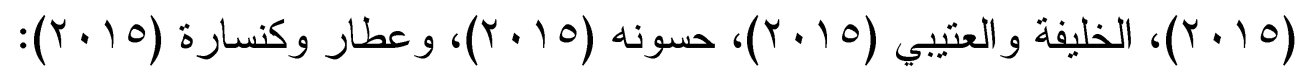

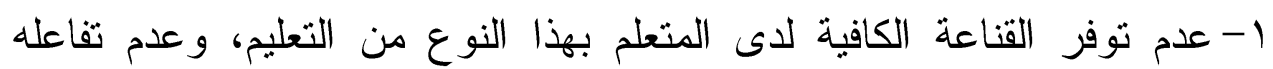

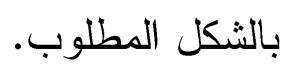
ץ- تقتصر على مجموعات صغيرة من المتعلمين وغير متوفرة على نطاق و اسع.

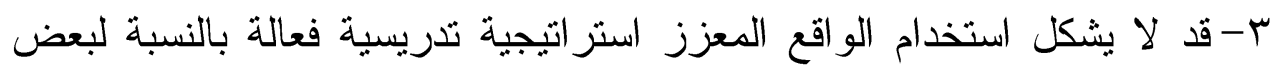

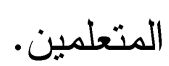
ع - التركيز على كم كبير من المعلومات المتداخلة، قد يؤثر على الدماغ مما يؤدي إلى تشتت الرؤية لدى المتعلم. 0- تباين قدرات المتعلمين في التعامل مع التقنيات الحديثة (الواقع المعزز).

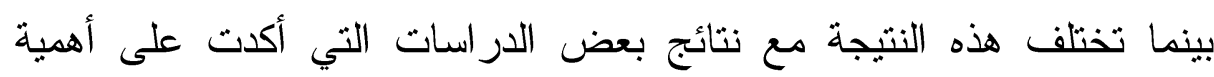

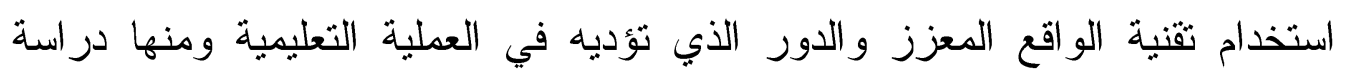

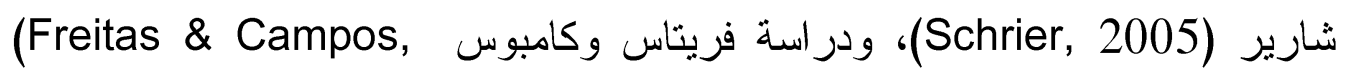

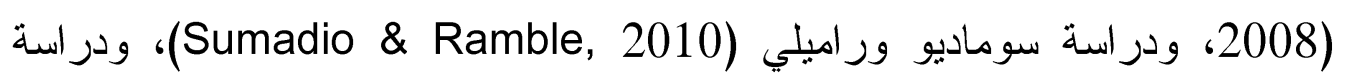
تشن، تساي (Chen \& Tsai, 2011)، ودر اسة باربير ا وبيسا وبيرير ا وأداو وبيريز

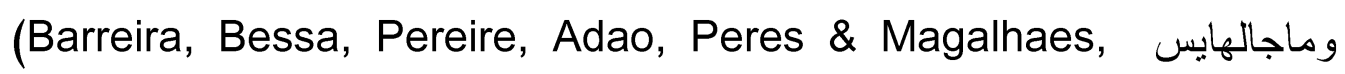

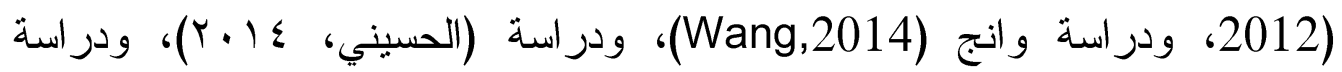

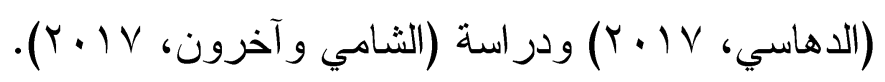

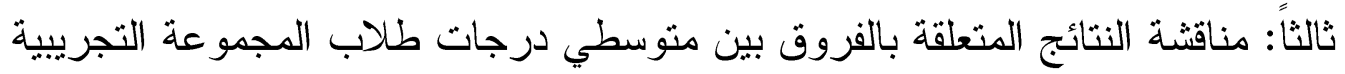

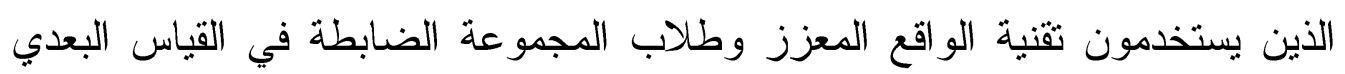
على اختبار التحصيل المعرفي

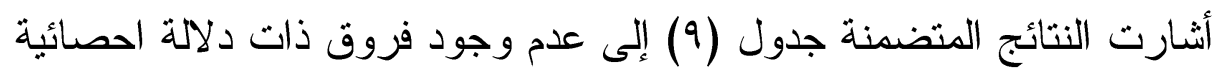
عند مستوى (0...) بين منوسطي درجات طلاب المجموعة التجريبية الذين يستخدمون تقنية الواقع المعزز وطلاب المجموعة الضابطة في القياس البعدي على دلى 
اختبار التحصيل المعرفي، حيث كانت قيمة (t) الحسوبة تساوي (-r اسM. ) لاختبار

$$
\text { والتحصيل المعرفي، وهي غير دالة عند مستوى (0. . .). }
$$

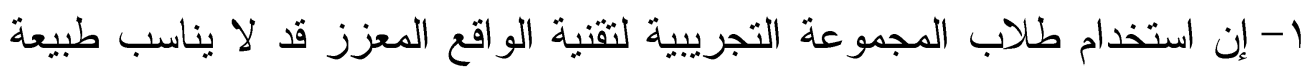

$$
\text { المقرر النظرى الذى درسوه (مقدمة فى تقنيات التعليم). }
$$

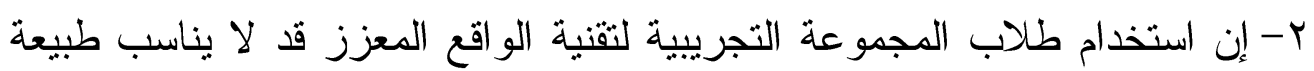

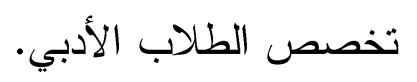

r- إن استخدام طلاب المجموعة التجريبية لتقنية الواقع المعزز قد لا يتتاسب مع

$$
\text { قدر ات الطالب في التعامل مع هذه التقنية. }
$$

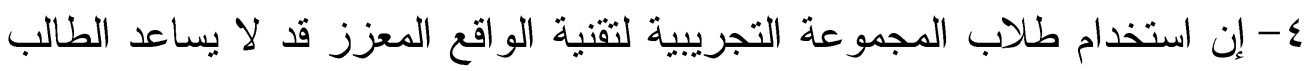
على تفاعله مع المحتوى بالثكل المطلوب أثناء عملية التعلم. وتتقق هذه النتيجة مع الدر اسات التى أكدت على بلى وجود عدد من التحديات التي

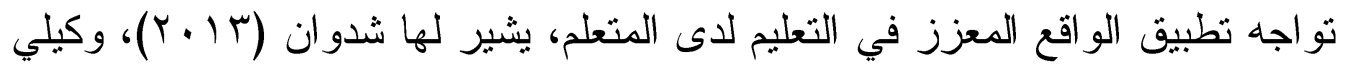
(Kelly)

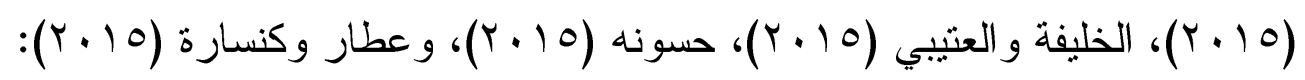
1- عدم توفر القناعة الكافية لاى المتعلم بهذا النوع من التعليم، وعدم تفاعله

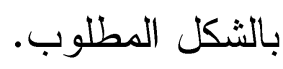
r- تقتصر على مجموعات صغيرة من المتعلمين وغير متوفرة على نطاق واسع.

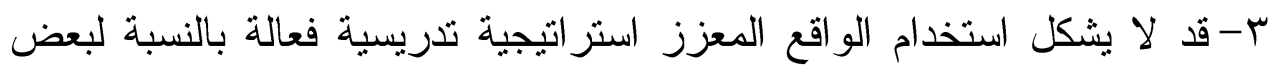
المتعلمين. ع - التركيز على كم كبير من المعلومات المتداخلة، قد يؤثر على الدماغ مما يؤدي إلى تشتت الرؤية لاى المتعلم. 0- تباين قدرات المتعلمين في التعامل مع التقنيات الحديثة (الواقع المعزز). بينما تختلف هذه النتيجة مع نتائج بعض الدراسات التي أكدت على ألى أهمية

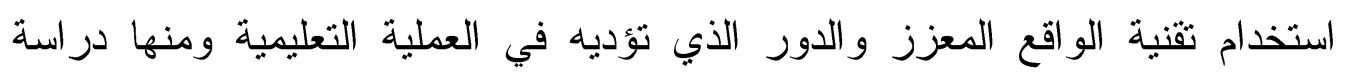

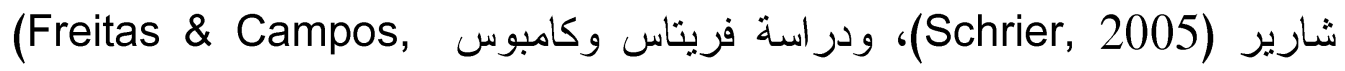


(2008، ودر اسة سوماديو وراميلي (Sumadio \& Ramble, 2010)، ودراسة تشن، تساي (Chen \& Tsai, 2011)، ودر اسة باربير ا وبيسا وبيرير ا و أداو وبيريز

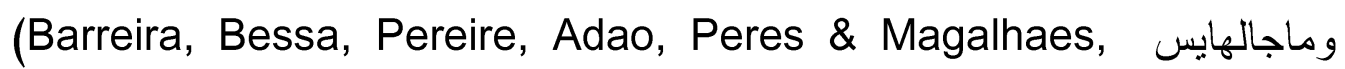

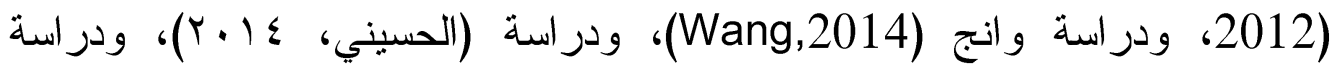

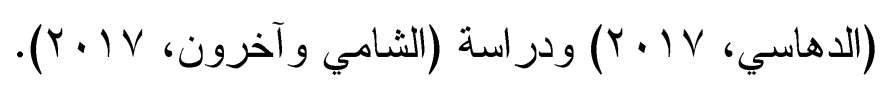

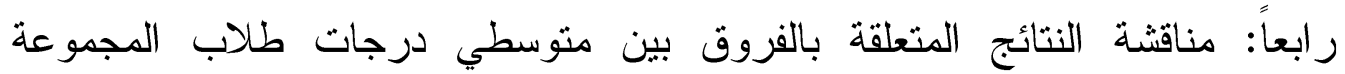

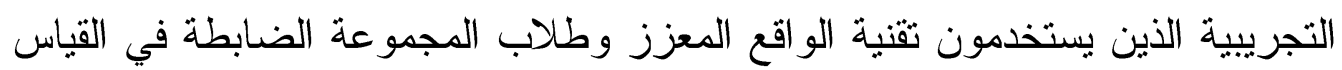
البعدي على مقياس الاتجاه. أثارت النتائج المتضمنة جدول (· • () إلى عدم وجود فروق ذاتهاه دات دلالة احصائية عند مستوى (0...) بين منوسطي درجات طلاب المجموعة التجريبية الذين بستخدمون

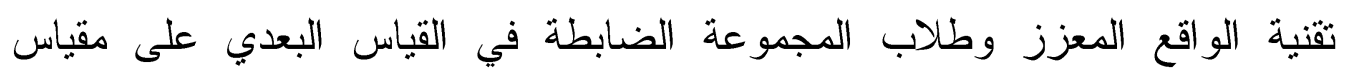

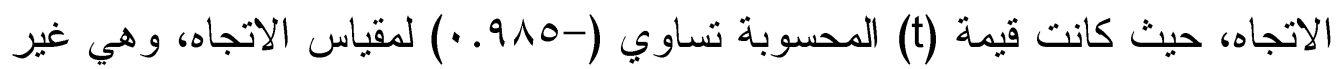
دالة عند مستوى (0.0. (•).

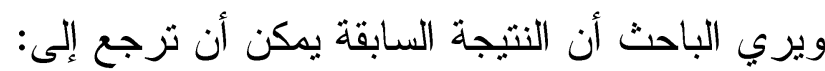

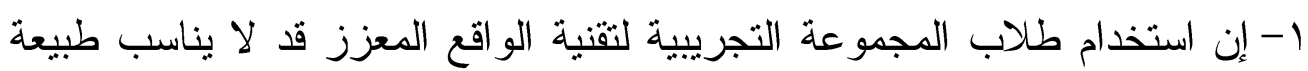
المقرر النظرى الذى درسوه (مقدمة فى تقنيات التعليم).

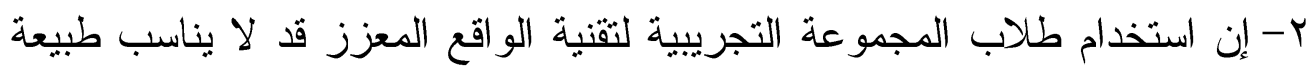

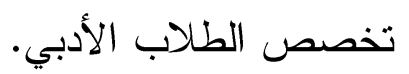
r- إن استخدام طلاب المجموعة التجريبية لتقنية الواقع المعزز قد لا يتتاسب مع قدر ات الطالب في التعامل مع هذه التقنية.

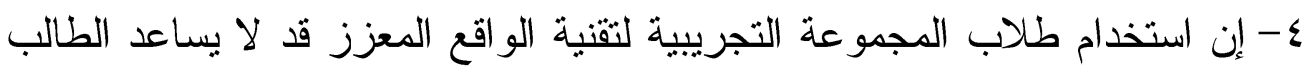
على تفاعله مع المتوى بالشكل المطلوب أثناء عملية التعلم. وتتقق هذه النتيجة مع الدراسات التى أكدت على وجود بلى عدد من التحديات التي

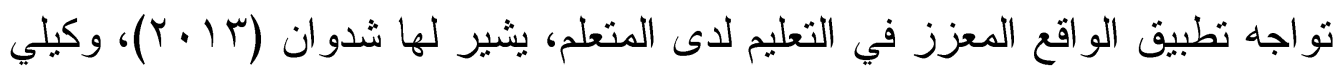
(Kelly)

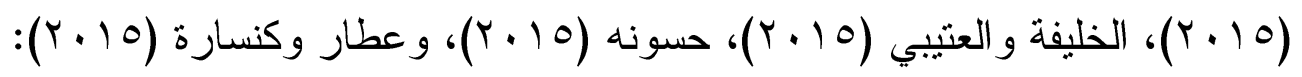




\section{rMo}

1- عدم نوفر القناعة الكافية لدى المتعلم بهذا النوع من التعليم، وعدم تفاعله

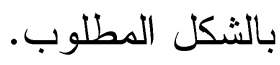
r- تقتصر على مجموعات صغيرة من المتعلمين وغير متوفرة على نطاق واسع.

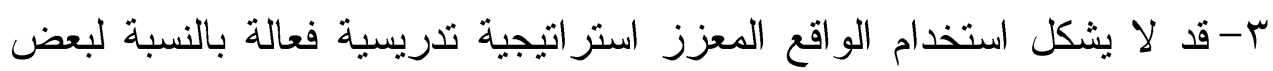

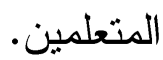

ع - التركيز على كم كبير من المعلومات المتداخلة، قد يؤثر على الدماغ مما يؤدي

$$
\text { إلى تشتت الرؤية لدى المتعلم. }
$$

0- تباين قدرات المتعلمين في التعامل مع التقنيات الحديثة (الو اقع المعزز). بينما تختلف هذه النتيجة مع نتائج بعض الدراسات التي أكدات على ألى أهمية

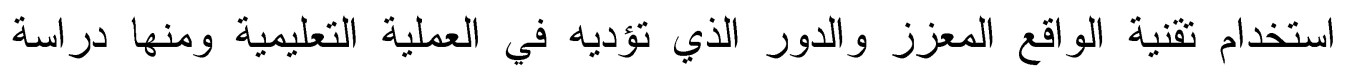

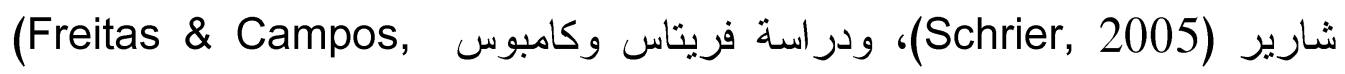

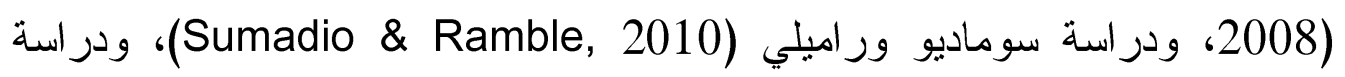
تشن، تساي (Chen \& Tsai, 2011)، ودر اسة باربير ا وبيسا وبيرير ا وأداو وبيريز

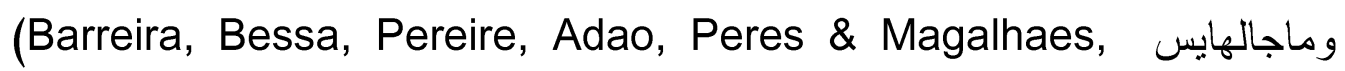

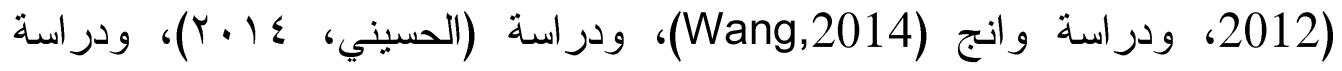

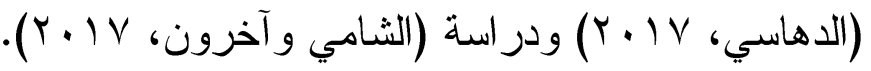

$$
\begin{aligned}
& \text { التوصيات: }
\end{aligned}
$$

في ضوء النتائج التي أسفر عنها البحث تم إير اد عدد من التوصيات التي يمكن

$$
\text { أن تسهم في تعزيز استخدام تقنية الو اقع المعزز كما يلي: }
$$

1-تقديم ورش عمل للطالب المعلم لتنريبهم على استخدام استراتيجات التعليم

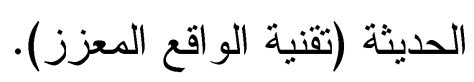

ץ-تتمية الاتجاهات الايجابية للطالب المعلم نحو استخدام استراتيجات التعليم

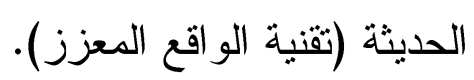

r-نطوير توصيف المقررات الدراسية للطالب المعلم لتتضمن استراتيجات

$$
\text { التعليم الحديثة (تقنية الو اقع المعزز) . تودئ. }
$$

في ضوء نتائج البحث ونوصياته يقتر ح الباحث القيام بالبحوث التالية: 
1- در اسة الاتجاهات العالمية الحديثة في استخدام تقنية الواقع المعزز . ץ- إجر اء دراسات مشابهة للار اسة الحالية في تخصصات ومر احل مختلفة لكلا الجنسين (طلاب - طالبات).

ץ- در اسة مدى احتياج المؤسسات التعليمية العربية للمستلزمات المادية و العلمية

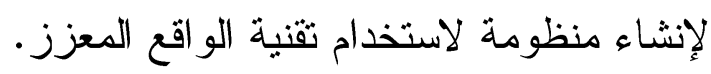




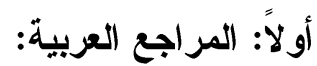

1. إبراهيم، أسامه خليل. (10 ( ب). نقد مناهج الرياضيات في الوطن العربي، مكتبة الكويت الوطنية للنشر و التوزيع: الكويت.

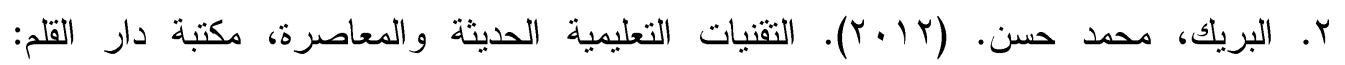

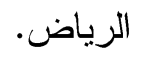

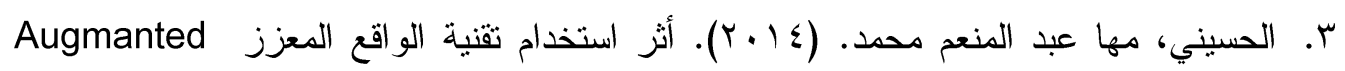
Reality

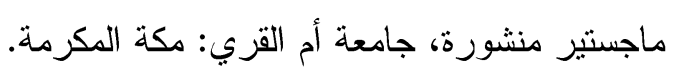

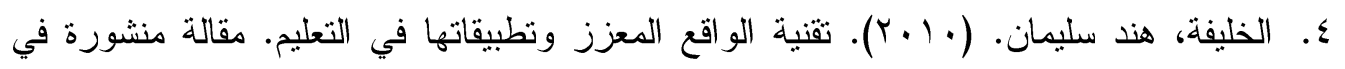

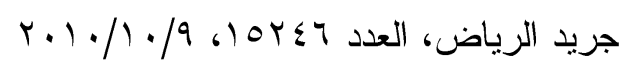

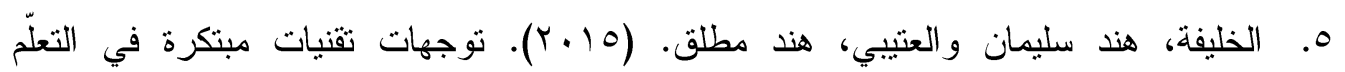

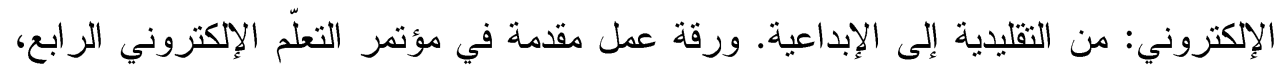
الرياض.

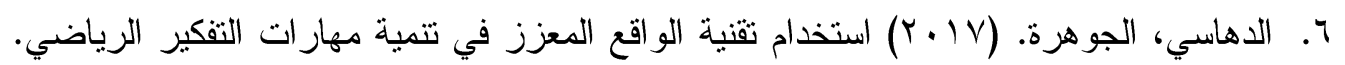
رسالة ماجستير . كلية الدر اسات العليا للتربية. جامعة القاهرة.

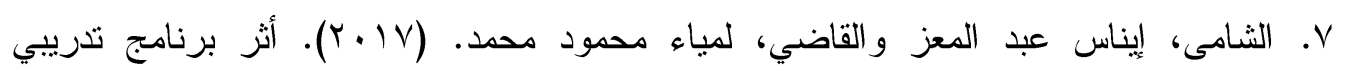
لاستخدام تقنيات الواقع المعزز في تصميم و إنتاج الدروس الإلكترونية لدى الطالبة المعلمة بكلية

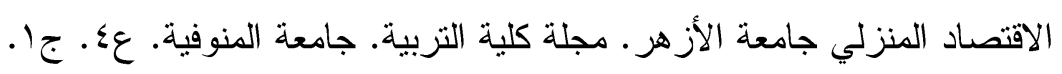

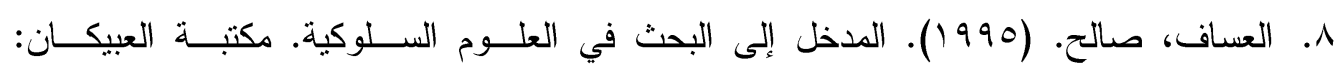

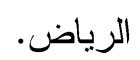

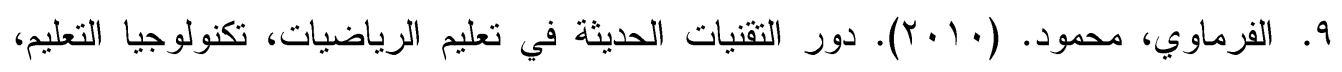
مكتبة المتنبي: الرياض.

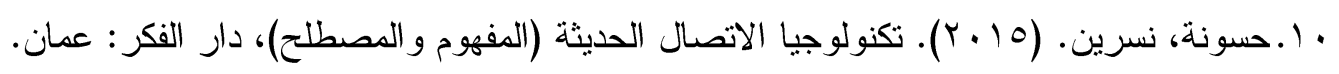

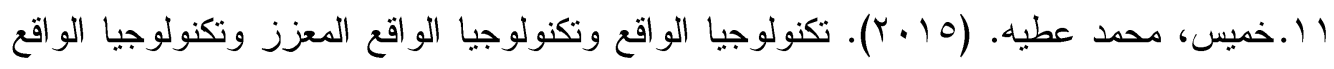

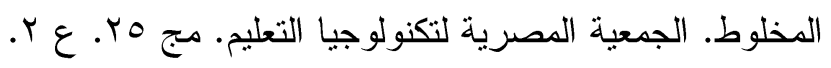

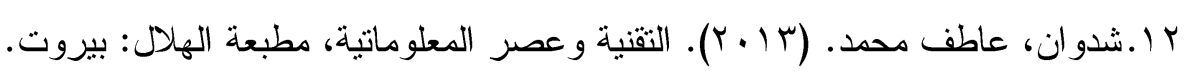

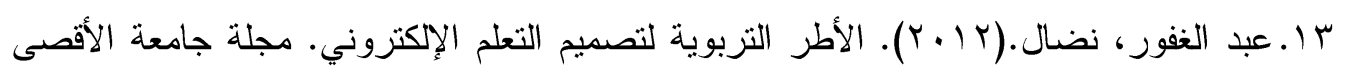

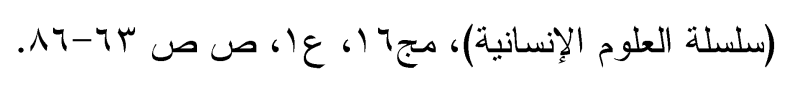

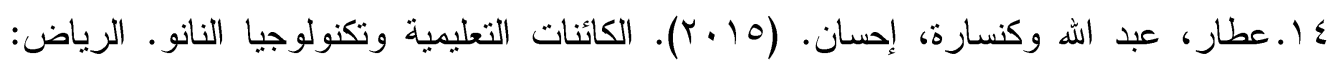

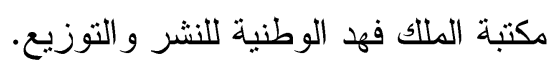
1 ا.فهمي، مصطفى محمد. (1 . …). طرق تدريس الرياضيات، مكتبة مصر : القاهرة. 


$$
\begin{aligned}
& \text { rrA } \\
& 17 \\
& \text { الفكر العربي. } \\
& \text { V V أسم، أمجد. (د.ت)، أهمية نوظيف التكنولوجيا الحديثة في التعليم، مكتب التربية العربي لدول } \\
& \text { الخليج، }
\end{aligned}
$$

From: http://www.abegs.org/aportal/blog/blogdetail.html?id=5161246653

$$
\text { 41542, 9/4/2017 }
$$

11.منهل الثقافة التربوية. الثقافة التقنية، استخدام تقنية الواقع المعزز في التعليم، From:https://www.manhal.net/article-module-art-action-s-id20172.htm, 18/2/2017

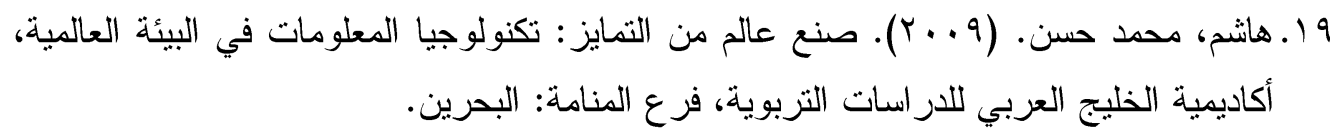$$
\text { ثانياً: المراجع الأجنبية: الته }
$$

1- Anderson, E \& Liarokapis, F. (2014). Using Augmented Reality as a Medium to Assist Teaching in Higher Education. Coventry University, UK. Retrived 2/4/2017, from: http://s.v22v.net/j19D.

2- Azuma, R., Baillot, Y., Behringer, R., Feiner, C., Julier, N\& Maclntyre, G. (2001). Recent Advances in Augmented Reality.Retrived 2/7/2017, from: http://s.v22v.net/pJh.

3- Azuma, R. (1997). A Survey of Augmented Reality. Presence:Teleoperators and Virtual, Environments, Vol. 1, No. 6,pp.355385.

4- Barreira, J., Bessa, M., Pereira, L.C., Adao, T., Peres, E., \& Magalhaes, L.(20-23 June, 2012) Augmented Reality Game to Learn Words in Different Languages .Paper Presented at the Information Systems and Technologies (CISTI), $7^{\text {th }}$ Iberian Conference, Madrid.

5- Catenazz, N. \& Sommaruga, L.(2013).social media: challenges and opportunities for education in modern society,mobile learning and augmented reality :new learning opportunities, International Interdisciplinary scientific Conference, Vol. 1. No. 1.

6- Chen, C., \& tsai, Y. (2011). Interactive augmented reality system for enhancing library instruction in elementary schools.(Computers and Education) ,unpublished master's thesis, Graduate Institute of Library, Information and Archival Studies, National Chengchi University .Wenshan District, Taipei City 116, Taiwan.

7- Choi,Dong Hwa\&Hebert,Amber D ailey.(2016).Emerging Tools and Applications of Virtual Reality in Education.p.168-185

8- Dunleavy, M., \& Dede, C. (2006). Augmented Reality Teaching and Learning. Augmented reality, USA: Harvard Education Press. 
9- Dunleavy, M., \& Dede, C. (2014). Augmented reality teaching and learning. In J.M. Spector, M.D Merrill, J. Elen, \& M.J. Bishop (Eds.), The Handbook of Research for Educational Communications and Technology (4th ed.). New York: Springer. P3

10- El Sayed, N. (2011).Applying Augmented Reality Techniques in the Field Of Education.Computer Systems Engineering.unpublished master's thesis, Benha University.Egypt.

11- Freitas, R., \& Campos, P. (1 - 5 September, 2008). SMART: a System of Augmented Reality for Teaching 2nd Grade Students, The 22nd British HCI Group Annual Conference, Liverpool, UK.

12- Kelly Sparks, Misty Antonioli, Corinne Blake. (2014), Augmented Reality. Applications in Education, the Journal of Technology Studies. Retrieved on 181312017, from: http://scholar.lib.vt.edu/ejournals/JOTS. Kieron Sheehy Rebecca

13- Kerawalla, L., Luckin, R., Seljeflot, S., \& Woolard, A. (2006). Making It Real: Exploring The Potential Of Augmented Reality For Teaching Primary School Science. Virtual reality, Vol. 10, No. 3-4, pp. 163-174.

14- Kipper, G., \& Rampolla, J. (2013): Augmented Reality: An Emerging Technologies Guide to AR, Elsevier.

15- Larsen, Y., Bogner, F., Buchholz, H., \& Brosda, C. (27- 29 October, 2011).Evaluation Of A Portable And Interactive Augmented Reality Learning System By Teachers And Students, open classroom conference augmented reality in education, Ellinogermaniki Agogi, Athens, Greece, pp. 41-50.

16- Lee, K. (2012). Augmented Reality in education and training, TechTrends: Linking Research \& Practice to Improve Learning, Vol.56, No. 2, pp. 13-21.

17- Instructional Design expert. com (2010). available at: http://www.instructionaldesignexpert.com/addie.html, $\quad$ Retrieved: $8 / 5 / 2017$.

18- Ivanova, M., \& Ivanov, G. (2011). Enhancement of Learning and Teaching in Computer Graphics Through Marker Augmented Reality Technology, International Journal on New Computer Architectures and Their Applications, (IJNCAA), Vol.1 No.1, pp. 176-184.

19- Radu, L. (5 - 8 November, 2012). Why Should My Students Use AR? A Comparative Review of the Educational Impacts of Augmented Reality, IEEE International Symposium on Mixed and Augmented Reality, Atlanta.

20- Schrier, K. (2005). Revolutionizing History Education: Using Augmented Reality Games to Teach Histories. Department of comparative media studies in Partial. Unpublished master's thesis. Massachusetts institute of technology. Cambridge.

21- Sumadio, D., \& Rambli, D. (19-21 March, 2010), Preliminary Evaluation on User Acceptance of the Augmented Reality use for Education, Second 
International Conference on Computer Engineering and Applications, Bali Island.

22- Wang, S. (2014). Making the Invisible Visible in Science Museums through Augmented Reality Devices, Unpublished Thesis, University of Pennsylvania.

23- Yuen, S., Yaoyune, G., \& Johnson, E. (2011), Augmented reality: An overview and five directions for AR in education. Journal of Educational Technology Development and Exchange, Vol. 4, No. 1, pp. 119-140. 